\title{
Anesthesiological strategies to modulate the surgical stress response : a focus on the cardiovascular consequences
}

Citation for published version (APA):

Willigers, H. M. (2007). Anesthesiological strategies to modulate the surgical stress response : a focus on the cardiovascular consequences. [Doctoral Thesis, Maastricht University]. Datawyse / Universitaire Pers Maastricht. https://doi.org/10.26481/dis.20071018hw

Document status and date:

Published: 01/01/2007

DOI:

10.26481/dis.20071018hw

Document Version:

Publisher's PDF, also known as Version of record

Please check the document version of this publication:

- A submitted manuscript is the version of the article upon submission and before peer-review. There can be important differences between the submitted version and the official published version of record.

People interested in the research are advised to contact the author for the final version of the publication, or visit the DOI to the publisher's website.

- The final author version and the galley proof are versions of the publication after peer review.

- The final published version features the final layout of the paper including the volume, issue and page numbers.

Link to publication

\footnotetext{
General rights rights.

- You may freely distribute the URL identifying the publication in the public portal. please follow below link for the End User Agreement:

www.umlib.nl/taverne-license

Take down policy

If you believe that this document breaches copyright please contact us at:

repository@maastrichtuniversity.nl

providing details and we will investigate your claim.
}

Copyright and moral rights for the publications made accessible in the public portal are retained by the authors and/or other copyright owners and it is a condition of accessing publications that users recognise and abide by the legal requirements associated with these

- Users may download and print one copy of any publication from the public portal for the purpose of private study or research.

- You may not further distribute the material or use it for any profit-making activity or commercial gain

If the publication is distributed under the terms of Article $25 \mathrm{fa}$ of the Dutch Copyright Act, indicated by the "Taverne" license above, 


\section{Anesthesiological strategies to modulate the surgical stress response A focus on the cardiovascular consequences}


ISBN 9789052786582

(C) Copyright HMM Willigers, Maastricht 2007

Layout en druk: Datawyse bv / Universitaire Pers Maastricht 


\section{Anesthesiological strategies to modulate the surgical stress response}

A focus on the cardiovascular consequences

\section{PROEFSCHRIFT}

ter verkrijging van de graad van doctor aan de Universiteit Maastricht, op gezag van de Rector Magnificus, Prof. mr. G.P.M.F. Mols

volgens het besluit van het College van Decanen,

in het openbaar te verdedigen

op donderdag 18 oktober 2007 om 12.00 uur

door

Henriëtte Maria Margaretha Willigers

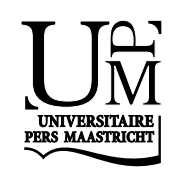


Promotor

Prof. dr. M. van Kleef

Copromotores

Dr. P.M.H.J. Roekaerts

Dr. F.W. Prinzen

Beoordelingscommissie

Prof. dr. H.J.G.M. Crijns (voorzitter)

Prof. dr. H. ten Cate

Prof. dr. M.E. Durieux (University of Virginia, USA)

Prof. dr. G.J. Scheffer (Universitair Medisch Centrum St Radboud, Nijmegen)

Prof. dr. H.A.J. Struijker Boudier 


\section{Contents}

Chapter 1 Introduction 7

Chapter 2 The anesthesiologist and optimising cardiac outcome: Strategies to modulate the perioperative stress response 15

Chapter 3 Homeostatic responses after cardiac surgery: Effect of anaesthesia management 37

Chapter 4 Dexmedetomidine decreases perioperative myocardial lactate release in dogs 51

Chapter 5 Comparison of the effects of dexmedetomidine and esmolol on myocardial oxygen consumption in dogs 69

Chapter 6 The effects of esmolol and dexmedetomidine on myocardial oxygen consumption during sympathetic stimulation in dogs 87

Chapter 7 Contrasting baroreceptor effects of esmolol and dexmedetomidine in dogs 103

Chapter 8 General discussion 119 



\title{
CHAPTER 1
}

\author{
Introduction
}




\section{Introduction}

A main goal of anesthesiologists is to protect their patients from risks associated with surgery. The stress response to tissue injury is a natural response which generally restores tissue homeostasis. However, the physiological effects associated with a large stress response or a defective stress response may be a major risk for patients having surgery. Therefore, anesthesiologists should further refine their strategies to control the surgical stress response. However, this is not an easy task.

Surgical procedures such as reposition of fractured bones and trepanation of the skull have been performed since prehistoric times ${ }^{1}$. However, it is only for about one century that the systemic adaptive response associated with these procedures has attracted the interest of scientists. First, physiologists introduced terms related to adaptive systems in general such as: "milieu interieur" (Claude Bernard, 1898) "homeostasis" and "fight or flight" (Walter Cannon, 1929). Later, terms in relation to the stress of tissue injury were introduced like "metabolic stress response"(D. Cuthbertson, 1932), "general adaptation syndrome" (Hans Selye, 1936) and "wound hormones"(Egdahl, 1959). Since then a growing number of studies continue to reveal the enormous complexity of the stress response to tissue injury. This complexity is not surprising because there are data indicating that this response is also present in fish and therefore has evolved over more than 400 million years ${ }^{2}$. Our current understanding of this response may be summarized as follows (fig. 1). Tissue trauma initiates a local inflammatory response that, through blood-borne and neuro-sensory signals, initiates a systemic stress response with the ultimate goal to restore homeostasis. In general, the stress response to tissue trauma may be divided into an immunological component and a neuro-endocrine component ${ }^{3}$. The immunological component, which includes activation of the inflammatory response and amplification of the innate (natural) immune system, is important for tissue healing and prevention of infections. The neuro-endocrine component, which consists of activation of the autonomic nervous system and of the hypothalamic-pituitary-adrenal (HPA) axis, has an important role in providing energy sources for the injured tissue. Additionally it helps to prevent an overreaction of the inflammatory-immunological response. It is important to realise that these two components of the systemic stress response are tightly interconnected ${ }^{3-5}$. For example, cytokines, important mediators of the inflammatory-immune response, are known to stimulate the HPA axis. Conversely, immune cells contain receptors for hormones and transmitters of the HPA axis. In addition to this hormonal interaction between both systems there is exciting evidence that the nervous system may directly control the immune system ${ }^{5}$. 


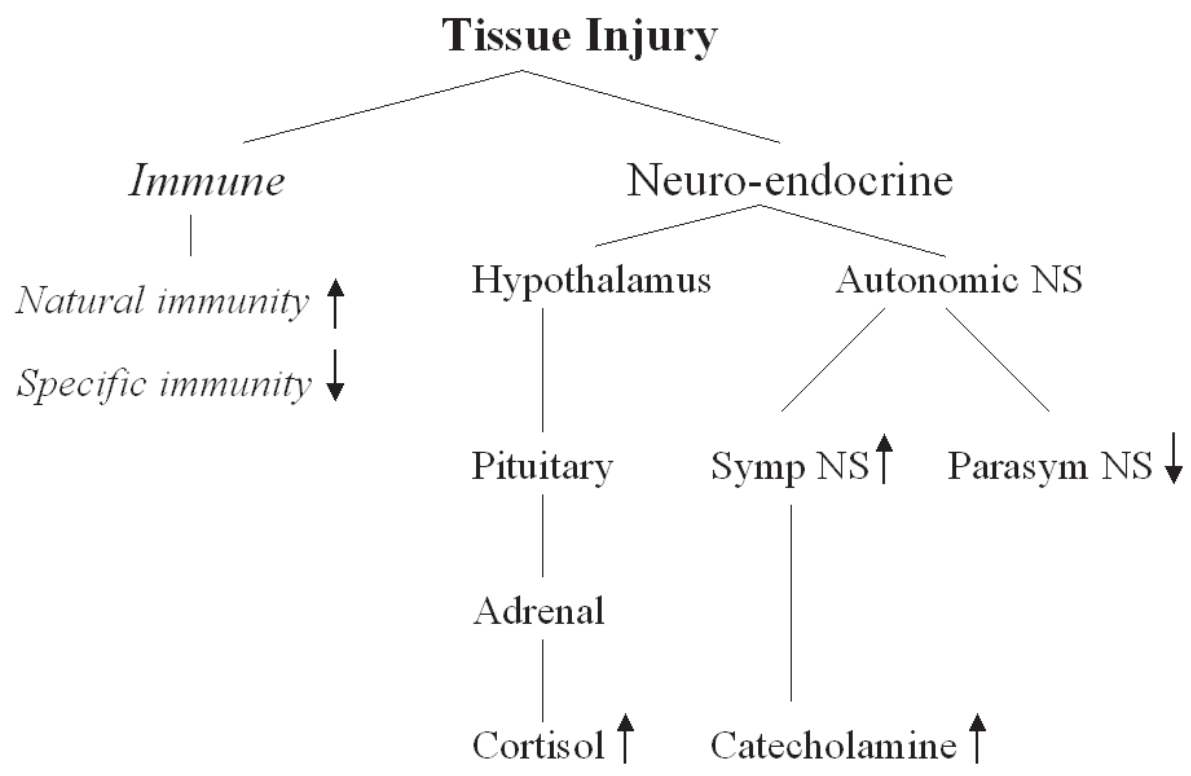

Figure 1 Schematic representation of the stress response to tissue injury.

Symp NS: sympathetic nervous system; Parasym NS: parasympathetic nervous system.

Homeostasis may not be restored if the stress response is too weak or too strong in relation to the stressor or in relation to the patient. If the stress response is too weak the patient suffers from infections and impaired tissue healing. In contrast, excessive inflammatory or neuro-endocrine responses may result in the systemic inflammatory response syndrome or excessive cardiovascular activation respectively. Especially in patients at the extremes of ages and in patients having co-morbidity this may cause significant morbidity.

The introduction of anesthetic techniques in the 19th century was a key event in surgical practice because the associated sedation and tissue relaxation allowed for increasingly invasive surgical procedures. However, patients frequently died after major surgical procedures. Later, a study in neonates showed the importance of attenuation of the neuro-endocrine stress response in reducing postoperative morbidity and mortality ${ }^{6}$. Also, various studies in adults suggested an important relation between the neuro-endocrine stress response and adverse cardiac outcome after surgery. So, diminishing the neuro-endocrine stress response to surgery became a major goal for anesthesiologists. 
Recently, evidence has emerged that inflammatory immunological phenomena underlie postoperative complications such as the systemic inflammatory response syndrome, postoperative infections, and coronary thrombotic events $^{7,8}$. Additionally, there is evidence that anesthesiological techniques can affect these immunological phenomena ${ }^{9}$. So, anesthesiological techniques may improve outcome from their effect on both the neuro-endocrine and the immunological component of the stress response.

Various recent developments in health care have created a renewed interest in strategies to modulate the surgical stress response. Also, the research questions in this thesis may be seen as part of this renewed interest. The main focus of these questions is on modulation of the stress response in relation to the cardiovascular system. This is because cardiovascular complications have an important effect on postoperative outcome.

A first development in health care is that economic forces have resulted in surgical programs aiming at a faster recovery from anesthesia and surgery. However, these fast track surgical programs incorporate the use of short-acting anesthetic drugs, and thus may leave the patient relatively unprotected from potential harmful stress responses during the early period after major surgery ${ }^{10}$. One fast track anesthetic strategy for cardiac surgery is a technique based on the short-acting opioid remifentanil, which allows for the intra-operative use of high dose opioids without delaying extubation ${ }^{11}$. Alternatively, an anesthetic technique based on thoracic epidural analgesia can be used. This is because this technique has additional potential benefits such as profound attenuation of the neuro-endocrine stress response and thoracic cardiac sympathectomy ${ }^{12}$. There are indications that an epidural-based anesthetic technique results in superior analgesia and haemodynamic stability compared to a remifentanil based technique ${ }^{13}$. However, the simultaneous effects of these fast-track anesthetic techniques on both the neuro-endocrine and the immunological component the surgical response have not been studied. Therefore, our first research question was: "How does the choice of anesthesiological techniques affect homeostatic responses to fast track coronary artery bypass surgery?"

Another development in health care is that there are increasingly less restrictions regarding age and comorbidity in surgical patients. This has resulted in an increased incidence of coronary artery disease, an important risk factor for myocardial ischemia, in surgical patients ${ }^{14}$. Currently, the most important strategy to decrease the risk at myocardial ischemia in these patients is to suppress the stress response to surgery . However, many basal questions in relation to this strategy are still unanswered. We decided to focus at pharmacological modulation of the autonomic nervous system and the associated cardiovascular 
effects. This resulted in two research questions which were studied in dogs because this species allowed for detailed measurements in a controlled experimental setting and because our laboratory has extensive experience with cardiovascular studies in dogs.

First, there is uncertainty regarding the exact pathophysiology of postoperative myocardial ischemia. Postoperative myocardial ischemia may result from myocardial oxygen supply-demand mismatch or from thrombosis on coronary plaques. It is generally believed that sympatholytic therapy may decrease myocardial ischemia purely from its effect on myocardial oxygen supplydemand balance. However, this remains unknown from clinical studies because in these studies it cannot be excluded that sympatholytic therapy reduces myocardial ischemia by decreasing shear stress on plaques. ${ }^{8}$ Therefore, our research question was: "Has pharmacological sympatholysis the potential to decrease myocardial ischemia during emergence from anesthesia purely from its effect on myocardial oxygen balance?"

The next question was related to choosing the optimal drug for modulation of autonomic nervous system. The American Heart Association advices to use either beta-adrenergic antagonists or alpha ${ }_{2}$-adrenergic receptor agonists for perioperative pharmacological sympatholysis ${ }^{15}$. These are fundamentally different classes of drugs. The principal action of beta-adrenergic blockade is to decrease beta-adrenoreceptor signalling at the end-organ receptor level. Alpha ${ }_{2}-$ agonists lower central sympathetic tone via activation of alpha ${ }_{2}$-receptors in the medullary dorsal motor complex and in the nucleus tractus solitarius. However, few studies concentrated on differences between both classes of sympatholytic drugs. Therefore we studied differences between beta-blockers and alpha $_{2}{ }^{-}$ agonists on myocardial oxygen demand and on autonomic nervous system mediated cardiovascular control. This is because these two variables seem to have an important role in the anti-ischemic effects of sympatholytic drugs.

In summary, the following three research questions have been addressed in this thesis:

1. How does the choice of anesthesiological techniques affect homeostatic responses to fast track coronary artery bypass surgery?

2. Has pharmacological sympatholysis potential to decrease myocardial ischemia during emergence from anesthesia purely from its effect on myocardial oxygen balance?

3. Do fundamentally different classes of sympatholytic drugs have different effects on:

A. Myocardial oxygen demand?

B. Autonomic nervous system mediated cardiovascular control mechanisms? 


\section{Overview of the thesis}

We started with an overview of the literature on anesthesiological strategies to decrease myocardial ischemia associated with the stress response to surgery (chapter 2).

The first research question has been addressed in chapter 3. In this chapter we compare the effects of two different anesthetic techniques on the inflammatory and the sympathetic stress response after fast-track coronary bypass surgery. We studied an epidural-based fast track technique and a technique based on the short-acting opioid remifentanil.

To answer our second research question we applied a critical coronary stenosis in dogs that were instrumented for detailed measurements of myocardial oxygen balance. Then either a sympatholytic drug (the alpha ${ }_{2}$-agonist dexmedetomidine) or a placebo drug was infused and the dogs were allowed to emerge from anesthesia. Myocardial lactate release was measured as a gold standard indicator of myocardial ischemia (chapter 4).

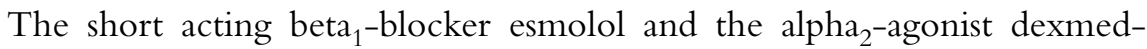
etomidine were compared to study our third research question. The effects of both classes of sympatholytic drugs on changes in myocardial oxygen demand and in cardiovascular variables were measured both in absence (chapter 5) and in presence of a sympathetic stimulus (chapter 6). A selective decrease in carotid artery pressure from bilateral carotid artery occlusion was used as a sympathetic stimulus. Differences in the effects of esmolol and dexmedetomidine on autonomic nervous system function and associated hemodynamic stability have been studied in chapter 7. Autonomic nervous system tone and baroreceptor mediated cardiovascular control was evaluated from; the power of frequency spectra of heart rate and aortic pressure variability, plasma norepinephrine concentrations, the response to a decrease in carotid artery pressure, and cardiac baroreflex sensitivity. Our findings are discussed and suggestions for future research are proposed in chapter 8. Finally, the previous chapters are summarized in chapter 9.

\section{References}

1 Ellis H. A history of surgery. London: Greenwich Medical Media Limited, 2001.

2 Metz JR, Huising MO, Leon K, Verburg van Kemenade BM, Flik G. Central and peripheral interleukin-1beta and interleukin-1 receptor I expression and their role in the acute stress response of common carp, Cyprinus carpio L. J Endocrinol 2006; 191: 25-35.

3 Chrousos GP. Stressors, stress, and neuroendocrine integration of the adaptive response. The 1997 Hans Selye Memorial Lecture. Ann N Y Acad Sci 1998; 851: 311-35.

4 Molina PE. Neurobiology of the stress response: contribution of the sympathetic nervous system to the neuroimmune axis in traumatic injury. Shock Augusta, Ga. 2005; 24: 3-10. 
5 Tracey KJ. The inflammatory reflex. Nature 2002; 420: 853-9.

6 Anand K, Hickey P. Halothane-morphine compared with high-dose sufentanil for anesthesia and postoperative analgesia in neonatal cardiac surgery. N Engl J Med 1992; 326: 1-9.

7 Laffey JG, Boylan JF, Cheng DC. The systemic inflammatory response to cardiac surgery: implications for the anesthesiologist. Anesthesiology 2002; 97: 215-52.

8 Landesberg G. The pathophysiology of perioperative myocardial infarction: facts and perspectives. Journal of cardiothoracic and vascular anesthesia 2003; 17: 90-100.

9 Homburger JA, Meiler SE. Anesthesia drugs, immunity, and long-term outcome. Current opinion in anaesthesiology 2006; 19: 423-8.

10 Myles PS, Daly DJ, Djaiani G, Lee A, Cheng DC. A systematic review of the safety and effectiveness of fast-track cardiac anesthesia. Anesthesiology 2003; 99: 982-7.

11 Royston D. Patient selection and anesthetic management for early extubation and hospital discharge: CABG.J Cardiothorac Vasc Anesth1998; 12: 11-9.

12 Chaney MA. Intrathecal and Epidural Anesthesia and Analgesia for Cardiac Surgery. Anesth Analg 2006; 102: 45-64.

13 Kessler P, Aybek T, Neidhart G et al. Comparison of three anesthetic techniques for off-pump coronary artery bypass grafting: general anesthesia, combined general and high thoracic epidural anesthesia, or high thoracic epidural anesthesia alone.J Cardiothorac Vasc Anesth 2005; 19: 32-9.

14 Mahla E, Vicenzi MN, Schrottner B et al. Coronary artery plaque burden and perioperative cardiac risk. Anesthesiology 2001; 95: 1133-40.

15 Eagle KA, Berger PB, Calkins $\mathrm{H}$ et al. ACC/AHA Guideline Update for Perioperative Cardiovascular Evaluation for Noncardiac Surgery-Executive Summary: A Report of the American College of Cardiology/American Heart Association Task Force on Practice Guidelines. Anesth Analg 2002; 94: 1052-64. 


\section{CHAPTER 2}

The anesthesiologist and optimising cardiac outcome: Strategies to modulate the perioperative stress response 


\section{Perioperative myocardial ischemia, a serious problem}

Cardiac complications are a major cause of morbidity and mortality after surgery ${ }^{1}$. Early postoperative myocardial ischemia is the most important predictor of these cardiac complications, increasing their relative risk 9 to 21 times. It is important to realize that myocardial ischemia and cardiac complications constitute a continuum of biological processes. With a shortage of myocardial oxygen supply, anaerobic glycolysis replaces oxidative phosphorylation as the primary source for ATP. This results in an increase in lactate, ADP, AMP, glucose-6-phosphate, and fructose-6-fosphate. After one minute the function of the ischemic area starts to deteriorate proportionally to the decrease in myocardial blood flow ${ }^{2}$. Thereafter electrophysiological abnormalities start as reflected by ECG changes. Irreversible myocardial damage (i.e. myocardial infarction) occurs after approximately 30 minutes cessation of myocardial blood flow. Congestive heart failure and cardiac death may result from changes in myocardial function and electrical stability during or after this process.

The incidence of myocardial infarction is approximately $0.06 \%$ in one month in a population-based cohort of men and women aged 55 years and older $^{3}$. In contrast, the incidence of in-hospital myocardial infarction after surgery varies between $1.4 \%$ in relatively unselected patients, and $5.6 \%$ in cardiac risk patients ${ }^{4}$. These figures suggest that surgery increases the risk for myocardial infarction more than ten-fold. Why is this?

\section{The stress response to surgery}

The most important reason for the increased incidence of myocardial infarction after surgery is related to the stress response associated with tissue trauma. This response incorporates profound immunological and neuro-endocrine changes with the ultimate goal to restore tissue homeostasis. A simplified picture of this response and its feedback mechanisms is shown in fig. 1.

The immunological part of the surgical stress response starts as a tissue based reaction to trauma and is designed to decrease infections and promote healing. As far back as $\mathrm{AD} 40$, Celsus defined this response as rubor, calor, dolor, and tumor. Currently we know that this response includes complex cascades, such as the complement, cytokine, and the coagulation-fibrinolytic cascades, and changes in cellular components of the immune system.

The cytokine cascade is of key importance and starts with the release of the cytokines IL-1 and TNF- $\alpha$ from activated macrophages and monocytes in injured tissue ${ }^{5}$. These cytokines stimulate the release of IL-6 which is mainly a pro-inflammatory cytokine and responsible for inducing the production of 


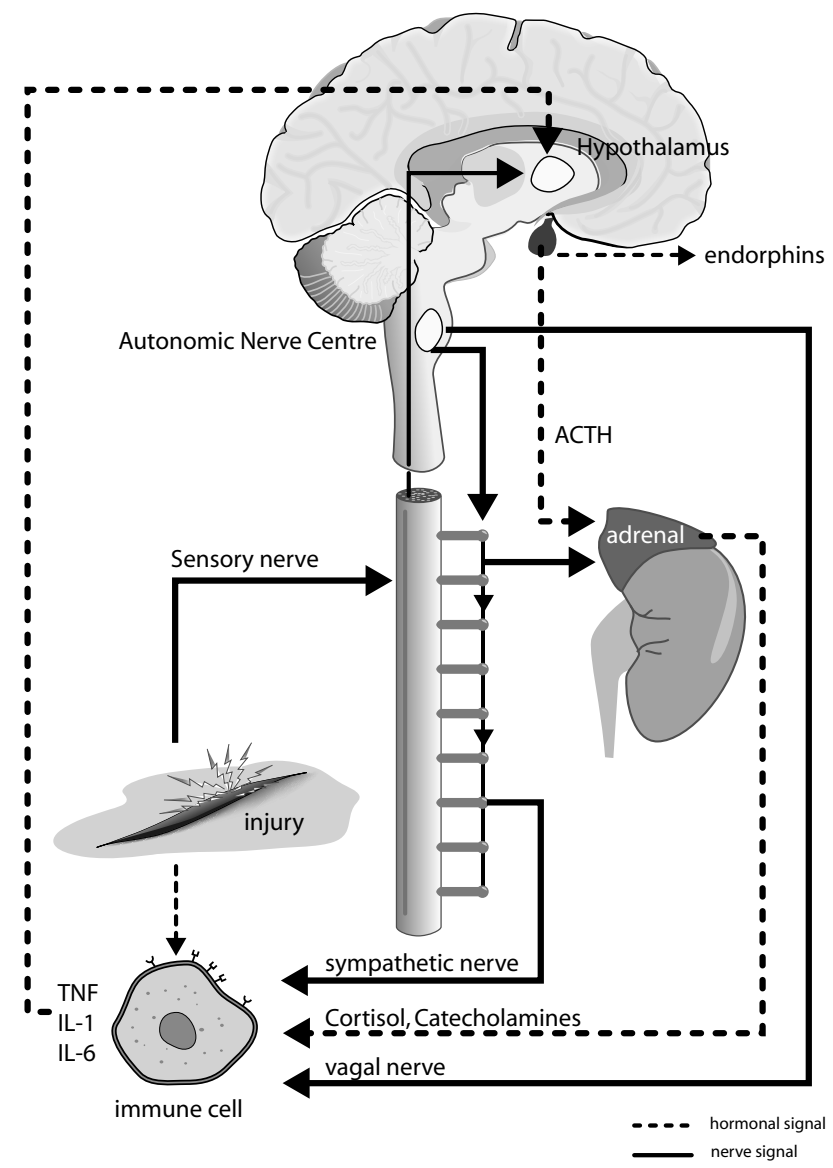

Figure 1. Some of the hormonal and neural pathways involved in the neuro-endocrine and the immunological response to tissue injury . TNF: tissue necrosis factor; IL-1: interleukine-1; IL-6: interleukine-6.

acute phase proteins such as C-reactive protein, fibrinogen and $\alpha_{2}$-macroglobulin in the liver. These acute phase proteins act as inflammatory mediators and as anti-proteinases, and promote tissue repair. To prevent a systemic overreaction of this pro-inflammatory response, tissue trauma also stimulates the production and release of anti-inflammatory cytokines such as IL-10, IL-1ra, and TNF soluble receptors. There are indications that it is this balance, between pro- and anti-inflammatory cytokine responses, which is most important for the clinical prognosis after surgery ${ }^{6}$. Closely interconnected with this cytokine cascade are changes in the coagulation-fibrinolytic cascades ${ }^{7}$. Proinflammatory cytokines increase the expression of tissue factor and of intravascular leukocyte 
adhesion molecules, activate the endothelium, and stimulate the production of platelet activation factors. Also, the fibrinolytic and protein-C anticoagulant pathways are down regulated. As a result, the immune response to tissue injury is associated with a marked procoagulant state.

The immune response to tissue injury also includes profound changes in the cellular components of the immune system. There is an immunoconversion from the acquired immune response to the natural immune response ${ }^{8}$. This increased activity of the natural immune system assures the highest level of host defence because it is capable of instantaneously attacking pathogenenic agents and detecting infected and injured cells. The down-side of this immunoconversion manifests as anergy in response to skin testing and failure to produce specific antibodies. Theoretically, this may result in an increased risk of sepsis and increased metastatic tumour spread after surgery ${ }^{9,10}$.

The neuro-endocrine part of the surgical stress response is a central nervous system mediated response. It peaks early after surgery, when the effects of anesthesia wear off. Its magnitude and duration are influenced by factors such as the amount and location of tissue damage, pain, anxiety, infection, hypovolemia, and hypoxemia. The most important function of the neuro-endocrine response is to promote an adaptive redirection of oxygen and nutrients to the stressed body sites and the central nervous system ${ }^{11}$. Additionally, it has a role in preventing an overreaction of the immune response. Neural and cytokine signalling of tissue trauma results in activation of the paraventricular nucleus of the hypothalamus. The increase in hypothalamic releasing factors in turn stimulate the pituitary to release vasopressin, growth hormone, prolactin and propiomelanocortin. Propiomelanocortin is metabolised to ACTH, which stimulates the secretion of corticosteroids, and to beta-endorphin, an endogenous opioid. Hypothalamic activation also changes the activity of autonomic nervous centra towards an increased sympathetic tone and a decreased parasympathetic tone. Clinical consequences are: 1) down-regulation of the beta-adrenoreceptor system related to increased plasma concentrations of catecholamines and 2) a decrease in vagal mediated heart rate variability in patients after major surgery ${ }^{12}$. In this way changes in autonomic nervous balance may explain increased blood pressure fluctuations after surgery ${ }^{13}$

The immunological and the neuro-endocrine parts of the stress response are no separate entities. Instead, the system is designed as a neuro-endocrineimmune feedback loop which allows regulation of host defence mechanisms ${ }^{14-}$ ${ }^{18}$. For example, immune mediators and cytokines activate the neuro-endocrine stress response because they can pass the blood-brain barrier and because they can stimulate vagal and sensory afferent nerves ${ }^{19}$. Simultaneously, glucocorticoids and catecholamines activate receptors on immune cells which 
results in a negative-feedback control of the immune response. The dynamic nature of mediators of the stress response adds to the complexity of the stress response. For example, the actions of some cytokines switch from pro-inflammatory to anti-inflammatory, depending on timing and context ${ }^{16}$.

In conclusion, surgery leaves the patient with much more than a tissue scar. Studies focussing on homeostatic responses to tissue injury continue to reveal the enourmous complexity of these responses. It is this increase in basic knowledge on homeostatic responses which offers exciting opportunities to increase our knowledge on the relation between homeostatic responses and perioperative morbidity.

\section{Linking the surgical stress response to myocardial ischemia}

The atherosclerotic coronary plaque is the common morphological risk factor of perioperative myocardial ischemia and infarction. Over the past decade we have learned that the immune response occupies a central position in the pathophysiology of these plaques ${ }^{20}$. We have also appreciated the dynamic nature of inflammatory-immune processes in these plaques which may be divided into two extremes. At one end of the spectrum is the structural vulnerable plaque, which has a central lipid core, many inflammatory cells and a thin cap. At the other end of the spectrum is the stable plaque which has few inflammatory cells and a thick fibrous cap.

Parallel to this variability of inflammatory-immune processes in plaques the aetiology of perioperative myocardial infarction may be divided into the following two common mechanisms ${ }^{21}$ (Fig. 2).

First, myocardial infarction may result from thrombosis on, or rupture of, coronary plaques. Potential triggers of this mechanism are: increased systemic inflammatory and procoagulant activity, increased sympathetic mediated shear stress on plaques, and increased sympathetic or local mediated coronary vasoconstriction. This mechanism accounts for less than $50 \%$ of perioperative myocardial infarctions and the timing of these infarctions has no specific correlation to the end of surgery.

Another mechanism for perioperative myocardial infarction is prolonged myocardial oxygen supply-demand mismatch in the presence of severe, but stable, coronary stenosis. The postoperative increase in sympathetic tone seems to be central to this type of myocardial infarction. Myocardial oxygen demand may increase from associated increases in heart rate, arterial pressure, and myocardial contractility. Simultaneously, myocardial oxygen supply may decrease from coronary vasoconstriction and a decreased diastolic filling time. These changes in myocardial oxygen demand and supply may result in 


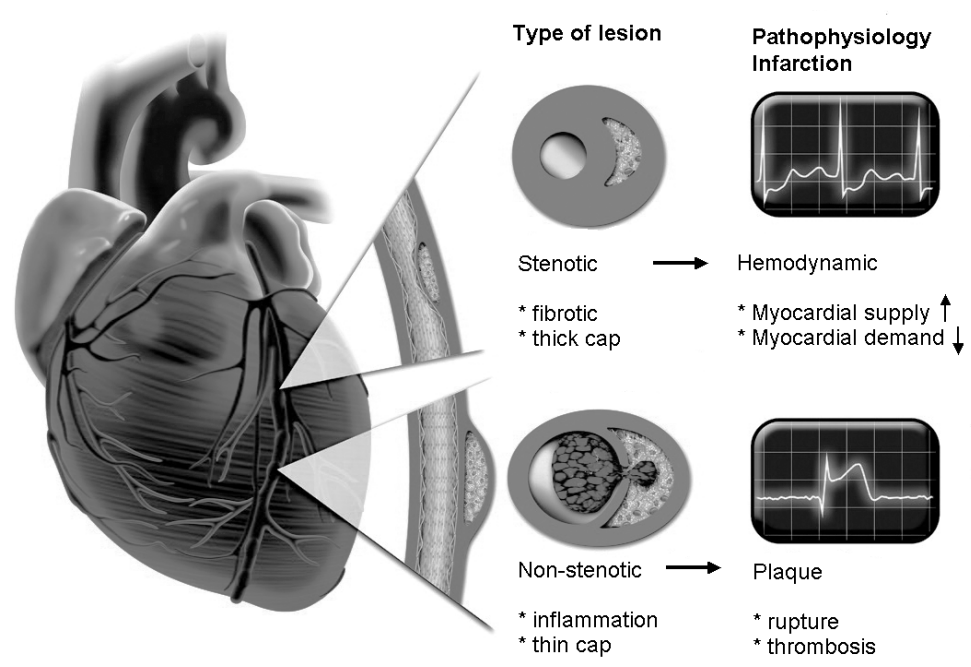

Figure 2. Two common pathophysiological mechanisms of perioperative myocardial infarction. These are;1) long-term mismatch in myocardial oxygen demand and supply in presence of a severe stable coronary artery stenosis and, 2) rupture and thrombosis in presence of an unstable coronary plaque. Adapted with permission from Libby et al (Circulation 2005; 111:3481-8.)

subendocardial ischemia, and if prolonged, in circumferential myocardial infarction. Typically, this ST-depression type of myocardial ischemia occurs within 8 to 24 hours from the end of surgery, and the peak incidence of associated cardiac death is in the first 1-3 postoperative days.

However, although these two pathophysiological mechanisms are clearly associated with perioperative myocardial infarction, the exact mechanism of perioperative myocardial ischemia remains unknown. To date, it remains unknown if myocardial infarction can result purely from mismatches in myocardial oxygen supply and demand. This is because the coronary plaque is the common morphological lesion in patients having perioperative myocardial infarction. Rupture of, and thrombosis on, coronary plaques may resolve spontaneously and therefore it can never be excluded that this mechanism contributed to the etiology of perioperative myocardial infarction. Another problem in studying the pathophysiological mechanisms of perioperative myocardial infarction is that methodological limitations prevent accurate measurement of myocardial oxygen consumption and demand. Finally, the diagnosis of myocardial ischemia and infarction is very difficult. Selecting ST-segment changes as an outcome measure may not always be clinically relevant because they also result 
from changes in temperature, serum electrolytes, position of electrodes, and from administration of $\operatorname{drugs}^{22}$. A more precise measure of myocardial ischemia, but difficult to obtain in patients, is the presence of lactate release from the myocardial area at risk. For the diagnosis of myocardial infarction several combinations of criteria such as typical ischemic chest pain, typical ECG findings, and increases in plasma concentrations of biochemical markers of myocardial injury are used. However, chest pain is often masked by analgesics in patients recovering from surgery and there is no generalised accepted standardization of these criteria $^{1}$.

It is likely that both inflammatory mediated coronary thrombotic events and sympathetic mediated mismatches in myocardial oxygen balance contribute to myocardial infarction in the perioperative period. This implicates that multimodal strategies are needed to decrease the incidence or severity of perioperative myocardial infarction.

\section{Strategies to decrease the surgical stress response}

The surgeon may decrease the immunological response to tissue injury by further developing surgical techniques with lesser tissue trauma. However, these techniques seem to have relatively little effect on the neuro-endocrine response $^{23}$. Also, there seems to be no immunologic advantage of laparoscopic surgery in relatively uncomplicated operations such as inguinal herniorrhaphies and in advanced procedures such as colectomies ${ }^{24}$.

The anesthesiologist may decrease the neuro-endocrine response to surgery by carefully choosing anesthetic strategies. In contrast to earlier beliefs, there are recent indications that these techniques also affect the immune response to surgery $^{25}$. Anesthetic strategies may affect the immune response to surgery indirectly by modulating the neuro-endocrine response or directly by affecting the functions of immune competent cells. In addition to choosing anesthetic strategies, the anesthesiologist may implement pharmacological strategies to modulate the perioperative stress response. Of these, sympatholytic drugs receive most attention because of their potential to decrease cardiac complications.

1. Anesthetic and analgesic strategies to decrease the surgical stress response. In general, either an epidural based or an opioid based anesthetic strategy may be used to decrease the stress response to major surgery.

\section{Epidural anesthesia and analgesia}

Epidural analgesia involves the administration of local anesthetics through a catheter placed in the epidural space thus interrupting peripheral nerve traffic. The level of the cathetertip and the infusion rate of local anesthestics determine 
the extend and spinal level of nerve blockade. Epidural analgesia has profound sympatholytic effects because it decreases the afferent neural input from the site of injury and because it may decrease the efferent neural input to the adrenal gland. Additionally, epidural anesthesia may also suppress the response of the hypothalamic-pituitary-adrenal (HPA)- axis to surgical stress. However, this suppression of the HPA axis applies mainly to patients having surgery below the umbilicus. In high abdominal and thoracic surgery epidural analgesia does not consistently suppress the HPA-axis response. The reason for this is unknown, but afferent neural input may not be blocked adequately or the inflammatory response may have an important role in activation of the HPA-axis in this type of surgery ${ }^{26}$.

The cardiovascular effects of epidural anesthesia depend on the extend and level of epidural blockade and associated sympatholysis ${ }^{27}$. The heart is innervated by sympathetic nerves from thoracic level 2 to 4 . Blockade of cardiac sympathetic fibers associated with a high level epidural block (above the fifth thoracic level) may therefore decrease myocardial oxygen demand. Additionally, the diameter of stenotic coronary arteries and the endo- to epicardial blood flow ratio may increase as a result of a decrease in sympathetic mediated coronary vasoconstriction. In contrast, during lumbar epidural anesthesia a reflex compensatory increase in thoracic sympathetic nerve activity may compromise myocardial oxygen balance.

In addition to these neuro-endocrine effects there are indications that epidural techniques also modulate the immunological response to surgery. This seems to be an indirect effect because epidural infusion of local anesthetics alone, in the absence of surgery, seems to have only transient and minor effects on human immune function ${ }^{28}$. In contrast, in presence of surgery epidural anesthesia does have immunological effects. Epidural analgesia decreased IL-6 production after low abdominal surgery ${ }^{29}$ and decreased circulating levels of the anti-inflammatory cytokine IL-10 in patients having coronary artery bypass ${ }^{30}$. Also, epidural analgesia attenuated post surgical lymphocyte depression in patients having spine surgery ${ }^{31}$. The exact mechanism of these immunological effects remains unknown. They may be related to the neuro-endocrine effects of epidural anesthesia or to direct effects of local anesthetics on neutrophils ${ }^{32}$.

Clinically, an epidural technique has profound analgetic effects and reduces many of the potential adverse physiological consequences of surgery. However, the impact of epidural analgesia on postoperative mortality and morbidity remains uncertain. In a large randomised controlled trial in high-risk patients undergoing major intra-abdominal surgery an epidural technique improved analgesia, and reduced respiratory failure ${ }^{33}$. However, this trial failed to show an effect of epidural analgesia on cardiovascular morbidity. Further, it is important 
to realise that potentially serious complications of an epidural technique include epidural hematoma, epidural abscess, and post-dural puncture headache.

\section{Opioid anesthesia and analgesia}

As alternative to an epidural based anesthetic strategy, an opioid based strategy may be used to modulate surgical stress responses. Opioids exert their effects through the $\mu, \kappa$, and $\delta$ - opioid receptors which belong to the family of $\mathrm{G}-$ protein coupled receptors. These receptors are present on various cells involved in the stress response, including central neurons and immune cells.

Opioids modulate neuro-endocrine stress responses because of their analgesic effects and because of their effects on receptors in the hypothalamus and brainstem ${ }^{17,34}$. It has been known for many years that stimulation of $\mu$-opioid receptors in the hypothalamus suppresses the response of the HPA-axis . Stimulation of central $\mu$-opioid receptors also affects autonomic nervous system activity. Vagal outflow increases, but variable effects on sympathetic outflow have been reported. It has been suggested that these effects on sympathetic outflow depend on which hypothalamic nucleus is stimulated ${ }^{34}$. In the surgical patient opioids favour a sympatholytic effect. However, this effect does not seem to be very strong because high doses of morphine are needed to suppress the increase in catecholamines during thoracic and upper abdominal surgery ${ }^{35}$. Also, further increasing the dose of opioids has no additional sympatholytic effect ${ }^{36}$.

Opioids also modulate the immunological stress response. This may result from direct interaction with opioid receptors on cells of the immune system, or indirectly from their effect on neuro-endocrine stress response. Stimulation of opioid receptors on immune cells results in a suppression of numerous components of the immune system such as natural killer cell activity, neutrophil complement and immunoglobulin receptor expression, chemokine induced chemotaxis, and phagocytosis ${ }^{37}$. Also most clinical studies point toward an overall immunosuppressive effect and an increased susceptibility to infections of chronic administration of opioids ${ }^{38}$. However, the immunological consequences of short-term opioid analgesia are less clear.

Opioids may have a beneficial effect on cardiac outcome. In a study in cardiac surgical patients intensive postoperative opioid analgesia decreased the severity of myocardial ischemia ${ }^{39}$. Also, there are indications that direct stimulation of opioid receptors on cardiac myocytes may limit myocardial ischemic injury ${ }^{40}$. However, no definite data are available on the effects of opioids on cardiac outcome.

\section{Pharmacological strategies}

In addition to choosing anesthetic strategies the anesthesiologist may also modulate perioperative stress responses by adding drugs. Of these, beta-blockers 
and $\alpha_{2}$-agonists, two fundamentally different classes of sympatholytic drugs, are most commonly used.

\section{Beta-blockers}

The principle action of beta-adrenergic blockade is to decrease betaadrenoreceptor signalling at the end-organ receptor level ${ }^{41}$. Beta-1 selective beta-blockers have been used in most studies on perioperative beta blockade. However, the clinical importance of beta1-receptor selectivity on cardiac mortality remains to be determined ${ }^{42}$. Esmolol, a beta-1 selective blocker, has been advocated for use in the perioperative period because of its extremely short elimination half-life of approximately 9 minutes ${ }^{43}$.

In general, beta-blockers seem to have no major effects on the neuro-endocrine stress response. They have been found to either increase or to have no effect on the activity of the sympathetic and parasympathetic nervous system ${ }^{44-}$ 46. These differences in findings may be explained from differences in methods of measurements, and from differences in route and in duration of the administration of the beta-blocker. The effect of beta-adrenergic blockade on the HPAresponse is largely unknown. In a study in healthy adults the beta-blocker propanolol had no effect on the HPA-response associated with a pentagastrine induced panic attack ${ }^{47}$. Also, a study in volunteers showed that the adrenal betareceptor plays no major role in steroid secretion ${ }^{48}$.

There is increasing evidence that beta-adrenergic receptors on immune cells have a central role in the connection between sympathetic activation and immune function ${ }^{49}$. However, there are very few studies focussing on the immunological effects of beta-blockers. In studies in mice beta blockade changed cellular immune functions and reduced survival from septic or hemorrhagic shock ${ }^{50} 51,52$.

The effect of perioperative beta-blockade on cardiac outcome has been intensively studied. Mangano and colleagues showed that perioperative atenolol administration decreased long term overall mortality by $55 \%$ and cardiac mortality by $65 \%$ in patients having or being at risk for coronary artery disease and undergoing major surgery ${ }^{53}$. Poldermans and colleagues showed in a placebo controlled study that bisopropol significantly decreased perioperative cardiac morbidity and mortality in a very high cardiac risk group ${ }^{54}$. Based on this evidence the American Heart Association guidelines strongly support the perioperative use of beta-blockers in patients having an increased cardiac risk ${ }^{55}$. However, there are also indications that this evidence is too optimistic. In the study of Mangano and colleagues the in-hospital deaths were excluded, betablockers were stopped in the control group, and there were more diabetic patients in the control group. The study of Poldermans and colleagues has been criticized for the lack of blinding and the implausibly large treatment effects. 
More recent trials did not demonstrate any benefit from perioperative betablocker therapy ${ }^{56}$. Very recently, a meta-analysis of 69 controlled trials showed that beta-blockers reduce myocardial ischemia, but have no effect on myocardial infarction or mortality ${ }^{57}$.

The exact mechanism by which beta blockers reduce myocardial ischemia remains unknown ${ }^{21}$. In general, suppression of sympathetic beta-receptor mediated cardiovascular responses is believed to be their most important antiischemic mechanism. In this way beta-blockers may prevent prolonged, stress induced mismatches in myocardial oxygen balance. More specifically, there is quite convincing evidence that the protective effect of beta blockers is related to their heart rate lowering effect. Controlling the heart rate below the individual ischemic threshold for 48 hour after surgery reduced myocardial ischemia in patients at high risk of cardiac complications ${ }^{58}$. Also, high doses of beta-blockers and tight heart rate control were associated with reduced perioperative myocardial ischemia and troponin-T release in vascular surgery patients ${ }^{59}$.

\section{Alpha ${ }_{2}$-agonists}

The principal action of alpha $a_{2}$-agonists is to decrease central sympathetic outflow. Other well-documented effects of alpha ${ }_{2}$-agonists include anxiolysis, sedation, and analgesia. Clonidine is the prototypical alpha ${ }_{2}$-agonist to which all other alpha $2_{2}$-agonists are compared, and has been used for more than 40 years in treatment of hypertension and in opioid and alcohol withdrawal syndromes. The alpha $_{2}$-agonist dexmedetomidine is very selective for alpha $a_{2}$-receptors (dexmedetomidine: $\alpha_{2} / \alpha_{1}$ selectivity: 1600, versus clonidine: $\alpha_{2} / \alpha_{1}$ selectivity: 40) and its shorter plasma half live makes titration to effect more easy(dexmedetomidine plasma half life: 2 hours, versus clonidine plasma half life: 9 hours). In 1999 the US Food and Drug Administration approved dexmedetomidine for sedation of intensive care patients. Since that time the number of studies focussing on this drug has increased enormously. A recent study in human volunteers showed that dexmedetomidine has a profound sympatholytic effect which is already clinically significant at the lowest plasma concentration $^{60}$.

$\mathrm{Alpha}_{2}$-agonists affect mainly the autonomic nervous system mediated effects of the neuro-endocrine stress response. They lower central sympathetic tone via activation of alpha ${ }_{2}$-receptors in the medullary dorsal motor complex and in the nucleus tractus solitarius. These central sympatholytic effects of alpha $\mathrm{a}_{2}$-agonists are augmented by inhibition of peripheral ganglionic transmission ${ }^{61}$. Additionally, there are indications that alpha ${ }_{2}$-agonists enhance parasympathetically mediated heart rate control from their effects on alpha ${ }_{2}$-receptors in the vagal nuclei of the medulla oblongata ${ }^{62}$. A recent study demonstrated the clinical importance of central alpha 2 -receptors on autonomic responses to stress ${ }^{63}$. It 
showed that persons which have a genetic polymorphism of the central alpha $2^{-}$ adrenergic receptor have an increased autonomic responsiveness to various stressors. In addition to their direct sympatholytic effects, alpha $a_{2}$-agonists may decrease sympathetic responses from their analgetic, anxiolytic, and sedative effects. These effects are mediated by stimulation of alpha 2 -receptors in the locus coeruleus and nucleus reticularis lateralis. In contrast to their profound autonomic nervous system effects, alpha 2 -agonists do not seem to have an important effect on the HPA-axis mediated effects. Clonidine did not affect cortisol release in patients undergoing pancreatico- biliary surgery ${ }^{64}$ or CABG surgery $^{65}$. Also, dexmedetomidine infusion had no effect on serum cortisol or ACTH concentrations after major surgery ${ }^{66}$.

There are few data on the immunological effect of alpha $a_{2}$-agonists. In an in vitro study, clonidine and dexmedetomidine did not affect chemotaxis, phagocytosis, or superoxide production by human neutrophils ${ }^{67}$. The immunological effects of alpha ${ }_{2}$-agonists in the presence of surgery are equivocal. Clonidine reduced the interleukin-6 production in response to total abdominal hysterectomy ${ }^{68}$. In contrast, clonidine had no effect on the IL-6 response after pancreatico- biliary surgery ${ }^{64}$. Also, a postoperative sedative infusion of dexmedetomidine had no significant effects on IL-6 plasma concentrations ${ }^{66}$. A study focussing on the cellular immunological response of clonidine after CABG surgery showed that this alpha2-agonist changed the T-lymphocyte subpopulation in favour of a pro-inflammatory response ${ }^{69}$. However, the clinical relevance of these data remains to be determined.

Alpha $_{2}$-agonists have been less well studied than beta-blockers for perioperative myocardial protection; 6 versus 11 randomized controlled trials up to November $2002^{70}$. The potential benefit of alpha ${ }_{2}$-agonists on myocardial ischemia was initially controversial because of their direct coronary vascular effects. Alpha ${ }_{2}$-agonists may jeopardize coronary flow reserve from stimulation of vascular smooth muscle alpha ${ }_{2 \mathrm{~B}}$-receptors ${ }^{71}$. However, activation of alpha $2^{-}$ adrenoreceptors on vascular endothelial cells may cause vasodilatation. Also, multiple clinical studies and two meta-analyses have shown that alpha ${ }_{2}$-agonists decrease perioperative myocardial ischemia in cardiac risk patients ${ }^{72,73}$. In the largest study this beneficial effect resulted mainly from the effect of an alpha $2_{2}$ agonist in a subgroup of patients with known coronary heart disease and undergoing vascular surgery ${ }^{74}$. Recently, a prospective double blind trial in 190 patients showed that clonidine reduces perioperative ischemia and postoperative mortality in patients undergoing non-cardiac surgery and having or being at risk for coronary artery disease ${ }^{75}$. 
It is important to realise that studies on the effect of an intervention on the stress response are very difficult to interpret. Firstly, this is because the stress response is part of a feedback system. Another difficulty is that there is a paucity of basal data on "normal" quantitative relationships between the type and duration of stressor and sequential changes in plasma concentrations of mediators of the stress response $\mathrm{e}^{76}$. Studies having perioperative myocardial ischemia or myocardial infarction as an outcome measure are even more difficult to interpret. This is because these outcome measures are difficult to diagnose and have a low incidence $^{1}$. It has been calculated that more than 6000 patients are needed to detect an effect of an intervention on myocardial infarction ${ }^{77}$.

In conclusion, anesthesiological strategies and sympatholytic pharmacological strategies have the potential to decrease perioperative myocardial ischemia. Also, all of these strategies seem to affect both the immune and the neuro-endocrine component of the stress response. However, these strategies have different locations of action within the pathways of the stress response (fig. 3). This seems to result in important qualitative and quantitative differences in their potential to modify various components of the stress response (table 1).

\section{Different strategies to modulate the perioperative stress response: comparative studies}

It is important to focus on differences between the various stress modulating strategies because this knowledge may help to define the optimal strategy for an individual patient. For example, a patient at risk for developing an excessive inflammatory response after surgery may benefit from a strategy which is known to reduce this inflammatory response. With the exception of studies comparing epidural based to opioid based strategies, there is a paucity of comparative data on how various strategies affect different components of the stress response (Table 2). From these data a speculative ranking can only be made for the potential of the various strategies to decrease sympathetic outflow: Epidural $>\mathrm{alpha}_{2}-$ agonist $>$ opioid $>$ beta-blocker. Below we will discuss differences of frequently used anesthesiological and sympatholytic strategies into more detail.

\section{Differences in modulation of the stress response of two important} anesthesiological strategies

Differences between the neuro-endocrine effects of an epidural based and an opioid based anesthetic technique have been studied extensively ${ }^{78,79}$. Collectively, the available studies indicate that an epidural-based technique reduces sympathetic and cortisol responses more effectively than an opioid technique, 


\section{CHAPTER 2

Table 1. General effect of different strategies on various components of the surgical stress response. $\downarrow$ : decrease; $\uparrow:$ increase; $\leftrightarrow:$ no effect; ?: unknown because of very few studies.

\begin{tabular}{lcccc}
\hline & $\begin{array}{c}\text { Thoracic } \\
\text { Epidural }\end{array}$ & Opioid & Beta blocker & $\begin{array}{c}\text { Alpha }_{2} \\
\text { agonist }\end{array}$ \\
\hline Sympathetic outflow & $\downarrow \downarrow$ & $\uparrow \downarrow$ & $\uparrow \leftrightarrow$ & $\downarrow$ \\
Parasympathetic outflow & $\leftrightarrow \uparrow$ & $\uparrow$ & $\uparrow \leftrightarrow$ & $\uparrow$ \\
HPA-axis hormones & $\downarrow \leftrightarrow$ & $\downarrow$ & $\leftrightarrow$ & $\leftrightarrow$ \\
Activity immune cells & $\uparrow ?$ & $\downarrow$ & $\downarrow ?$ & $?$ \\
\hline
\end{tabular}

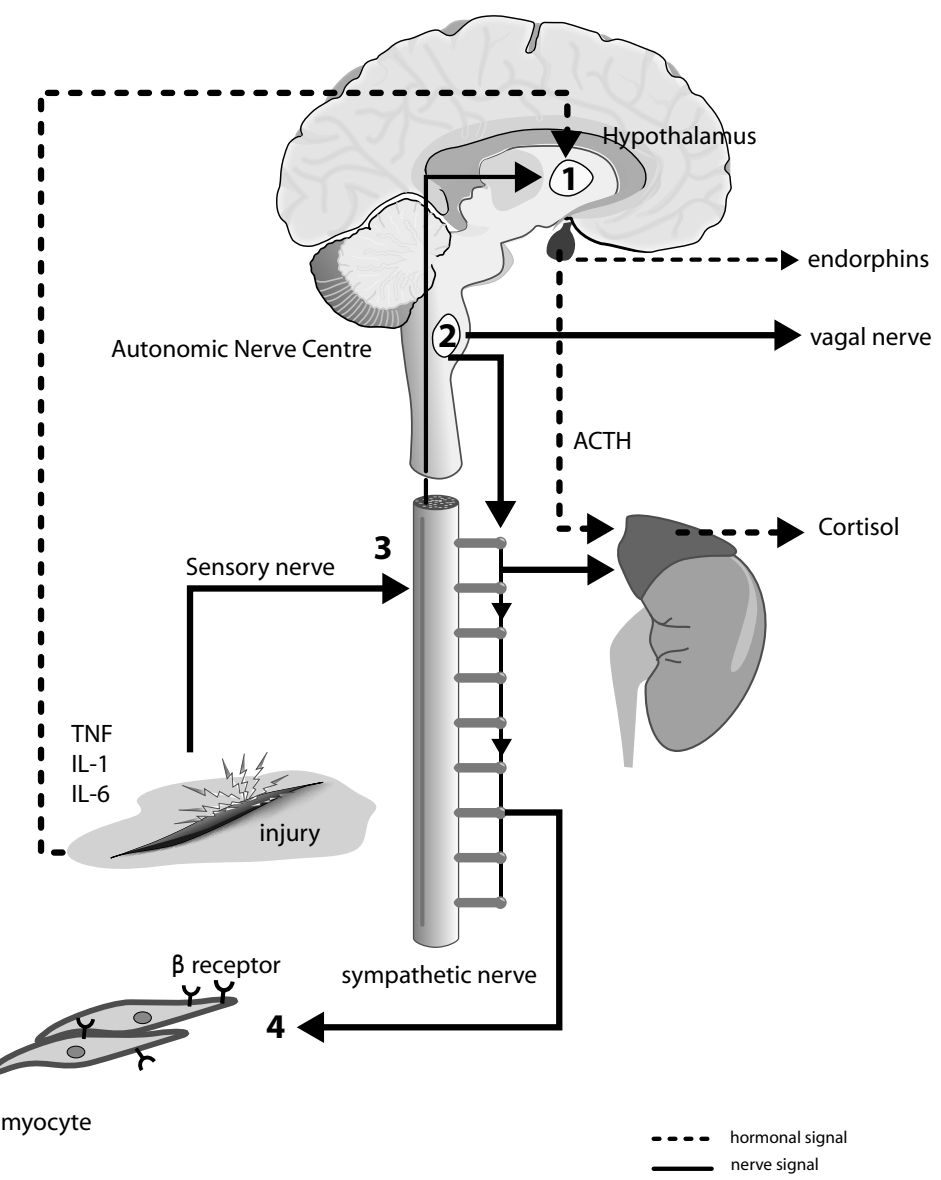

Figure 3. Strategies to decrease the stress response to tissue injury and their main location of action within the pathways of the stress response. 1 : opioids; 2 : alpha ${ }_{2}$-adrenergic agonists; $\mathbf{3}$ : epidural; $\mathbf{4}$ : beta-adrenergic antagonist. TNF:tissue necrosis factor;IL-1:interleukine-1;IL-6:interleukine-6. 
Table 2 . Studies in which the effects of different strategies on the stress response are directly compared

\begin{tabular}{|c|c|c|}
\hline & Neuro-endocrine response & Immune response \\
\hline Epidural vs opioid & $\begin{array}{l}\text { Epidural suppresses sympathetic and cortisol } \\
\text { response more effectively } 78,79\end{array}$ & $\begin{array}{l}\text { Epidural maintains lymphocyte } \\
\text { function after surgery better } \\
\text { than opioid } 29,31 \text {. } \\
\text { Epidural has no effect on IL-6 } \\
\text { response } 26,30,80\end{array}$ \\
\hline $\begin{array}{l}\text { Alpha }_{2} \text {-agonist } v s \\
\text { beta-blocker }\end{array}$ & $\begin{array}{l}\alpha_{2} \text {-agonist suppressed the increase in plasma } \\
\text { catecholamines to intubation } 85 \text { and to a rapid } \\
\text { increase in desflurane }{ }^{86} \text { more than the beta- } \\
\text { blocker. Cortisol response: not determined }\end{array}$ & Not determined \\
\hline $\begin{array}{l}\text { Epidural vs alpha } 2^{-} \\
\text {agonist }\end{array}$ & $\begin{array}{l}\text { Addition of epidural analgesia decreased } \\
\text { plasma epinephrine concentrations compared } \\
\text { to addition of clonidine in patients having } \\
\text { CABG surgery }{ }^{5} \text {. Cortisol response: not } \\
\text { different. }\end{array}$ & Not determined \\
\hline $\begin{array}{l}\text { Epidural } v s \\
\text { beta-blocker }\end{array}$ & $\begin{array}{l}\text { Addition of epidural anesthesia to beta- } \\
\text { blocked patients suppressed the increase in } \\
\text { myocardial oxygen consumption related to } \\
\text { surgery } 87 \text {. A high thoracic epidural decreased } \\
\text { angina pectoris in beta-blocked patients } 88 \text {. } \\
\text { Cortisol response: not determined }\end{array}$ & Not determined \\
\hline $\begin{array}{l}\text { Opioid } v s \\
\text { alpha }_{2} \text {-agonist }\end{array}$ & $\begin{array}{l}\text { In CABG surgery the addition of clonidine } \\
\text { to a general anesthetic resulted lower plasma } \\
\text { catecholamine levels compared to a high dose } \\
\text { opioid regimen } 89 \text {. Cortisol response: not } \\
\text { determined }\end{array}$ & Not determined \\
\hline $\begin{array}{l}\text { Opioid } v s \\
\text { beta-blocker }\end{array}$ & $\begin{array}{l}\text { Opioids suppressed the neuro-endocrine } \\
\text { stress response to laryngeal stimulation more } \\
\text { profoundly than beta-blockers } 90,91 \text {. Cortisol } \\
\text { response: not determined }\end{array}$ & Not determined \\
\hline
\end{tabular}

especially in surgery below the umbilicus. However, less data are available on immunological differences between these two techniques. Epidural analgesia seems to maintain postoperative lymphocyte function better than opioid analgesia $^{29,31}$. However, no effect of epidural analgesia on the IL-6 response has been found ${ }^{26,30,80}$. There are tight feedback connections between the immunological and neuro-endocrine components of the stress response. Therefore, it seems logical to study the effect of an intervention on both components of the stress response. However, most studies concentrate on only one of these components. The short-acting opioid remifentanil is increasingly used since the introduction of fast track surgical programs. These programs aim at shortening recovery time 
and therefore incorporate the use of short-acting anesthetic drugs or the combination of a regional anesthetic technique with a low dose general anesthetic. The fear is that these techniques thus may leave the patient relatively unprotected from potential harmful stress responses during the early period after major surgery ${ }^{81}$. Recently, it has been shown that an epidural-based anesthetic technique results in superior analgesia and haemodynamic stability compared to a remifentanil based technique ${ }^{82}$.

\section{Differences in modulation of the stress response of two pharmacological sympatholytic therapies.}

Only a few studies have compared the effects of an alpha ${ }_{2}$-agonist and a betablocker on the neuro-endocrine stress response and the related cardiovascular effects. This is surprising because it is very likely that these fundamentally different classes of sympatholytic drugs have different effects on the neuroendocrine stress response. Alpha 2 -agonists have a central sympatholytic effect, thus decreasing both alpha- and beta-receptor mediated sympathetic effects. In contrast, beta-blockers decrease only beta-receptor mediated sympathetic effects. Knowing differences between both classes of drugs on autonomic nervous system mediated cardiovascular control is important. This is because of its relation to myocardial oxygen balance and because evidence has emerged that cardiovascular control as such may be important in decreasing cardiac complications $^{83}$. An example of this evidence is that heart rate variability, one of the indicators of impaired cardiovascular control, is an independent predictor of adverse cardiac outcome in certain groups of patients ${ }^{84}$. The few comparative studies on the neuro-endocrine effects of alpha ${ }_{2}$-agonists and beta-blockers showed that the alpha ${ }_{2}$-agonist clonidine suppressed the increase in plasma catecholamines to intubation $^{85}$ and to a rapid increase in desflurane ${ }^{86}$ more than the beta-blocker esmolol. However, to date, differences in parasympathetic nervous system activation and baroreceptor mediated cardiovascular control of these groups of drugs have not been studied.

To conclude, the stress response to surgery consists of an immunological component and a neuro-endocrine component which interact closely. Each of these components seems to be involved in increasing the risk at perioperative myocardial ischemia. The anesthesiologist has a pivotal role in modulating the stress response to surgery and thus decreasing the risk at perioperative myocardial ischemia. To this, several anesthesiological techniques and pharmacological sympatholytic therapies may be used. There are indications that these various options affect the perioperative stress response differently. Knowing these differ- 
ences may help to define the optimal stress response modulating strategy. However, these differences and the associated cardiovascular effects are largely unknown because they have not been studied into detail. The studies presented in this thesis were designed to fill parts of these gaps in our knowledge.

\section{References}

1 Priebe HJ. Triggers of perioperative myocardial ischaemia and infarction. Br J Anesth 2004;93: 9-20.

2 Vatner SF. Correlation between acute reductions in myocardial blood flow and function in conscious dogs. Circ Res 1980; 47: 201-7.

3 de Torbal A, Boersma E, Kors JA et al. Incidence of recognized and unrecognized myocardial infarction in men and women aged 55 and older: the Rotterdam Study Eur Heart J 2006; 27: 729-36.

4 Devereaux PJ, Goldman L, Cook DJ et al. Perioperative cardiac events in patients undergoing noncardiac surgery: a review of the magnitude of the problem, the pathophysiology of the events and methods to estimate and communicate risk CMAJ 2005; 173: 627-34.

5 Mastorakos G, Ilias I. Interleukin-6: A Cytokine and/or a Major Modulator of the Response to Somatic Stress. Ann N Y Acad Sci 2006; 1088: 373-81.

6 Nathan N, Preux PM, Feiss P, Denizot Y. Plasma interleukin-4, interleukin-10, and interleukin-13 concentrations and complications after coronary artery bypass graft surgery. $J$ Cardiothorac Vasc Anesth 2000; 14: 156-60.

7 Cirino G, Napoli C, Bucci M, Cicala C. Inflammation-coagulation network: are serine protease receptors the knot? Trends Pharmacol Sci 2000; 21: 170-2.

8 Berczi I, Bertok L, Chow DA. Natural immunity and neuroimmune host defense. Ann N Y Acad Sci 2000; 917: 248-57.

9 Vallejo R, Hord ED, Barna SA, Santiago-Palma J, Ahmed S. Perioperative immunosuppression in cancer patients. J Environ Pathol Toxicol Oncol 2003; 22: 139-46.

10 Tsuchiya Y, Sawada S, Yoshioka I et al. Increased surgical stress promotes tumor metastasis. Surgery 2003; 133: 547-55.

11 Chrousos GP. Stressors, stress, and neuroendocrine integration of the adaptive response. The 1997 Hans Selye Memorial Lecture. Ann N Y Acad Sci 1998; 851: 311-35.

12 Amar D, Fleisher M, Pantuck CB et al. Persistent alterations of the autonomic nervous system after noncardiac surgery. Anesthesiology 1998; 89:30-42.

13 Wray DW, Formes KJ, Weiss MS et al. Vagal cardiac function and arterial blood pressure stability. Am J Physiol Heart Circ Physiol 2001; 281: H1870-80.

14 Tracey KJ. The inflammatory reflex. Nature 2002; 420: 853-9.

15 Sternberg EM. Neural regulation of innate immunity: a coordinated nonspecific host response to pathogens. Nat Rev Immunol 2006; 6: 318-28.

16 Nathan C. Points of control in inflammation. Nature 2002; 420: 846-52.

17 Desborough JP. The stress response to trauma and surgery. Br J Anesth 2000; 85: 109-17.

18 Besedovsky HO, del Rey A. Immune-neuro-endocrine interactions: facts and hypotheses. Endocr Rev 1996; 17: 64-102.

19 Molina PE. Neurobiology of the stress response: contribution of the sympathetic nervous system to the neuroimmune axis in traumatic injury. Shock Augusta, Ga. 2005; 24: 3-10.

20 Libby P. Inflammation in atherosclerosis. Nature 2002; 420: 868-74. 


\section{CHAPTER 2}

21 Landesberg G. The pathophysiology of perioperative myocardial infarction: facts and perspectives. J Cardiothorac Vasc Anesth 2003; 17: 90-100.

22 Fleisher LA, Zielski MM, Schulman SP. Perioperative ST-segment depression is rare and may not indicate myocardial ischemia in moderate-risk patients undergoing noncardiac surgery. $J$ Cardiothorac Vasc Anesth 1997; 11: 155-9.

23 Kehlet H. Manipulation of the metabolic response in clinical practice. World J Surg 2000; 24: 690-5.

24 Novitsky YW, Litwin DE, Callery MP. The net immunologic advantage of laparoscopic surgery. Surg Endosc 2004; 18: 1411-9.

25 Bauer M. Anasthesie und perioperative Immunfunktion. Anesthesist, Der 1998; 47: 939.

26 Naito Y, Tamai S, Shingu K et al. Responses of plasma adrenocorticotropic hormone, cortisol, and cytokines during and after upper abdominal surgery. Anesthesiology 1992; 77: 426-31.

27 Waurick R, Van Aken H. Update in thoracic epidural anesthesia. Best Pract Res Clin Anesthesiol 2005; 19: 201-13.

28 Procopio MA, Rassias AJ, DeLeo JA et al. The in vivo effects of general and epidural anesthesia on human immune function. Anesth Analg 2001; 93: 460-5.

29 Beilin B, Shavit Y, Trabekin E et al. The effects of postoperative pain management on immune response to surgery. Anesth Analg 2003; 97: 822-7.

30 Volk T, Dopfmer UR, Schmutzler M et al. Stress induced IL-10 does not seem to be essential for early monocyte deactivation following cardiac surgery. Cytokine 2003; 24: 237-43.

31 Volk T, Schenk M, Voigt K et al. Postoperative epidural anesthesia preserves lymphocyte, but not monocyte, immune function after major spine surgery. Anesth Analg 2004;98:1086-92.

32 Hollmann MW, Durieux ME. Local anesthetics and the inflammatory response: a new therapeutic indication? Anesthesiology 2000; 93: 858-75.

33 Rigg JR, Jamrozik K, Myles PS et al. Epidural anesthesia and analgesia and outcome of major surgery: a randomised trial. Lancet 2002; 359: 1276-82.

34 Feuerstein G, Siren AL. Hypothalamic mu-opioid receptors in cardiovascular control: a review. Peptides 1988; 9 Suppl 1:75-8.

35 Mistraletti G, Donatelli F, Carli F. Metabolic and endocrine effects of sedative agents. Curr Opin Crit Care 2005; 11:312-7.

36 Philbin DM, Rosow CE, Schneider RC, Koski G, D’Ambra MN. Fentanyl and sufentanil anesthesia revisited: how much is enough? Anesthesiology 1990; 73: 5-11.

37 Molina PE. Opioids and opiates: analgesia with cardiovascular, haemodynamic and immune implications in critical illness. J Intern Med 2006; 259: 138-54.

38 Vallejo R, de Leon-Casasola O, Benyamin R. Opioid therapy and immunosuppression: a review. Am J Ther 2004; 11: 354-65.

39 Mangano DT, Siliciano D, Hollenberg M et al. Postoperative myocardial ischemia. Therapeutic trials using intensive analgesia following surgery. The Study of Perioperative Ischemia (SPI) Research Group. Anesthesiology 1992; 76: 342-53.

40 Lessa MA, Tibirica E. Pharmacologic evidence for the involvement of central and peripheral opioid receptors in the cardioprotective effects of fentanyl. Anesth Analg 2006; 103: 815-21.

41 Zaugg M, Schaub MC, Pasch T, Spahn DR. Modulation of $\beta$-adrenergic receptor subtype activities in perioperative medicine: mechanisms and sites of action. $\mathrm{Br} J$ Anesth 2002; 88: 103-23.

42 Gottlieb SS, McCarter RJ. Comparative effects of three beta blockers (atenolol, metoprolol, and propranolol) on survival after acute myocardial infarction. Am J Cardiol 2001; 87: 823-6.

43 Wiest D. Esmolol. A review of its therapeutic efficacy and pharmacokinetic characteristics. Clin Pharmacokinet 1995; 28: 190-202. 
44 Hayano J, Sakakibara Y, Yamada A et al. Accuracy of assessment of cardiac vagal tone by heart rate variability in normal subjects. Am J Cardiol 1991; 67: 199-204.

45 Melenovsky V, Simek J, Sperl M, Malik J, Wichterle D. Relation between actual heart rate and autonomic effects of beta blockade in healthy men. Am J Cardiol 2005; 95: 999-1002.

46 Cogliati C, Colombo S, Ruscone TG et al. Acute beta-blockade increases muscle sympathetic activity and modifies its frequency distribution. Circulation 2004; 110: 2786-91.

47 Khan S, Liberzon I, Abelson JL. Effects of propranolol on symptom and endocrine responses to pentagastrin. Psychoneuroendocrinology 2004; 29: 1163-71.

48 Nonell A, Kerk S, Lederbogen F et al. No major effect of orciprenaline and propranolol upon ACTH-induced cortisol secretion. Exp Clin Endocrinol Diabetes 2004; 112: 59-61.

49 Wong J, Murthy A, Patterson M. Beta-adrenergic receptors (BAR): role in modulating the host immune response. Seminars in anesthesia, Perioperative Medicine and Pain 2007: 10-6.

50 Schmitz D, Wilsenack K, Lendemanns S, Schedlowski M, Oberbeck R. beta-Adrenergic blockade during systemic inflammation: Impact on cellular immune functions and survival in a murine model of sepsis. Resuscitation 2006.

51 Oberbeck R, van Griensven M, Nickel E et al. Influence of beta-adrenoceptor antagonists on hemorrhage-induced cellular immune suppression. Shock 2002; 18: 331-5.

52 Oberbeck R, Schmitz D, Wilsenack K et al. Adrenergic modulation of survival and cellular immune functions during polymicrobial sepsis. Neuroimmunomodulation 2004; 11: 214-23.

53 Mangano DT, Layug EL, Wallace A, Tateo I. Effect of atenolol on mortality and cardiovascular morbidity after noncardiac surgery. Multicenter Study of Perioperative Ischemia Research Group. N Engl J Med 1996; 335: 1713-20.

54 Poldermans D, Boersma E, Bax JJ et al. The effect of bisoprolol on perioperative mortality and myocardial infarction in high-risk patients undergoing vascular surgery. Dutch Echocardiographic Cardiac Risk Evaluation Applying Stress Echocardiography Study Group. N Engl J Med 1999; 341: 1789-94.

55 Eagle KA, Berger PB, Calkins $\mathrm{H}$ et al. ACC/AHA Guideline Update for Perioperative Cardiovascular Evaluation for Noncardiac Surgery-Executive Summary: A Report of the American College of Cardiology/American Heart Association Task Force on Practice Guidelines (Committee to Update the 1996 Guidelines on Perioperative Cardiovascular Evaluation for Noncardiac Surgery). Anesth Analg 2002; 94: 1052-64.

56 Wetterslev J, Juul AB. Benefits and harms of perioperative beta-blockade. Best Pract Res Clin Anesthesiol 2006; 20: 285-302.

57 Wiesbauer F, Schlager O, Domanovits $\mathrm{H}$ et al. Perioperative beta-blockers for preventing surgery-related mortality and morbidity: a systematic review and meta-analysis. Anesth Analg 2007; 104: 27-41.

58 Raby KE, Brull SJ, Timimi F et al. The effect of heart rate control on myocardial ischemia among high-risk patients after vascular surgery. Anesth Analg 1999; 88: 477-82.

59 Feringa HH, Bax JJ, Boersma E et al. High-dose beta-blockers and tight heart rate control reduce myocardial ischemia and troponin $\mathrm{T}$ release in vascular surgery patients. Circulation 2006; 114: I344-9.

60 Ebert TJ, Hall JE, Barney JA, Uhrich TD, Colinco MD. The effects of increasing plasma concentrations of dexmedetomidine in humans. Anesthesiology 2000; 93: 382-94.

61 McCallum JB, Boban N, Hogan Q et al. The mechanism of alpha2-adrenergic inhibition of sympathetic ganglionic transmission. Anesth Analg 1998; 87: 503-10.

62 Robertson HA, Leslie RA. Noradrenergic alpha 2 binding sites in vagal dorsal motor nucleus and nucleus tractus solitarius: autoradiographic localization. Can J Physiol Pharmacol 1985; 63: 1190-4. 


\section{CHAPTER 2}

63 Finley JC,Jr., O'Leary M, Wester D et al. A genetic polymorphism of the alpha2-adrenergic receptor increases autonomic responses to stress. J Appl Physiol 2004; 96: 2231-9.

64 Dorman T, Clarkson K, Rosenfeld BA et al. Effects of clonidine on prolonged postoperative sympathetic response. Crit Care Med 1997; 25: 1147-52.

65 Loick HM, Schmidt C, Van Aken H et al. High thoracic epidural anesthesia, but not clonidine, attenuates the perioperative stress response via sympatholysis and reduces the release of troponin $\mathrm{T}$ in patients undergoing coronary artery bypass grafting. Anesth Analg 1999; 88: 701-9.

66 Venn RM, Bryant A, Hall GM, Grounds RM. Effects of dexmedetomidine on adrenocortical function, and the cardiovascular, endocrine and inflammatory responses in post-operative patients needing sedation in the intensive care unit. Br J Anesth 2001; 86: 6506.

67 Nishina K, Akamatsu H, Mikawa K et al. The effects of clonidine and dexmedetomidine on human neutrophil functions. Anesth Analg 1999; 88: 452-8.

$68 \mathrm{Kim} \mathrm{MH}$, Hahn TH. The effect of clonidine pretreatment on the perioperative proinflammatory cytokines, cortisol, and ACTH responses in patients undergoing total abdominal hysterectomy. Anesth Analg 2000; 90: 1441-4.

69 von Dossow V, Baehr N, Moshirzadeh M et al. Clonidine attenuated early proinflammatory response in T-cell subsets after cardiac surgery. Anesth Analg 2006; 103: 809-14.

70 Stevens RD, Burri H, Tramer MR. Pharmacologic Myocardial Protection in Patients Undergoing Noncardiac Surgery: A Quantitative Systematic Review. Anesth Analg 2003; 97: 62333.

71 Indolfi C, Piscione F, Villari B et al. Role of alpha 2-adrenoceptors in normal and atherosclerotic human coronary circulation. Circulation 1992; 86: 1116-24.

72 Nishina K, Mikawa K, Uesugi T et al. Efficacy of clonidine for prevention of perioperative myocardial ischemia: a critical appraisal and meta-analysis of the literature. Anesthesiology 2002; 96: 323-9.

73 Wijeysundera DN, Naik JS, Beattie WS. Alpha-2 adrenergic agonists to prevent perioperative cardiovascular complications: a meta-analysis. Am J Med 2003; 114: 742-52.

74 Oliver MF, Goldman L, Julian DG, Holme I. Effect of mivazerol on perioperative cardiac complications during non- cardiac surgery in patients with coronary heart disease: the European Mivazerol Trial (EMIT). Anesthesiology 1999; 91: 951-61.

75 Wallace AW, Galindez D, Salahieh A et al. Effect of clonidine on cardiovascular morbidity and mortality after noncardiac surgery. Anesthesiology 2004; 101: 284-93.

76 Pruett SB. Quantitative aspects of stress-induced immunomodulation. Int Immunopharmacol 2001; 1: 507-20.

77 Devereaux PJ, Leslie K, Yang H. The effect of perioperative beta-blockers on patients undergoing noncardiac surgery - is the answer in? Can J Anesth 2004; 51: 749-55.

78 Liu S, Carpenter RL, Neal JM. Epidural anesthesia and analgesia. Their role in postoperative outcome. Anesthesiology 1995; 82: 1474-506.

79 Guay J. The benefits of adding epidural analgesia to general anesthesia: a metaanalysis. $J$ Anesth 2006; 20: 335-40.

80 Brix Christensen V, Tonnesen E, Sorensen IJ et al. Effects of anesthesia based on high versus low doses of opioids on the cytokine and acute-phase protein responses in patients undergoing cardiac surgery. Acta Anaesthesiol Scand 1998; 42: 63-70.

81 Myles PS, Daly DJ, Djaiani G, Lee A, Cheng DC. A systematic review of the safety and effectiveness of fast-track cardiac anesthesia. Anesthesiology 2003; 99: 982-7.

82 Kessler P, Aybek T, Neidhart G et al. Comparison of three anesthetic techniques for offpump coronary artery bypass grafting: general anesthesia, combined general and high 


\section{OPTIMISING CARDIAC OUTCOME}

thoracic epidural anesthesia, or high thoracic epidural anesthesia alone. J Cardiothorac Vasc Anesth 2005; 19: 32-9.

83 Parlow JL, Begou G, Sagnard P et al. Cardiac baroreflex during the postoperative period in patients with hypertension: effect of clonidine. Anesthesiology 1999; 90: 681-92.

84 Filipovic M, Jeger R, Probst C et al. Heart rate variability and cardiac troponin I are incremental and independent predictors of one-year all-cause mortality after major noncardiac surgery in patients at risk of coronary artery disease. J Am Coll Cardiol 2003; 42: 1767-76.

85 Zalunardo MP, Zollinger A, Szelloe $\mathrm{P}$ et al. Cardiovascular stress protection following anesthesia induction.Comparison of clonidine and esmolol. Anesthesist 2001; 50: 21-5.

86 Weiskopf RB, Eger EId, Noorani M, Daniel M. Fentanyl, esmolol, and clonidine blunt the transient cardiovascular stimulation induced by desflurane in humans. Anesthesiology 1994; 81: 1350-5.

87 Reiz S, Haggmark S, Rydvall A, Ostman M. Beta-blockers and thoracic epidural analgesia. Cardioprotective and synergistic effects. Acta Anesthesiol Scand Suppl 1982; 76: 54-61.

88 Gramling B, P., Miller MJ, Reeves ST, Roy RC, Zile MR. Treatment of medically and surgically refractory angina pectoris with high thoracic epidural analgesia: initial clinical experience. American heart journal 1997; 133: 648-55.

89 Gerlach K, Uhlig T, Huppe M et al. Remifentanil-clonidine-propofol versus sufentanilpropofol anesthesia for coronary artery bypass surgery. Cardiothorac Vasc Anesth 2002; 16: 7038.

90 Maguire A, Thompson JP, Guest C et al. Comparison of the effects of intravenous alfentanil and esmolol on the cardiovascular response to double-lumen endobronchial intubation. Anesthesia 2001; 56: 319-25.

91 Magnusson J, Werner O, Carlsson C, Norden N, Pettersson KI. Metoprolol, fentanyl and stress responses to microlaryngoscopy. Effects on arterial pressure, heart rate and plasma concentrations of catecholamines, ACTH and cortisol. Br J Anesth 1983; 55: 405-14. 


\section{CHAPTER 3}

Homeostatic responses after cardiac surgery

Effect of anaesthesia management

Henriëtte M. Willigers, John H. Heijmans, Jos G. Maessen and Paul M.H.J. Roekaerts

Submitted to European journal of anaesthesiology 


\section{Abstract}

Background and objective. Epidural-based and remifentanil-based anaesthetic techniques have different effects on the haemodynamic and analgetic responses after cardiac surgery. The purpose of this study was to compare their effects on sympathetic and inflammatory responses during the first day after surgery.

Methods. Patients received propofol anaesthesia combined with either thoracic epidural anaesthesia and low dose remifentanil (TEA group) or with high dose remifentanil (REMI group). Postoperative analgesia consisted of epidural bupivacaine and morphine (TEA group) or intravenous piritramide (REMI group).

Results. Plasma catecholamines and the pro-inflammatory interleukin-6 (IL6) were measured as measures of sympathetic and inflammatory responses respectively. Additionally, bactericidal permeability increasing protein, lipopolysaccharide binding protein, and C-reactive protein, and white blood cell count were measured. Ventilator dependency and analgesia were also evaluated. Plasma concentrations of epinephrine were less in the TEA group compared to the REMI group (300 (100 - 1300) versus $1000(600-1600)$ pmol $\mathrm{L}^{-1}$, median (interquartile range), $\left.\mathrm{P}<0.05\right)$ during the first 4 hours after surgery. In contrast, release of IL-6 was less in the REMI group (140 (100 - 290) versus (400 (200 - 500) $\left.\mathrm{pg} \mathrm{ml}^{-1}, \mathrm{P}<0.05\right)$. Analgesia was superior and ventilator dependency shorter in the TEA group. All other variables were not different.

Conclusions. The epidural-based anaesthetic technique had a superior sympatholytic effect and was associated with an increased IL-6 response, indicating the immunologic modulatory effects of anaesthesia management.

Keywords. Epidural, immune response, surgery - cardiovascular, opioid, sympathetic nervous system. 


\section{Introduction}

Recently, there has been much discussion about the safety of fast track cardiac anaesthesia because it may leave the patient relatively unprotected from potential harmful homeostatic stress responses during the early postoperative period [1]. Traditionally, there was much attention for the neuro-endocrine responses to cardiac surgery, which resulted in the concept of high-dose opioid anaesthesia. Over the past decades there is increasing interest in modulating the immune response to cardiac surgery with the expectation to decrease postoperative complications such as the systemic inflammatory response syndrome and infections [2].

Several different fast track anaesthetic strategies for cardiac surgery have been described. One is a technique based on the short-acting opioid remifentanil, which allows for the intra-operative use of high dose opioids without delaying extubation [3]. Alternatively, a thoracic epidural-based anaesthetic technique can be used because this technique has additional potential benefits such as profound stress response attenuation and thoracic cardiac sympathectomy [4]. Recently, it has been shown that an epidural-based anaesthetic technique results in superior analgesia and haemodynamic stability compared to a remifentanil based technique [5]. However, to our knowledge, studies comparing the early postoperative neuro-endocrine and the immunological effects of these two techniques are lacking. Therefore, we prospectively studied indicators of these homeostatic stress responses in patients managed with either an epidural-based or a remifentanil-based fast-track technique during the first day after elective on-pump coronary artery bypass surgery $(\mathrm{CABG})$.

\section{Methods}

After local ethics committee approval and written informed consent from the patients, 30 adult patients undergoing elective on-pump CABG were allocated to this prospective trial. The sample size was chosen on the basis of power calculation from a pilot study. It was calculated that a sample size of 15 in each group would provide $80 \%$ power using a Student's $t$-test with a significance level of 0.05 for detecting a difference in IL-6 and in catecholamines of at least 100\%. The current trial consisted of the following two anaesthetic treatment groups;1) Thoracic Epidural Analgesia (TEA group), 2) high dose remifentanil (REMI group). Exclusion criteria included left ventricular ejection fraction less than $25 \%$, recent myocardial infarction, pre-operative inotropic or intra-aortic balloon pump support, and significant pulmonary, endocrine, renal, or neurolog- 
ical disease. Patients who were not suitable for epidural blockade according to our National Guidelines were also excluded.

\section{Experimental design}

All patients continued their usual medications and received standardized premedication with oral midazolam $0.1-0.2 \mathrm{mg} \mathrm{kg}^{-1}$. After arrival in the induction room, the radial artery was cannulated and blood was sampled for baseline (BL) measurements. In the TEA group, the epidural catheter was inserted more than one hour before surgery at the C7 - T1 level. It was tested with $2 \mathrm{ml}$ of lidocaine $2 \%$. A loading dose of $10 \mathrm{ml}$ bupivacaine $0.25 \%$ and 2.5 mg morphine was infused over 1 hour, and sensible block heights were tested with application of cold. Anaesthesia was induced using target-controlled infusion (TCI) of propofol with the target at $2 \mu \mathrm{g} \mathrm{ml}^{-1}$ (BD Master Diprifusor TCI system, Brezins, France), remifentanil (GlaxoSmithKline, Zeist, The Netherlands) $2.5 \mu \mathrm{g} \mathrm{kg}^{-1}$ in 4 minutes, and pancuronium $0.1 \mathrm{mg} \mathrm{kg}^{-1}$ to facilitate orotracheal intubation. The patients were ventilated with oxygen-enriched air (40\% oxygen) and a pulmonary artery catheter was inserted into the right internal jugular vein. Anaesthesia was maintained with TCI propofol (target 1-2 $\mu \mathrm{g} \mathrm{ml}^{-1}$ ) and a remifentanil infusion protocol, which was different for both groups (REMI group $0.5 \mu \mathrm{g} \mathrm{kg}^{-1} \mathrm{~min}^{-1}$, TEA group $0.125 \mu \mathrm{g} \mathrm{kg}^{-1} \mathrm{~min}^{-1}$ ). Additionally, an epidural infusion of bupivacaine $\left[3.75 \mathrm{mg} \mathrm{ml}^{-1}\right]$ and morphine [0.2 mg ml $\mathrm{mas}^{-1}$ ] was started at a rate of $1.5 \mathrm{ml} \mathrm{hour}^{-1}$ in the TEA group. Cardiopulmonary bypass was standardized and performed using a hollow fibre membrane oxygenator, haemodilution, and moderate hypothermia $\left(34^{\circ} \mathrm{C}\right)$.

At arrival in the intensive care unit (ICU) patients were kept sedated with propofol $\left(0.5 \mathrm{mg} \mathrm{kg}^{-1} \mathrm{~h}^{-1}\right)$ and remifentanil $\left(0.025 \mu \mathrm{g} \mathrm{kg}^{-1} \mathrm{~min}^{-1}\right)$ for four hours. If necessary, propofol was increased to achieve moderate sedation (Ramsay sedation score 3-5) [6]. Acetaminophen, 1 gram every 6 hours was started as a basic analgesic. In the TEA group bupivacaine $0.125 \%$ and morfine $0.2 \mathrm{mg} \mathrm{ml}^{-1}$ were infused into the epidural catheter at a rate of $1.5 \mathrm{ml} \mathrm{h}^{-1}$ for 48 hours. The REMI group received $0.15 \mathrm{mg} \mathrm{kg}^{-1}$ intravenous piritramide, a $\mu$-receptor agonist with a potency of 0.7 compared with morphine, 15 minutes before stopping the sedative infusion. Tracheal extubation was performed when the patients had stable haemodynamics, were normothermic (core temperature $>36.5^{\circ} \mathrm{C}$ ), not bleeding (chest tube drainage $<100 \mathrm{~mL} \mathrm{~h}^{-1}$ ), and had adequate spontaneous ventilation (tidal volume $>5 \mathrm{~mL} \mathrm{~kg}^{-1}$, respiratory rate $>10$ breaths $\mathrm{min}^{-1}$, minute ventilation $>90 \mathrm{~mL} \mathrm{~kg}^{-1} \mathrm{~min}^{-1}, \mathrm{FiO}_{2}<40 \%$, peak end-expiratory pressure $<5 \mathrm{~cm} \mathrm{H}_{2} \mathrm{O}$, and arterial $\mathrm{PO}_{2}>12 \mathrm{kPa}$ ). Time to extubation from stop sedation was recorded.

The nursing staff evaluated pain scores every 30 minutes on a 5-point scale from "no pain" to "very severe pain" after stopping the sedative infusion. 
Piritramide $0.3 \mathrm{mg} \mathrm{kg}^{-1}$ was injected intramuscularly as an escape analgesic if the patient had more than slight pain. Quality of postoperative analgesia was evaluated from the number of piritramide administrations during the first 18 hours in the ICU. Then the patients were discharged to a step-down unit.

\section{Plasma Sampling and Measurements}

Plasma concentrations of catecholamines (norepinephrine and epinephrine) were measured as indicators of sympathetic tone, and interleukin-6 (IL-6) as a key mediator in the inflammatory response. Additionally, we measured bactericidal permeability increasing protein (BPI), as an indicator of neutrophil activation, lipopolysaccharide binding protein (LPB) and C-reactive protein (CRP) as indicators of the acute phase response, and leukocyte numbers and percentage of lymphocytes as indicators of the immunological cell response.

Samples for measurement of catecholamines and of BPI, LPB, and IL-6 were taken at five time-points: BL (baseline, before start of epidural or anaesthesia), T0 (at arrival in the ICU), T-4 (four hours after arrival in the ICU), T-8 (eight hours in ICU), and T-18 (eighteen hours in ICU). Blood samples for CRP and white blood cell count were taken on day 1,2, 4, and 6 after surgery. Arterial plasma epinephrine and norepinephrine concentrations were analysed with high-performance liquid chromatography with colorimetric electrochemical detection [7]. Plasma levels of BPI, IL-6 and LBP were measured using sandwich enzyme linked immunosorbent assays (Elisa's) as described previously [8]. CRP concentrations were measured using a turbidimetric method; the white blood cell count and the percentage of lymphocytes were measured with an automated white blood cell differential count according to the standard practice of our hospital laboratory.

\section{Statistical Analysis}

The SPSS (SPSS Inc., Chicago, IL) software for Windows, version 11.5 was used for statistical analysis. Differences between groups were analysed using the unpaired Student's $t$-test for patient characteristics, and the non-parametric Mann-Whitney U-test for all other data. Within group differences were analysed with the non-parametric Wilcoxon Matched-Pairs Signed-Ranks test followed by Bonferroni correction to allow for multiple comparisons as appropriate. Incidence of variables (the number of blood transfusions and of piritramide doses) were analysed using the chi-square test. A $P$-value of $<0.05$ was considered statistically significant. Results are presented as mean (SD) or median (interquartile range). 


\section{Results}

All 30 patients completed the study, had stable haemodynamic values without inotropic support throughout the study period, and had no postoperative complications necessitating prolonged hospitalization (data not shown). The epidural bolus dose resulted in sensory blockade from thoracic level 2 to 10 in all patients of the TEA group. Patient and perioperative data were similar in both groups (Table 1).

Plasma concentrations of epinephrine were about $80 \%$ less in the TEA group compared to the REMI group during the first 4 postoperative hours $(\mathrm{P}<0.05$ at T-0 and T-4, Fig. 1). Plasma concentrations of norepinephrine did not change and were similar in both groups (Fig. 1)

IL-6 remained unchanged in the REMI group, in contrast, epidural analgesia was associated with an approximately five-fold increase from baseline of this cytokine $(\mathrm{P}<0.01$, Fig. 2$)$. As a result plasma concentrations of IL-6 were different between both study groups $(\mathrm{P}<0.05$ at $\mathrm{T}-0, \mathrm{~T}-4$ and $\mathrm{T}-8$, Fig. 2$)$ during the first eight postoperative hours. Neutrophil activation, as indicated by the BPI response, peaked at arrival in the ICU $(200-300 \%$ increase from baseline, $\mathrm{P}<0.01)$ and was the same in both groups $(\mathrm{P}>0.1$ between both groups at all time points, Fig. 2). The increase in plasma concentrations of LBP and CRP, later markers of the inflammatory response, was also not different between both

Table 1 Patient characteristics and perioperative data of the two patient groups.

\begin{tabular}{lll}
\hline & REMI group & TEA group \\
\hline Age (yrs) & $57(11)$ & $61(10)$ \\
Height $(\mathrm{cm})$ & $172(8)$ & $171(9)$ \\
Weight $(\mathrm{kg})$ & $76(13)$ & $78(10)$ \\
Male : Female & $13: 2$ & $12: 3$ \\
Aortic Cross clamp time (min) & $57(25)$ & $46(17)$ \\
Cardiopulmonary bypass duration (min) & $80(31)$ & $74(23)$ \\
Coronary grafts (number) & $4(1)$ & $4(1)$ \\
Packed Cells: & 7 & 10 \\
Number of patients transfused & 24 & 26 \\
Number of packed cells transfused & 7 & $0 \star$ \\
Number of patients needing escape analgesia & $315(169)$ & $153(101) \star$ \\
Ventilator dependency time (min from stop sedation) &
\end{tabular}

REMI group $=$ remifentanil group. TEA $=$ thoracic epidural group. Data are presented as mean (SD). Statistical significance: ${ }^{\star} \mathrm{P}<0.001$ 

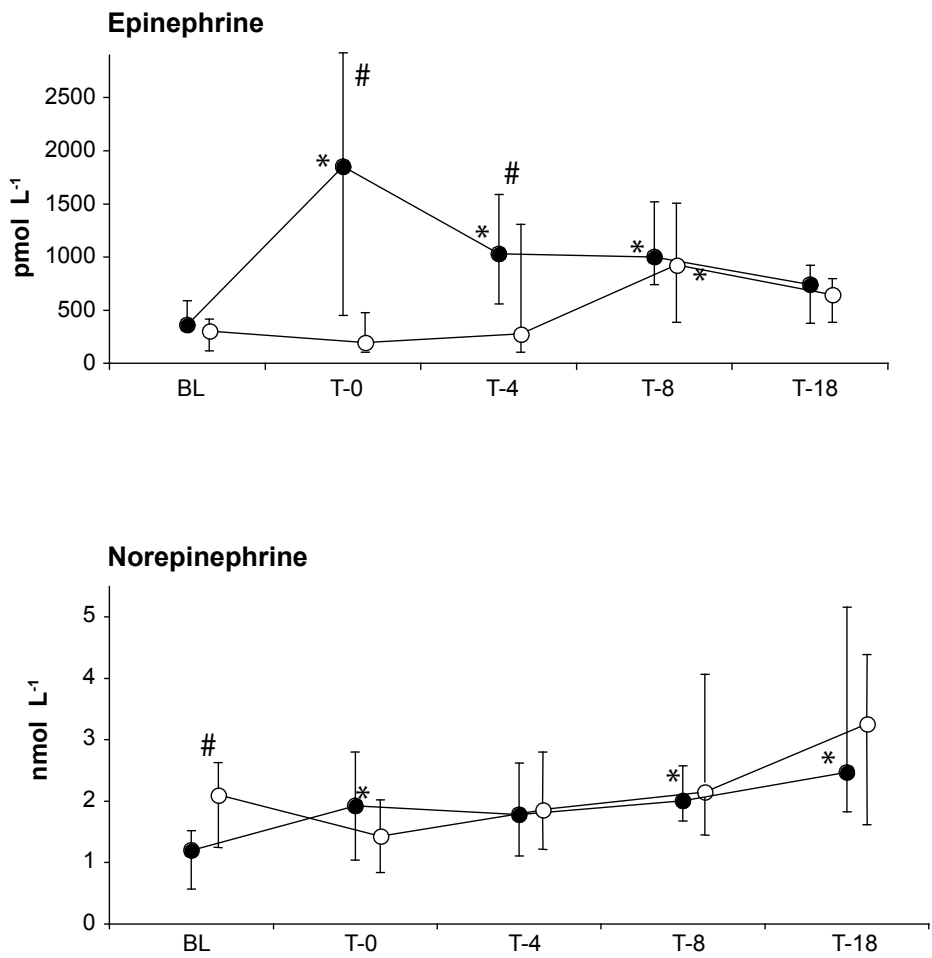

Figure 1. Time course of plasma catecholamines in the thoracic epidural group $(O)$ and in the remifentanil group $(-)$ during the first 18 hours after coronary artery bypass surgery. Dots and error lines indicate median and corresponding interquartile range of plasma concentrations of epinephrine and norepinephrine. ${ }^{\star}=\mathrm{P}<0.05 v$ s. corresponding baseline value (BL), $\#=\mathrm{P}<0.05$ thoracic epidural group $v$ s. remifentanil group. T-0, T-4, T-8, T-18 $=0,4,8,18$ hours after arrival in the intensive care unit. Plasma epinephrine was significantly less in the epidural group during the first four postoperative hours.

groups ( $\mathrm{P}>0.1$ at all time points, Fig. 2 and 3). White blood cell count and the relative fraction of lymphocytes, as indicators of the cellular immune response was also not different between both groups (Fig. 3). Epidural analgesia decreased pain and ventilator dependency more effectively than opioid analgesia (Table 1).

\section{Discussion}

The present data show that the choice of anaesthetic technique affects the inflammatory response to CABG surgery in addition to the well-known effect of anaesthesia on the neuro-humoral limb of the homeostatic stress response. We found that epidural analgesia had superior sympatholytic effects compared to 

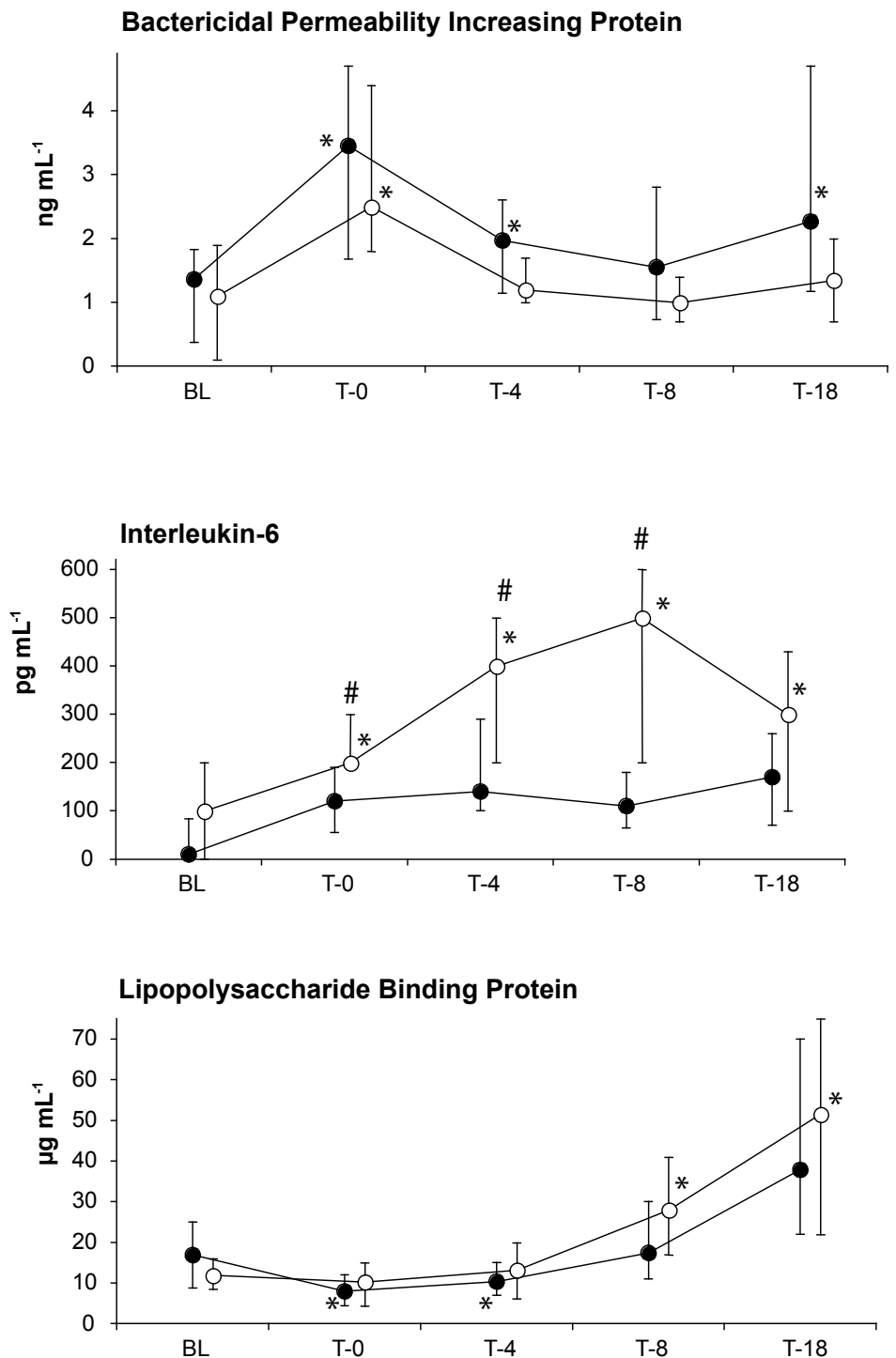

Figure 2. Time course of inflammatory mediators in the thoracic epidural group $(\mathrm{O})$ and in the remifentanil group $(-)$ during the first 18 hours after coronary artery bypass surgery. Dots and error lines indicate median and corresponding interquartile range of plasma concentrations of Bactericidal Permeability Increasing Protein, Interleukin-6, and Lipopolysaccharide Binding Protein. * = $\mathrm{P}<0.05 v$ s. corresponding baseline value $(\mathrm{BL}), \#=\mathrm{P}<0.05$ thoracic epidural group $v$ s. remifentanil group. T-0, T-4, T-8, T-18 $=0,4,8,18$ hours after arrival in the intensive care unit. Interleukin- 6 was significantly less in the remifentanil group during the first eight postoperative hours. 


\section{C-reactive Protein}

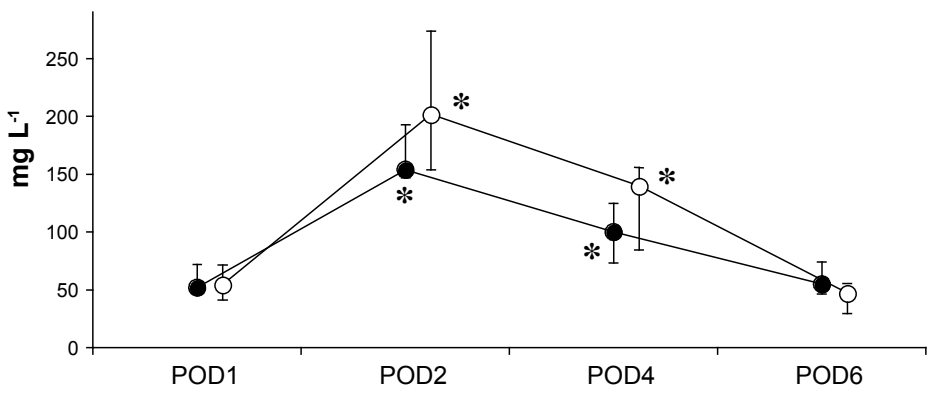

\section{Leukocytes}
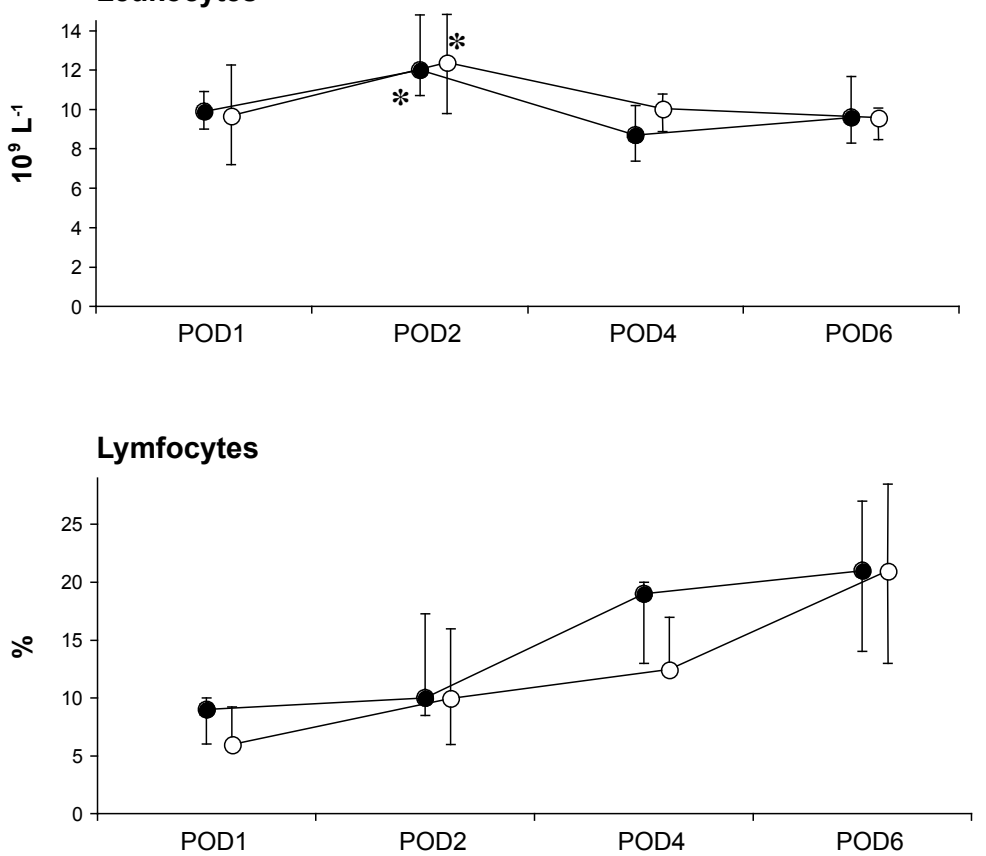

Figure 3. Time course of C-reactive Protein, number of leukocytes, and number fraction of Lymphocytes in the thoracic epidural group $(\bigcirc)$ and in the remifentanil group $(-)$ during the first 6 days after coronary artery bypass surgery. Dots and error lines indicate median values and corresponding interquartile range. ${ }^{\star}=\mathrm{P}<0.05$ vs. corresponding baseline value $(\mathrm{BL}), \#=\mathrm{P}<0.05$ thoracic epidural group $v s$. remifentanil group. PO1, POD2, POD4, POD $6=1,2,4$, and 6 days after surgery. No significant differences between groups of these immunological parameters were measured. 
opioid analgesia as indicated by decreased plasma epinephrine concentrations in the TEA group. These data confirm the findings of previous studies $[9,10]$, and can be explained from a decreased neural afferent input from the site of injury from epidural analgesia. In contrast, even large doses of opioids cannot completely prevent increases in plasma catecholamines during cardiac surgery [11,12], and it has been shown that the sympatholytic effect of the new opioid remifentanil is similar to that of the more traditional opioids [13]. The finding that epidural analgesia did not affect plasma norepinephrine concentrations is not in contradiction with its sympatholytic effect because it has been shown that high thoracic epidural analgesia decreases cardiac norepinephrine spill over from sternotomy without affecting plasma norepinephrine concentrations [14]. The relatively short duration of difference in sympatholytic effect may be explained by a decrease in the amount of the neural blockade associated with the use of a relatively small dose of local anaesthetics.

An important finding in this study is that the anaesthetic technique modulates the proinflammatory cytokine response after on-pump CABG. This can be concluded from the increased plasma concentration of IL-6 in the EPI group compared to the REMI group during the first eight hours after surgery. It is likely that intra-operative factors caused this difference because this cytokine is known to be produced 2 to 4 hours after tissue damage. Of these intra-operative factors, the anaesthetic technique most likely caused this difference because most other factors controlling the IL-6 response; surgical procedure, duration of bypass, and the amount of blood transfused [15], were similar in both groups. In accordance with our findings, there is growing evidence that anaesthetic techniques, and epidural anaesthesia in particular, modulate immunity of the surgical patient [16]. However, epidural analgesia, in general, does not affect the inflammatory IL-6 response to surgery. A possible explanation for the increased IL-6 response in our EPI group may be related to the improved sympatholysis in this group, because sympathetic activation is known to inhibit the production of proinflammatory cytokines [17]. However, in a previous study in CABG patients, differences in sympathetic tone were not translated into differences in IL-6 release [18]. Alternatively, a direct suppressive effect of remifentanil on the inflammatory cascade may explain the difference in IL-6. The IL-6 plasma concentrations of $100 \mathrm{pg} \mathrm{mL}^{-1}$ measured in our REMI group are similar to those measured previously after remifentanil anaesthesia [19]. These values are less than one fourth of those measured in presence of either epidural-based or long-acting opioid-based cardiac anaesthetic techniques $[18,20]$. There is growing evidence that opioids have a suppressive effect on cells of the immune system, either indirectly from their central nervous system mediated hormonal effects or from direct interactions with the $\mu 3$ opioid receptors on cells of the 
immune system [2]. Theoretically, opioids should affect also the IL-6 response to surgery because monocytes, which secrete IL-6, have opioid receptors [21]. However, the evidence for this theory is equivocal. Crozier and colleagues [22] showed that the opioid alfentanil diminished the IL- 6 response compared to inhalational anaesthesia, whereas Taylor and colleagues [23] showed no effect of fentanyl on IL-6 release. These contrasting results may be explained because there is evidence that opioids have differentiated immunological effects [24]. In accordance with a suppressive effect of remifentanil on inflammatory responses, it has been shown that this opioid suppresses natural killer function [25] and inhibits the early local inflammatory response in rats [26]. However, to date there are no studies which measure its effect on IL-6 release.

The clinical implications of this difference in IL-6 response remain uncertain, as the immune system is complex and difficult to assess from individual tests. It is important to stress that, in the current study, this effect of anaesthetic technique on IL-6 was not accompanied by differences in LBP, CRP, and number of leukocytes and leukocytes subsets, which are later markers of the immune response. An intriguing first implication of our finding could be a decreased likelihood for adverse outcome after remifentanil anaesthesia, because there are reports linking increased IL-6 levels with adverse outcome [27]. However, analgesia was superior, and ventilator dependency was shorter in the TEA group. Also, the association between IL-6 and adverse outcome seems to be only valid in the presence of an overwhelming systemic release of this cytokine, such as in sepsis. A second implication of the decreased IL-6 response during remifentanil anaesthesia is a potential increased risk at infectious complications. This is because IL-6 is necessary for initiating an effective inflammatory response against infection. In the current study there were no infectious complications in neither group but our study was underpowered to investigate such an effect.

A limitation of the current investigation is that the study period of approximately 24 hours was rather short, because neuro-endocriene and inflammatory changes after cardiac surgery are known to last about three days. However the peak change of most measured variables in the current study had already occurred within the study period. Another limitation is that this study could not be blinded, which could have influenced the results on detubation time and on pain measurement. However, the moment of detubation and administration of analgesics were strictly protocolized and performed by nurses not involved in the study.

In conclusion, this is the first study in which the effects of two different fast track anaesthetic techniques on both sympathetic and inflammatory responses during the early postoperative period after coronary artery surgery were evaluated. We showed that the epidural-based anaesthetic technique resulted in supe- 
rior sympatholysis and that the remifentanil-based technique was associated with a decreased proinflammatory cytokine response. Therefore, this study adds to the growing evidence that anaesthetic techniques affect immunological homeostatic responses in addition to their well-known effect on neurohumoral responses.

\section{References}

1 Myles PS, Daly DJ, Djaiani G, Lee A, Cheng DC. A systematic review of the safety and effectiveness of fast-track cardiac anesthesia. Anesthesiology 2003; 99: 982-7.

2 Laffey JG, Boylan JF, Cheng DC. The systemic inflammatory response to cardiac surgery: implications for the anesthesiologist. Anesthesiology 2002; 97: 215-52.

3 Royston D. Patient selection and anesthetic management for early extubation and hospital discharge: CABG. J Cardiothorac Vasc Anesth 1998; 12: 11-9.

4 Chaney MA. Intrathecal and Epidural Anesthesia and Analgesia for Cardiac Surgery. Anesth Analg 2006; 102: 45-64.

5 Kessler P, Aybek T, Neidhart G et al. Comparison of three anesthetic techniques for offpump coronary artery bypass grafting: general anesthesia, combined general and high thoracic epidural anesthesia, or high thoracic epidural anesthesia alone. J Cardiothorac Vasc Anesth 2005; 19: 32-9.

6 Barr J, Zomorodi K, Bertaccini EJ, Shafer SL, Geller E. A double-blind, randomized comparison of i.v. lorazepam versus midazolam for sedation of ICU patients via a pharmacologic model. Anesthesiology 2001; 95: 286-98.

7 Hoorn van der FAJ, Boomsma, Man in het Veld AJ, Schalekamp MADH. Determination of catecholamines in human plasma by high-performance liquid chromatography: comparison between a new method with fluorescence detection and an established method with electrochemical detection. Journal of Chromatography 1989; 487: 17-28.

8 Fransen E, Maessen J, Dentener M et al. Systemic inflammation present in patients undergoing CABG without extracorporeal circulation. Chest 1998; 113: 1290-5.

9 Liem TH, Booij LH, Gielen MJ, Hasenbos MA, van Egmond J. Coronary artery bypass grafting using two different anesthetic techniques: Part 3: Adrenergic responses.J Cardiothorac Vasc Anesth 1992; 6: 162-7.

10 Loick HM, Schmidt C, Van Aken H et al. High thoracic epidural anesthesia, but not clonidine, attenuates the perioperative stress response via sympatholysis and reduces the release of troponin $\mathrm{T}$ in patients undergoing coronary artery bypass grafting. Anesth Analg 1999; 88: 701-9.

11 Philbin DM, Rosow CE, Schneider RC, Koski G, D’Ambra MN. Fentanyl and sufentanil anesthesia revisited: how much is enough? Anesthesiology 1990; 73: 5-11.

12 Duncan HP, Cloote A, Weir PM et al. Reducing stress responses in the pre-bypass phase of open heart surgery in infants and young children: a comparison of different fentanyl doses. $\mathrm{Br}$. J. Anaesth. 2000; 84: 556-64.

13 Howie MB, Cheng D, Newman MF et al. A randomized double-blinded multicenter comparison of remifentanil versus fentanyl when combined with isoflurane/propofol for early extubation in coronary artery bypass graft surgery. Anesth Analg 2001; 92: 1084-93.

14 Kirno K, Friberg P, Grzegorczyk A et al. Thoracic epidural anesthesia during coronary artery bypass surgery: effects on cardiac sympathetic activity, myocardial blood flow and metabolism, and central hemodynamics. Anesth Analg 1994; 79: 1075-81. 


\section{HOMEOSTATIC RESPONSES AND CARDIAC SURGERY}

15 Fransen E, Maessen J, Dentener M, Senden N, Buurman W. Impact of blood transfusions on inflammatory mediator release in patients undergoing cardiac surgery. Chest 1999; 116: 12339.

16 Bauer M. Anasthesie und perioperative Immunfunktion. Erganzende Bemerkungen zur Ubersicht von M. Bauer, H. Rensing und T. Ziegenfuss . Anaesthesist 1998; 47: 538-56.

17 Sternberg EM. Neural regulation of innate immunity: a coordinated nonspecific host response to pathogens. Nat Rev Immunol 2006; 6: 318-28.

18 Volk T, Dopfmer UR, Schmutzler M et al. Stress induced IL-10 does not seem to be essential for early monocyte deactivation following cardiac surgery. Cytokine 2003; 24: 237-43.

19 Bauer M, Wilhelm W, Kraemer T et al. Impact of bispectral index monitoring on stress response and propofol consumption in patients undergoing coronary artery bypass surgery. Anesthesiology 2004; 101: 1096-104.

20 Brix Christensen V, Tonnesen E, Sorensen IJ et al. Effects of anaesthesia based on high versus low doses of opioids on the cytokine and acute-phase protein responses in patients undergoing cardiac surgery. Acta Anaesthesiol Scand 1998; 42: 63-70.

21 Bidlack JM. Detection and function of opioid receptors on cells from the immune system. Clin Diagn Lab Immunol 2000; 7: 719-23.

22 Crozier TA, Muller JE, Quittkat D et al. Effect of anaesthesia on the cytokine responses to abdominal surgery. Br J Anaesth 1994; 72: 280-5.

23 Taylor NM, Lacoumenta S, Hall GM. Fentanyl and the interleukin-6 response to surgery. Anaesthesia 1997; 52: 112-5.

24 Borgland SL, Connor M, Osborne PB, Furness JB, Christie MJ. Opioid Agonists Have Different Efficacy Profiles for G Protein Activation, Rapid Desensitization, and Endocytosis of Mu-opioid Receptors. J. Biol. Chem. 2003; 278: 18776-84.

25 Sacerdote P, Gaspani L, Rossoni G, Panerai AE, Bianchi M. Effect of the opioid remifentanil on cellular immune response in the rat. Int Immunopharmacol 2001; 1: 713-9.

26 Taylor BK, Peterson MA, Roderick RE et al. Opioid inhibition of formalin-induced changes in plasma extravasation and local blood flow in rats. Pain 2000; 84: 263-70.

27 Pinsky M, Vincent J, Deviere J et al. Serum cytokine levels in human septic shock. Relation to multiple- system organ failure and mortality. Chest 1993; 103: 565-75. 


\section{CHAPTER 4}

Dexmedetomidine decreases perioperative myocardial lactate release in dogs

Henriëtte M. Willigers, Frits W. Prinzen, Paul M. Roekaerts, Simon de Lange and Marcel E. Durieux.

Anesth Analg 2003; 96: 657-64. 


\begin{abstract}
The sympatholytic effect of the $\alpha_{2}$-adrenergic agonist dexmedetomidine may decrease emergence-related myocardial ischemic load in patients. However, a direct measure of myocardial ischemia such as myocardial lactate release is difficult to obtain in patients. Therefore, we studied mongrel dogs and measured myocardial lactate release, myocardial oxygen supply, hemodynamic parameters, and neurohumoral indices of the stress response. After induction of a standardized degree of borderline myocardial ischemia, either dexmedetomidine (Dexmed group, $\mathrm{n}=9$ ) or normal saline (Control group, $\mathrm{n}=9$ ) was infused. Measurements were repeated at the end of the anesthetic period, and every 10 minutes during the 90-minutes emergence period. In the Dexmed group cumulative emergence-related lactate release was 46\% lower than in the Control group (95\% CI $=20$ to $80 \%, \mathrm{P}=0.02)$. Simultaneously, dexmedetomidine increased the endo-/epicardial blood flow ratio by 35\% (Control group: $0.4 \pm$ 0.1 , Dexmed group: $0.6 \pm 0.1$ endo/epi ratio, $\mathrm{P}=0.03)$. These anti-ischemic effects of dexmedetomidine were accompanied by lower plasma concentrations of norepinephrine (126 vs. $577 \mathrm{pg} / \mathrm{ml})$ and epinephrine (158 vs.1909 pg/ml), and a lower heart rate $(123 \pm 6$ vs.160 \pm 10 beats $/$ min, Dexmed vs. Control) The anti-ischemic effect of dexmedetomidine started prior to emergence as evidenced by a lower prevalence of myocardial lactate release at that time (Dexmed: 0/8, Control 4/7 dogs lactate release prior to emergence, $\mathrm{P}=0.03$ ). Implications: Dexmedetomine decreases plasma catecholamines and heart rate during emergence from anesthesia. In dogs with a coronary stenosis these sympatholytic effects decrease myocardial lactate release, and therefore minimize emergence-related myocardial ischemia.
\end{abstract}

Key Words: myocardial ischemia, postoperative complications, $\alpha_{2}$-adrenergic agonists, sympatholysis. 


\section{Introduction}

Early postoperative myocardial ischemia is one of the most important risk factors for adverse cardiac outcome in surgical patients with coronary artery disease ${ }^{1}$. Because this risk factor appears related to the stress response associated with surgery and emergence from anesthesia, methods to reduce this stress response have been studied. Examples include epidural analgesia, profound opioid analgesia, and administration of $\beta$-adrenoceptor antagonists or $\alpha_{2}-$ adrenergic agonists ${ }^{2}$. The last modality in particular seems promising because, in contrast to $\beta$-adrenoceptor antagonists, $\alpha_{2}$-agonists reduce overall tonic sympathetic action, reduce anesthetic requirements, and induce analgesia and anxiolysis ${ }^{3}$.

It is well known that $\alpha_{2}$-adrenergic agonists can attenuate the stress response associated with emergence from anesthesia ${ }^{4-6}$. However, whether this translates to less postoperative myocardial ischemia is unknown. This is partly because until now only 2 studies have focused directly on this issue ${ }^{7,8}$. And, although these studies show that $\alpha_{2}$-agonists decrease the incidence of emergence-related ST-depression and postoperative cardiac deaths in high-risk surgical patients, no effect on myocardial infarction has been demonstrated.

One of the main reasons for the paucity of information on the effect of $\alpha_{2}-$ agonists on postoperative myocardial ischemia, is the difficulty to select a practical and clinical relevant outcome measure. The outcome measure myocardial infarction has a low incidence, necessitating studying a large number of patients. Selecting ST-segment changes as an outcome measure may not always be clinically relevant because they also result from changes in temperature, serum electrolytes, position, and from administration of drugs ${ }^{9}$. A more precise measure of myocardial ischemia, but difficult to obtain in patients, is the presence of lactate release from the myocardial area at risk. Also, it has been shown that not the incidence but the load (i.e. duration) of myocardial ischemia is most significantly associated with adverse cardiac outcome ${ }^{10}$, and therefore may be a more appropiate outcome measure.

Therefore, our aim was to determine in a placebo-controlled study if dexmedetomidine, the most specific $\alpha_{2}$-agonist available, can decrease cumulative myocardial lactate release in dogs having a coronary stenosis and emerging from surgery and anesthesia. To obtain more insight in potential mechanisms we also measured the effects of dexmedetomidine on hemodynamic parameters, neurohumoral indices of the stress response, and on indices of myocardial oxygen supply and demand. 


\section{Methods}

\section{Animal preparation}

With the approval of the Animal Care and Use Committee at the University of Maastricht we studied 18 adult mongrel dogs. After induction of anesthesia with $20 \mathrm{mg} / \mathrm{kg}$ sodium thiopental intravenously, the dogs were intubated and ventilated with halothane in oxygen / nitrous oxide. After thoracotomy, a screwdriven plastic occluder was placed non-constrictively distal to the first diagonal branch of the left anterior descending coronary artery (LAD). This occluder allows producing a fixed stenosis from controllable narrowing of coronary arteries. Catheters were inserted into the left femoral artery, the left anterior coronary vein, and a distal pulmonary artery for arterial (A), coronary venous $(\mathrm{CV})$, and mixed venous (MV) blood sampling. To measure regional myocardial blood flow, a catheter for injection of microspheres was implanted in the left atrial appendage. Pressure sensors (Sentron 180 S, Cordis, Roden, the Netherlands) were inserted through the right femoral artery into the ascending aorta and left ventricle (LV). Ultrasonic transit-time flow probes (Transonic Systems, Ithaca, NY) were placed around the aortic root and just proximal to the coronary occluder. Heart rate was monitored using limb lead II of the electrocardiogram. To measure regional myocardial shortening, a pair of $1.5 \mathrm{~mm}$-diameter piezoelectric crystals was inserted parallel to circumferential midwall fibers in the area perfused by the LAD and connected to a digital sonomicrometer (Sonometrics Corporation, London, Ontario, Canada)

Throughout the experiment, all signals were continuously displayed on monitors, and the corresponding values were stored every minute. During each period of measurement, digitized signals (12 bit A/D interface, sample frequency $200 \mathrm{~Hz}$ ) and corresponding beat-to-beat values were stored for 5 minutes. During off-line processing, all data of a 2 -minute stable period (i.e. less than $5 \%$ heart rate variation) within this 5 -minute acquisition period were averaged.

All blood samples were collected on ice. Those to be analyzed afterwards were centrifuged within $15 \mathrm{~min}$ at $4^{\circ} \mathrm{C}$ to separate plasma, and stored at $-70^{\circ} \mathrm{C}$.

\section{Study protocol (Fig. 1)}

At the start of the study protocol anesthesia was standardized to $1 \%$ halothane in oxygen / nitrous oxide (33\% / 66\%). After 20 minutes a stenosis of the LAD was applied, standardized as the tightest stenosis not resulting in myocardial lactate release during stable anesthesia. We aimed to increase the probability of myocardial lactate release from emergence-related stress responses by creating comparable degrees of borderline ischemia, and used lactate release as primary outcome variable. 


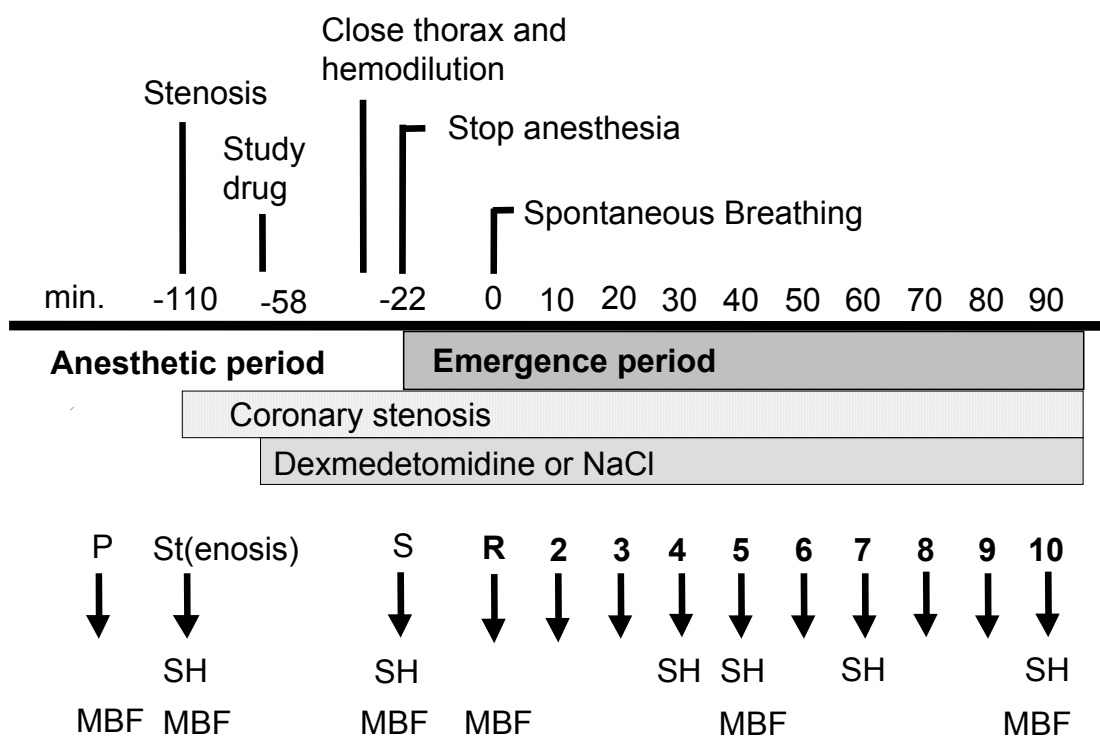

Figure 1. Schematic representation of the study protocol. Black arrows represent periods of measurements of hemodynamic variables; hemoglobin content; arterial and coronary venous blood gases; poststenotic coronary flow, lactate release, and regional myocardial contractile function. Stress hormones $(\mathrm{SH})$ and regional myocardial blood flow $(\mathrm{MBF})$ were measured less frequently. Time axis shows excact number of minutes from start sponteneous breathing (first emergence period measurement), and approximate number of minutes before this event. Note that baseline stenosis measurements were performed BEFORE study drug administration.

$\mathrm{P}=$ before coronary stenosis. $\mathrm{St}=$ coronary Stenosis. $\mathrm{S}=\mathrm{Stop}$ anesthesia. $\mathrm{R}=$ first emergence period measurement at start of spontaneous Respiration. $2,3,4, \ldots=$ emergence period measurements

To create similar borderline ischemia in both groups, the coronary artery was narrowed step by step at 5-minutes intervals until the poststenotic myocardium released lactate, i.e. $[(\mathrm{CV}-\mathrm{A})$ lactate $]>0$. Then the occluder was released step by step until lactate release just ceased. During this procedure, lactate concentrations were measured within 3 minutes using an absorption photometric method (DR Lange cuvette test LKM 140, Berlin, Germany). After a stabilization period of 15 minutes the following baseline variables were measured: 1) hemodynamic variables (heart rate, aortic pressure, end-diastolic and maximum first derivative of LV pressure ( $\mathrm{dPdT}_{\max }$ ), and aortic flow);2) stress hormones (arterial plasma concentrations of norepinephrine, epinephrine, and cortisol); 3) indicators of myocardial oxygen balance (LAD flow, regional myocardial blood flow, fractional oxygen extraction, and poststenotic myocardial lactate release). 
After these baseline stenosis measurements the study-drug was administered. Animals were randomly assigned to one of 2 groups: those receiving dexmedetomidine (loading dose $0.5 \mu \mathrm{g} \mathrm{kg}^{-1}$ followed by a continuous infusion of $0.6 \mu \mathrm{g} \cdot \mathrm{kg}^{-1} \cdot$ hour $^{-1}$, Dexmed group, $\left.\mathrm{n}=9\right)$, or those receiving placebo $(0.9 \%$ $\mathrm{NaCl}$, Control Group, $\mathrm{n}=9$ ). We did not blind administration of the studydrug because the marked bradycardic effect of dexmedetomidine makes this virtually impossible. The target plasma concentration of dexmedetomidine was $0.5 \mathrm{ng} \mathrm{ml}^{-1}$ because this concentration does not have major vasoconstrictive effects (11), and reduces sympathetic tone effectively in dogs(12) and in humans (4). The corresponding infusion scheme (timing and dose) was obtained from pharmacokinetic data of our pilot study.

About 10 minutes after starting the study-drug, the chest wall was closed and care was taken to maintain the position of the occluder by observing coronary flow and myocardial shortening signals. The pneumothorax was evacuated by careful manual inflation of the lungs. To mimic perioperative blood loss and to decrease the number of animals needed in our study, blood was collected from the femoral artery and replaced simultaneously with a colloid solution (Haemace ${ }^{\circledR}$, Behringwerke AG, Marburg) until a hemoglobin value of approximately $6.5 \mathrm{mmol} \mathrm{L}^{-1}$ was reached. After completion of surgery, $0.01 \mathrm{mg} \mathrm{kg}^{-1}$ buprenorphine was injected intramuscularly for postoperative analgesia (13), the dogs were restrained, and measurements were repeated. Then the emergence period was started by changing the inspiratory gas to $100 \%$ oxygen. The first emergence period measurement was made at the moment the dogs first breathed spontaneously. This was done to standardize the level of consciousness during the emergence period. Then, measurements were repeated every 10 minutes during 90 minutes. By protocol no interventions were made if ventricular fibrillation (VF) occurred. At the end of the experiment, the dogs were euthanized by pentobarbital overdose, and their hearts were stored at $-20^{\circ} \mathrm{C}$ for regional blood flow analysis.

\section{Measurements and calculations}

Myocardial ischemic load: Plasma lactate concentrations were determined spectrophotometrically (Cobas Bio System, Hoffman La Roche, Basel, Switzerland) afterwards, and the presence of myocardial lactate release ([(CV $-\mathrm{A})$ lactate] > 0) was identified. Of each dog the cumulative myocardial ischemic load of the emergence period, our primary outcome measure, was calculated as the percentage of measurements indicating myocardial lactate release. In dogs that died from VF, missing lactate measurements were added to the myocardial ischemic load provided that VF occurred during a period of lactate release. We consider this appropriate because VF is a more severe consequence of myocar- 
dial ischemia than is myocardial lactate release, and not coding these measurements would have underestimated myocardial ischemia in these dogs.

Myocardial oxygen extraction and consumption: Hemoglobin content $(\mathrm{Hb}$ $(\mathrm{mmol} / \mathrm{L}))$ and oxygen saturation $\left(\mathrm{SaO}_{2}(\%)\right)$ of $\mathrm{A}, \mathrm{CV}$, and $\mathrm{MV}$ samples were measured with a hemoxymeter (OSM-2, Radiometer, Copenhagen, Denmark), and oxygen tension $\left(\mathrm{PO}_{2}(\mathrm{kPa})\right)$ was measured with a blood gas analyzer (Radiometer ABL 3). The $\mathrm{O}_{2}$ content $\left(\mathrm{CaO}_{2}(\mathrm{mmol} / \mathrm{L})\right)$ was calculated as: $\mathrm{Hb} \times$ $\mathrm{SaO}_{2}+0.0102 \times \mathrm{PO}_{2}$. From this, oxygen extraction and consumption were calculated using standard formulas.

Regional myocardial shortening: Myocardial circumferential segment lengths at begin ejection (Be sl) and end ejection (Ee sl) were measured using the aortic flow signal to delineate the ejection period. From these, percentage systolic shortening during the ejection period (Sse) was calculated as SSe (\%) $=100 \times$ (Be sl - Ee sl)/ Be sl.

Regional myocardial blood flow: Regional myocardial blood flow was measured with fluorescent labeled microspheres (polystyrene, diameter: 15.5 $\mu \mathrm{m} \pm 2 \%$, Molecular Probes, Eugene, OR) of 6 different colors (blue-green, yellow-green, orange, red, crimson, and scarlet) as described in detail elsewhere (14). Briefly, for each measurement approximately $4 \times 10^{6}$ microspheres of a single color were injected into the left atrium; simultaneously a reference arterial blood sample was withdrawn. Afterwards, several adjacent myocardial samples were taken from the poststenotic myocardial wall and from the remote nonischemic myocardial wall, and divided into subendo- and subepicardial samples. Microspheres were isolated, their fluorescence determined, and regional myocardial flow was calculated. Of the poststenotic myocardial wall, the area with lowest flow immediately after aplication of the stenosis was used for analysis.

Plasma concentrations of stress hormones and dexmedetomidine: Catecholamines were measured fluorimetrically (15). Serum cortisol concentration was determined using solid-phase, chemiluminescent enzyme immunoassay (Immulite $^{\circledR}$, Cortisol kit, DPC, Los Angeles). Plasma concentrations of dexmedetomidine were determined by gas chromatography-mass spectrometry (16) at Farmos Research, Turku, Finland.

Pressure work index: The pressure work index (PWI, equivalent to $\left.\mu \mathrm{mol} \cdot \mathrm{min}^{-1} \cdot \mathrm{g}^{-1}\right)$ was calculated as a measure of myocardial oxygen demand (17)

$\mathrm{PWI}=\mathrm{C} 1(\mathrm{SBP} \times \mathrm{HR})+\mathrm{C} 2(0.8 \mathrm{SBP}+0.2 \mathrm{DBP}) \times \mathrm{HR} \times \mathrm{SV} / \mathrm{BW}+0.57$

Where

$\mathrm{SV}=$ stroke volume $(\mathrm{ml})$

$\mathrm{SBP}=$ systolic blood pressure $(\mathrm{mmHg})$

$\mathrm{DBP}=$ diastolic blood pressure $(\mathrm{mmHg})$ 


\section{CHAPTER 4}

58

$$
\begin{aligned}
& \mathrm{BW}=\text { body weight }(\mathrm{kg}) \\
& \mathrm{C} 1=1.63 \times 10^{-4} \\
& \mathrm{C} 2=1.30 \times 10^{-4}
\end{aligned}
$$

\section{Statistical analysis}

From the 18 dogs, 1 dog from each group was not included in the statistical analysis; in the control group because of VF before administration of the studydrug, in the dexmed group because of severe postoperative hemorrhage. Of some variables data from at most 1 experiment were missing due to technical problems. Data are presented as mean \pm SEM, unless stated otherwise.

Emergence period values of each experiment were summarized as median values. This was done because the use of a summary measure is considered the most appropriate approach to analyze serial measurements (18). Differences between groups were evaluated by Mann-Whitney $U$ test, within group changes by Wilcoxon Signed Rank Test with Bonferroni correction, and differences between ratios by Fisher's Exact Test. A P-value $<0.05$ was considered statistically significant. Additionally, individual timepoints were analyzed using Two Way Repeated Measures Anova followed by Tukey test for multiple comparisons.

\section{Results}

Effects of dexmedetomidine during the emergence period.

The cumulative myocardial ischemic load was $46 \%$ lower in the Dexmed group than in the Control group ( $95 \% \mathrm{CI}=20$ to $80 \%, \mathrm{P}=0.02$, Fig. 2). Simultaneously, dexmedetomidine increased total coronary blood flow distal to the stenosis (figure 3), especially in the endocardial layers, as indicated by a 35\% higher endo- / epicardial blood flow ratio (Table 1). The other determinants of myocardial oxygen supply, hemoglobin concentration and partial arterial oxygen pressure, were similar in both groups (Table 1). Regarding demand, dexmedetomidine decreased heart rate during the emergence period by approximately $23 \%$, but it did not affect aortic flow, aortic pressure and PWI (Table 2). In neither group myocardial ischemia was preceded by a change in heart rate, blood pressure, or coronary flow (data not shown). The differences in incidence (\%) between both groups of (1) myocardial lactate release $(95 \% \mathrm{CI}=$ $19 \%$ to $65 \%)$; and (2) VF $(95 \% \mathrm{CI}=-5$ to $+62 \%)$ were not statistically significant (Fig. 2B).

With regard to the emergence-related stress response, plasma catecholamines, heart rate, and oxygen consumption of the body were lower in the Dexmed group than in the Control group (Table 2, Fig. 3). Of these, dexmedetomidine 


\section{Control Dexmed}
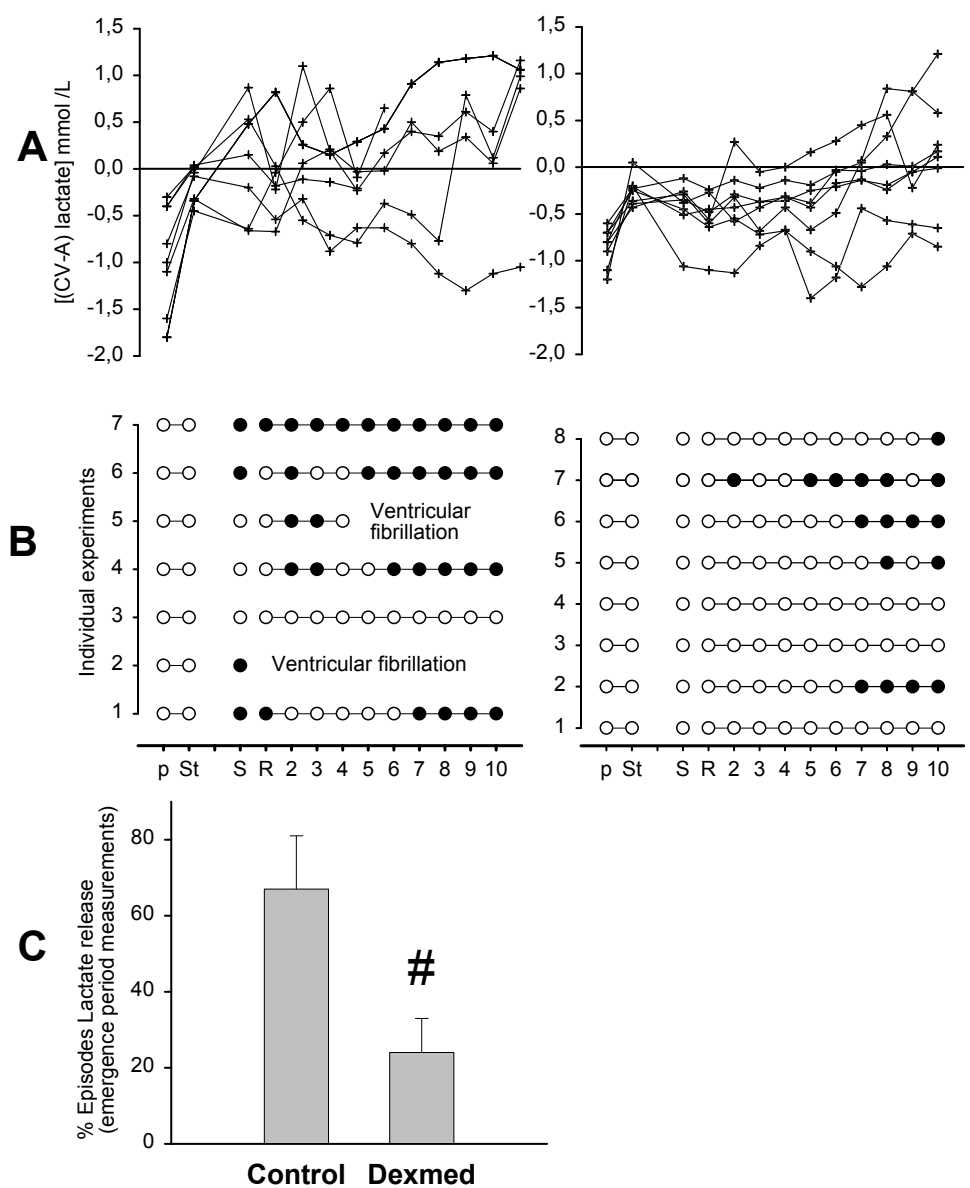

Figure 2. Effect of dexmedetomidine on poststenotic myocardial lactate release in dogs emerging from anesthesia. Panel A: Time course of individual coronary venous (CV) to arterial (A) lactate differences in the Control group (left panel) and Dexmed group (right panel). In $1 \mathrm{dog}$ of the Control group no lactate data were obtained because of technical problems. Panel B: Data from panel A represented as either presence $(-)$ or absence $(\bigcirc)$ of episodes myocardial lactate release. Panel C: Mean values \pm SEM of the cumulative myocardial ischemic load during the emergence period (= (episodes lactate release or VF / total emergence period measurements) X 100\%). $\mathrm{P}=$ before coronary stenosis. $\mathrm{St}=$ coronary Stenosis. $\mathrm{S}=$ Stop anesthesia. $\mathrm{R}=$ first emergence period measurement at start of spontaneous Respiration. $2,3,4, \ldots=$ emergence period measurements. \#: $\mathrm{P}<0.02$ : Dexmed vs. Control group. 

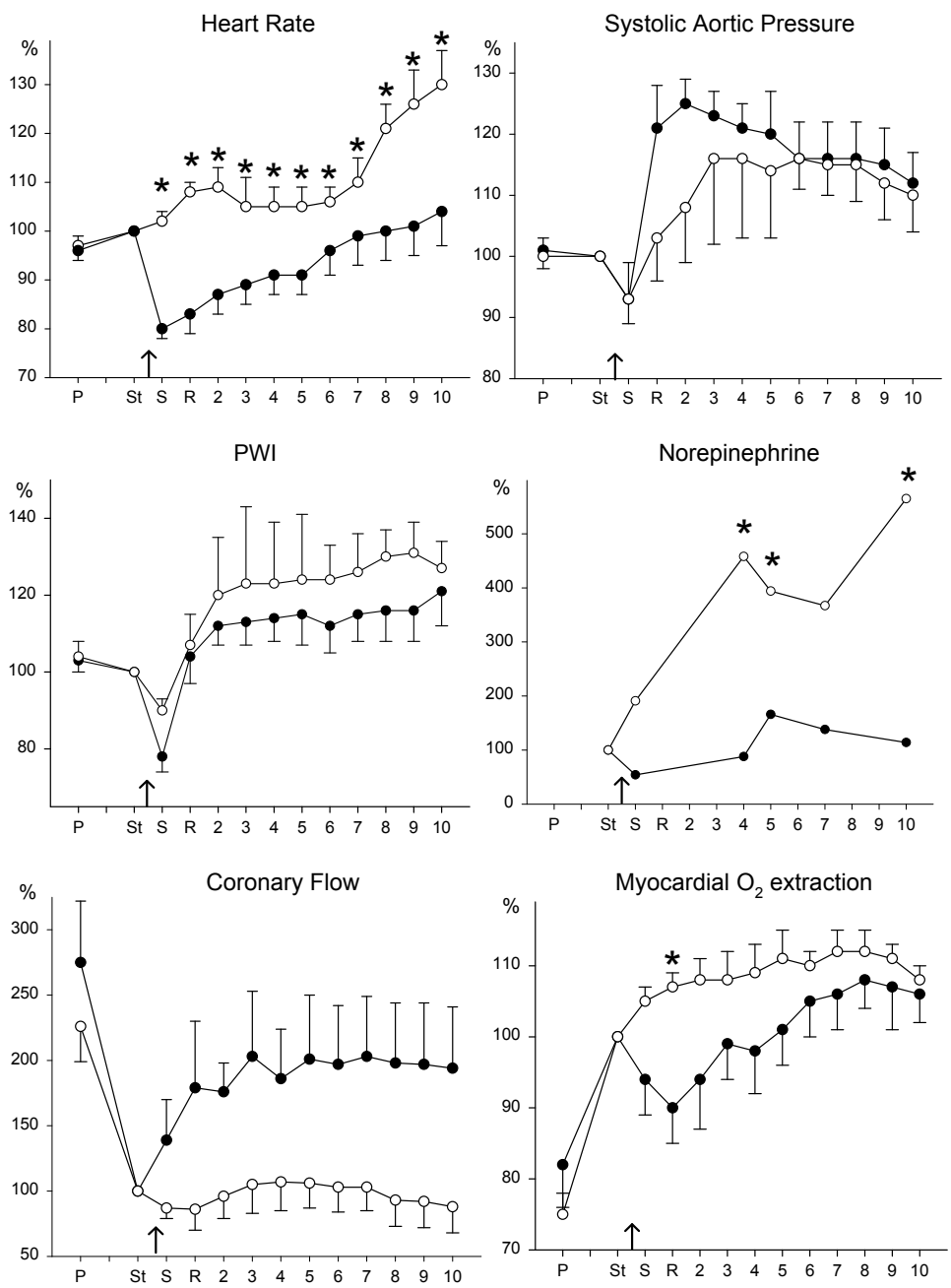

Figure 3. Changes in time in hemodynamics, plasma norepinephrine concentration, and poststenotic myocardial oxygenation in the Dexmed group $(\mathbf{O})$ and Control group $(\bigcirc)$. Values are plotted as mean percentages of baseline stenosis measurements. Error bars indicate SEM. For plasma norepinephrine concentrations median values are plotted. Arrow indicates start administration of study drug. $\mathrm{P}=$ before coronary stenosis. $\mathrm{St}=$ coronary Stenosis. $\mathrm{S}=\mathrm{Stop}$ anesthesia. $\mathrm{R}$ $=$ first emergence period measurement at start of spontaneous Respiration. $2,3,4, \ldots=$ emergence period measurements.

Absolute values of these data are given in table 1and 2. ${ }^{\star} \mathrm{P}<0.05$, Control group vs. Dexmed group (Two Way Repeated Measures Anova on absolute values followed by Tukey test for multiple comparisons). 
Table 1. Changes in Indices of Myocardial Oxygen Supply

\begin{tabular}{|c|c|c|c|c|c|c|}
\hline Variable & Area & Group & $\begin{array}{l}\text { Pre-stenosis } \\
\text { (Pre- drug) }\end{array}$ & $\begin{array}{l}\text { Stenosis } \\
\text { (Pre- drug) }\end{array}$ & $\begin{array}{l}\text { Stop } \\
\text { (Drug) }\end{array}$ & $\begin{array}{l}\text { Emergence } \\
\text { (Drug) }\end{array}$ \\
\hline \multirow{2}{*}{$\begin{array}{l}\text { Endocardial flow } \\
\mathrm{ml} \cdot \min ^{-1} \cdot \mathrm{g}^{-1}\end{array}$} & \multirow[t]{2}{*}{ Stenotic } & Control & $1.0 \pm 0.1$ & $0.3 \pm 0.1^{\star}$ & $0.3 \pm 0.1$ & $0.4 \pm 0.1$ \\
\hline & & Dexmed & $0.8 \pm 0.1^{\#}$ & $0.3 \pm 0.1^{\star}$ & $0.5 \pm 0.1$ & $0.6 \pm 0.1$ \\
\hline \multirow{2}{*}{$\begin{array}{l}\text { Epicardial flow } \\
\text { ml.min }{ }^{-1} \cdot \mathrm{g}^{-1}\end{array}$} & \multirow[t]{2}{*}{ Stenotic } & Control & $1.2 \pm 0.1$ & $0.8 \pm 0.1^{\star}$ & $0.8 \pm 0.1$ & $1.0 \pm 0.1$ \\
\hline & & Dexmed & $0.9 \pm 0.1$ & $0.9 \pm 0.2$ & $0.7 \pm 0.1$ & $1.0 \pm 0.1$ \\
\hline \multirow{2}{*}{$\begin{array}{l}\text { Endo-/epicardial } \\
\text { blood flow ratio }\end{array}$} & \multirow[t]{2}{*}{ Stenotic } & Control & $1.0 \pm 0.1$ & $0.5 \pm 0.1^{\star}$ & $0.4 \pm 0.1$ & $0.4 \pm 0.1$ \\
\hline & & Dexmed & $0.8 \pm 0.1$ & $0.4 \pm 0.1^{\star}$ & $0.7 \pm 0.1^{\star \#}$ & $0.6 \pm 0.1 \#$ \\
\hline \multirow{2}{*}{$\begin{array}{l}\text { Endocardial flow } \\
\mathrm{ml} . \mathrm{min}^{-1} \cdot \mathrm{g}^{-1}\end{array}$} & \multirow[t]{2}{*}{ Remote } & Control & $1.2 \pm 0.1$ & $1.1 \pm 0.2$ & $1.1 \pm 0.1$ & $1.4 \pm 0.2$ \\
\hline & & Dexmed & $0.9 \pm 0.1$ & $1.2 \pm 0.2$ & $0.9 \pm 0.1$ & $1.3 \pm 0.1$ \\
\hline \multirow{2}{*}{$\begin{array}{l}\text { Epicardial flow } \\
\text { ml.min }{ }^{-1} \cdot g^{-1}\end{array}$} & \multirow[t]{2}{*}{ Remote } & Control & $1.1 \pm 0.1$ & $1.0 \pm 0.2$ & $1.0 \pm 0.1$ & $1.4 \pm 0.1^{\star}$ \\
\hline & & Dexmed & $0.9 \pm 0.1$ & $1.2 \pm 0.2$ & $0.8 \pm 0.1$ & $1.2 \pm 0.1$ \\
\hline \multirow{2}{*}{$\begin{array}{l}\text { Endo-/epicardial } \\
\text { bloodflow ratio }\end{array}$} & \multirow[t]{2}{*}{ Remote } & Control & $1.1 \pm 0.1$ & $1.1 \pm 0.1$ & $1.1 \pm 0.1$ & $1.1 \pm 0.1$ \\
\hline & & Dexmed & $1.0 \pm 0.1$ & $1.0 \pm 0.1$ & $1.1 \pm 0.0$ & $1.0 \pm 0.0$ \\
\hline \multirow{2}{*}{$\begin{array}{l}\text { Fractional } \mathrm{O}_{2} \\
\text { extraction }\end{array}$} & \multirow[t]{2}{*}{ Stenotic } & Control & $0.55 \pm 0.03$ & $0.73 \pm 0.01^{\star}$ & $0.77 \pm 0.02$ & $0.79 \pm 0.03$ \\
\hline & & Dexmed & $0.60 \pm 0.04$ & $0.75 \pm 0.04^{\star}$ & $0.70 \pm 0.05$ & $0.76 \pm 0.04^{\star}$ \\
\hline \multirow{2}{*}{$\begin{array}{l}\text { LAD flow } \\
\mathrm{ml} / \mathrm{min} \text { (flow probe) }\end{array}$} & \multirow[t]{2}{*}{ Stenotic } & Control & $33 \pm 4$ & $16 \pm 2^{\star}$ & $14 \pm 3$ & $14 \pm 3$ \\
\hline & & Dexmed & $27 \pm 4$ & $12 \pm 2^{\star}$ & $14 \pm 2$ & $20 \pm 4 \star$ \\
\hline \multirow{2}{*}{$\begin{array}{l}\text { Hemoglobin (A) } \\
\text { mmol/L }\end{array}$} & & Control & $8.5 \pm 0.3$ & $9.0 \pm 0.3$ & $6.2 \pm 0.3^{\star}$ & $6.5 \pm 0.6$ \\
\hline & & Dexmed & $8.2 \pm 0.3$ & $7.7 \pm 0.6$ & $6.7 \pm 0.5$ & $6.9 \pm 0.4$ \\
\hline \multirow{2}{*}{\multicolumn{2}{|c|}{$\begin{array}{l}\mathrm{pO}_{2}(\mathrm{~A} \\
\mathrm{kPa}\end{array}$}} & Control & $13 \pm 1$ & $12 \pm 1$ & $18 \pm 1^{\star}$ & $16 \pm 2$ \\
\hline & & Dexmed & $16 \pm 2$ & $16 \pm 1$ & $18 \pm 2$ & $11 \pm 2^{\star}$ \\
\hline
\end{tabular}

Data are mean \pm SEM. Pre-stenosis and Stenosis values are measured just before, and just after application of the coronary stenosis. Stop values are measured just prior to stopping the anesthetics, Emergence values are median values of all time points during emergence. Pre- drug = before starting study drug (dexmedetomidine or $\mathrm{NaCl}$ ). Drug $=$ in presence of study drug. LAD $=$ left anterior descending coronary artery. $\mathrm{A}=$ Arterial, $\star=\mathrm{P}<0.05$ compared to preceding measurement in the same group, $\#=P<0.05$, Control group vs. Dexmed group. 


\section{CHAPTER 4}

Table 2. Changes in Hemodynamic Variables and Stress Hormones.

\begin{tabular}{|c|c|c|c|c|c|}
\hline Variable & Group & $\begin{array}{l}\text { Pre-stenosis } \\
\text { (Pre- Drug) }\end{array}$ & $\begin{array}{l}\text { Stenosis } \\
\text { (Pre- Drug) }\end{array}$ & $\begin{array}{l}\text { Stop } \\
\text { (Drug) }\end{array}$ & $\begin{array}{l}\text { Emergence } \\
\text { (Drug) }\end{array}$ \\
\hline Heart Rate & Control & $139 \pm 4$ & $145 \pm 6$ & $148 \pm 9$ & $160 \pm 10^{\star}$ \\
\hline beats/minute & Dexmed & $125 \pm 4^{\#}$ & $131 \pm 5$ & $104 \pm 3^{\star} \#$ & $123 \pm 6^{\star} \#$ \\
\hline \multirow{2}{*}{$\begin{array}{l}\text { Systolic Aortic Pres } \\
\text { sure } \mathrm{mmHg}\end{array}$} & Control & $109 \pm 4$ & $109 \pm 5$ & $100 \pm 5$ & $113 \pm 8$ \\
\hline & Dexmed & $99 \pm 5$ & $97 \pm 4$ & $90 \pm 5$ & $113 \pm 5$ \\
\hline \multirow{2}{*}{$\begin{array}{l}\mathrm{dPdT}_{\max } \\
\mathrm{mmHg} / \mathrm{sec}\end{array}$} & Control & $1365 \pm 97$ & $1368 \pm 90$ & $1384 \pm 123$ & $2153 \pm 185^{\star}$ \\
\hline & Dexmed & $1323 \pm 79$ & $1270 \pm 76$ & $1012 \pm 42^{\star \#}$ & $1781 \pm 152^{\star}$ \\
\hline \multirow{2}{*}{$\begin{array}{l}\text { Enddiastolic LVP } \\
\mathrm{mmHg}\end{array}$} & Control & $11 \pm 2$ & $12 \pm 1$ & $10 \pm 1$ & $5 \pm 1$ \\
\hline & Dexmed & $8 \pm 1$ & $8 \pm 1^{\#}$ & $9 \pm 1$ & $4 \pm 1^{\star}$ \\
\hline Aortic Flow & Control & $3.5 \pm 0.3$ & $2.8 \pm 0.3$ & $2.4 \pm 0.2$ & $2.8 \pm 0.3$ \\
\hline $\mathrm{L} / \mathrm{min}$ & Dexmed & $2.8 \pm 0.2$ & $2.4 \pm 0.1$ & $1.9 \pm 0.1^{\star \#}$ & $2.5 \pm 0.1^{\star}$ \\
\hline \multirow{2}{*}{$\begin{array}{l}\text { Pressure Work Index } \\
\mu \text { mol.min }{ }^{-1} \cdot \mathrm{g}^{-1}\end{array}$} & Control & $4.7 \pm 0.2$ & $4.5 \pm 0.3$ & $4.0 \pm 0.2$ & $5.1 \pm 0.5$ \\
\hline & Dexmed & $3.8 \pm 0.2$ & $3.7 \pm 0.2$ & $2.9 \pm 0.1^{\star \#}$ & $4.2 \pm 0.3^{\star}$ \\
\hline SSE & Control & $5 \pm 1$ & $6 \pm 1$ & $4 \pm 1$ & $5 \pm 1$ \\
\hline$\%$ & Dexmed & $7 \pm 1$ & $6 \pm 1$ & $3 \pm 1^{\star}$ & $7 \pm 1^{\star}$ \\
\hline \multirow{2}{*}{$\begin{array}{l}\text { O, consumption body } \\
\text { mmol. } \mathrm{kg}^{-1} \cdot \mathrm{min}^{-1}\end{array}$} & Control & $0.22 \pm 0.02$ & $0.24 \pm 0.02$ & $0.22 \pm 0.02$ & $0.31 \pm 0.02$ \\
\hline & Dexmed & $0.21 \pm 0.01$ & $0.19 \pm 0.02$ & $0.19 \pm 0.01$ & $0.22 \pm 0.02^{\#}$ \\
\hline Cortisol & Control & & $438 \pm 40$ & $405 \pm 46$ & $389 \pm 52$ \\
\hline $\mathrm{nmol} / \mathrm{L}$ & Dexmed & & $439 \pm 53$ & $400 \pm 80$ & $402 \pm 81$ \\
\hline Norepinephrine & Control & & $116(115-211)$ & $180(175-348)$ & $577(305-609)^{\star}$ \\
\hline $\mathrm{pg} / \mathrm{ml}$ & Dexmed & & $114(54-178)$ & $61(27-173)^{\#}$ & $126(51-286)^{\#}$ \\
\hline Epinephrine & Control & & $435(320-799)$ & $395(238-475)$ & $1909(136-3489)^{\star}$ \\
\hline $\mathrm{pg} / \mathrm{ml}$ & Dexmed & & $281(179-363)$ & $84(45-404)$ & $158(91-1448)^{\#}$ \\
\hline
\end{tabular}

Data are mean \pm SEM, except plasma catecholamines which are presented as median $(25-75 \%$ interval). Pre-stenosis and Stenosis values are measured just before, and just after application of the coronary stenosis. Stop values are measured just prior to stopping the anesthetics, Emergence values are median values of all time points during emergence. Pre-drug $=$ before starting study drug (dexmedetomidine or placebo). SSE $=$ systolic shortening of the ejection period. $\star=P<0.05$ compared to preceding measurement in the same group, $\#=\mathrm{P}<0.05$, Control group vs. Dexmed group. 


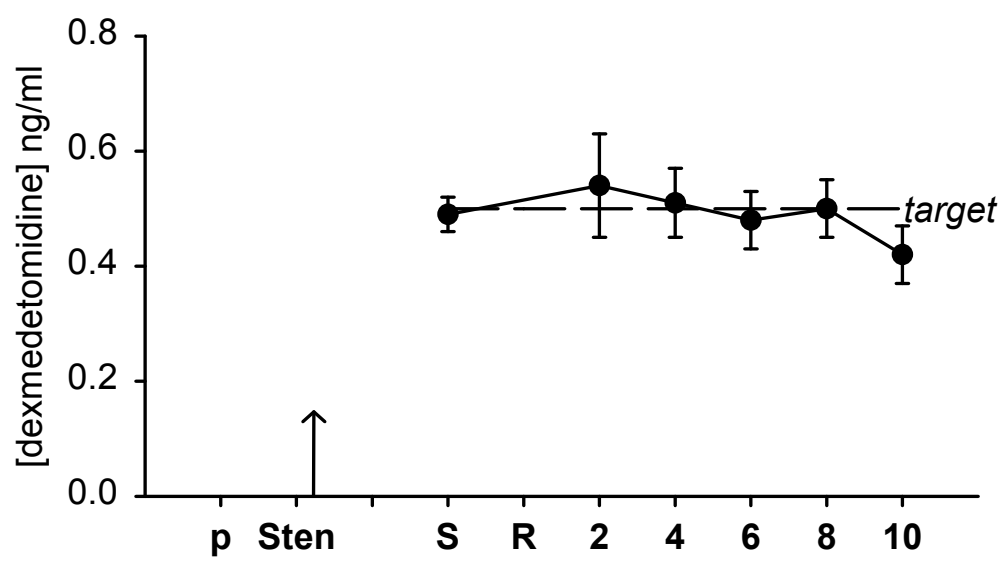

Figure 4. Stability of plasma concentrations of dexmedetomidine (mean \pm SEM, $\mathrm{n}=8 \mathrm{dogs}$ ) in relation to target plasma concentration of $0.5 \mathrm{ng} / \mathrm{ml} . \mathrm{P}=$ before coronary stenosis. $\mathrm{St}=$ coronary Stenosis. $\mathrm{S}=$ Stop anesthesia (about 35 minutes after starting dexmedetomidine). $\mathrm{R}=$ first emergence period measurement at start of spontaneous Respiration. $2,3,4, \ldots=$ emergence period measurements

prevented only an increase in plasma catecholamines compared to the preceding intraoperative measurements. The time to regain spontaneous breathing after stopping the anesthetics, as a measure of emergence, tended to be longer in the Dexmed group, but this was not statistically significant (Dexmed group: $30 \pm 6$, Control Group: $16 \pm 2 \mathrm{~min} ; 95 \% \mathrm{CI}$ for the difference between groups $=-3$ to $+29 \min , \mathrm{P}>0.2)$.

Effects of dexmedetomidine prior to emergence.

Prior to emergence the prevalence of myocardial lactate release was $57 \%$ lower in the Dexmed group than in the Control group (95\% CI $=20 \%$ to $94 \%, \mathrm{P}=$ 0.03 , Stop values Fig. $2 B$ ). Simultaneously, dexmedetomidine decreased plasma concentrations of norepinephrine by $66 \%$, decreased myocardial oxygen demand (PWI) by 29\% (Table 2) and increased the endo-/epicardial blood flow ratio by $45 \%$ (Table 1 ).

\section{Experimental model}

Intra-operative procedures were the same in both groups. First, application of the stenosis resulted in a similar decrease in myocardial oxygenation. This is because: 1 ) myocardial lactate release was abcent in both groups (Control Group: $-0.1 \pm 0.1$; Dexmed group $-0.2 \pm 0.0 \mathrm{mmol} / \mathrm{L}(\mathrm{CV}-\mathrm{A})$ [lactate], $\mathrm{P}=0.16$, Fig. 2A stenosis values), 2) endocardial flow decreased similarly (Dexmed group: 59 
$\pm 6 \%$, Control group: $66 \pm 8 \%$ decrease; $\mathrm{P}>0.5$, Table 1), and 3) baseline stenosis values were similar for all variables except EDP (stenosis values Table 1, 2, Fig. 2A). Second, the duration of surgery and anesthesia was the same in both groups because the time between 'stenosis' and 'stop anesthesia' measurements was $81 \pm 8$ minutes in the Dexmed group, and $76 \pm 9$ minutes in the Control Group (95\% CI $=-19$ to +20 minutes, $\mathrm{P}>0.5)$. Finally, intra-operative hemodilution resulted in a similar hemoglobin (Table 1)

Plasma concentrations of dexmedetomidine were stable and close to our target of $0.5 \mathrm{ng} / \mathrm{ml}$ (Fig. 4), and no animal in either group required additional buprenorphine.

\section{Discussion}

In the current study the $\alpha_{2}$-agonist dexmedetomidine decreased myocardial ischemic load in dogs with a coronary stenosis and emerging from anesthesia. This anti-ischemic effect of dexmedetomidine was associated with a decreased sympathetic tone and improved myocardial oxygen balance. The unique feature of our study was that we used invasive measurements of myocardial oxygenation of the area of risk that are not obtainable from human studies. Our data therefore may help explain clinical findings that perioperative infusion of an $\alpha_{2}$-agonist has potential to limit postoperative myocardial ischemia ${ }^{7}$.

A decrease in myocardial ischemic load is a clinically relevant outcome measure because it has been shown that several periods of myocardial ischemia have a cumulative effect and can cause subendocardial necrosis in dogs ${ }^{19}$. In accordance, in humans prolonged duration of ST-segment depression leads to myocardial damage as measured by cardiac troponin-1 levels ${ }^{20}$ and is associated with adverse cardiac outcome ${ }^{10}$. If dexmedetomidine can decrease the incidence of myocardial ischemia during emergence remains unknown from the current study because it was not powered for this outcome measure (e.g. to detect differences in incidence of myocardial ischemia with power: 0.80 and $\alpha$ $=0.05,62$ dogs in each group would have been necessary.) However, the importance of decreasing the incidence of myocardial ischemia, in addition to its load, remains unknown.

The decrease in emergence-related myocardial ischemic load from dexmedetomidine may be explained from its sympatholytic effects, improving the myocardial oxygen supply/demand ratio. In accordance with previous studies in humans ${ }^{6}$ and in $\operatorname{dogs}^{21}$, dexmedetomidine had sympatholytic effects during the emergence period, as indicated by a decrease in plasma catecholamines and heart rate. These effects coincided with a redistribution of supply to the vulnerable endocardium as indicated by an increased endo-/ epicardial 
blood flow ratio. Although relatively large doses of $\alpha_{2}$-adrenergic agonists may produce coronary vasoconstriction ${ }^{11}$, the redistribution of blood flow toward the endocardium indicates that the sympatholytic and heart rate-lowering effects of dexmedetomidine most likely prevailed at the dose used. Coronary artery thrombosis may also decrease myocardial blood flow, and thus supply. However, this is an unlikely event in the current study, because dogs are not prone to coronary atherosclerosis, and we did not observe any macroscopic intracoronary thrombi at dissection afterwards.

Other determinants of myocardial oxygen supply, plasma hemoglobin values and arterial oxygen tension, were not different between both groups, and therefore are not likely to confound the observed differences in myocardial lactate release. Hemoglobin values were 6-7 mmol/L after hemodilution. These values are generally accepted for almost all surgical patients ${ }^{22}$, and as such do not lead to myocardial ischemia. However, if the vasodilating capacity of the coronary artery is limited, moderate hemodilution may increase the risk of myocardial ischemia $^{23}$. This effect was considered ethically advantageous because it reduced the number of animals required.

Of the hemodynamic factors potentially involved in the genesis of emergence-related myocardial ischemia, dexmedetomidine decreased heart rate. A low heart rate is of pivotal importance in reducing myocardial ischemia because it improves supply from a prolonged diastolic perfusion time and is the most important determinant of myocardial oxygen demand ${ }^{24}$.

Thus, the decrease in myocardial ischemic load from dexmedetomidine in the current study most likely results from its sympatholytic effects, mitigating emergence-related tachycardia and improving myocardial oxygen balance.

The beneficial effect of dexmedetomidine started intra-operatively because it decreased the prevalence of myocardial ischemia prior to emergence. This coincided with a decrease in demand, as indicated by the PWI, and with an improved endo/epicardial blood flow ratio. The finding that dexmedetomidine decreased myocardial oxygen requirements during the intra-operative period is in accordance with our previous studies in halothane-anesthetized dogs ${ }^{11,25}$. We started the infusion of dexmedetomidine intra-operatively to obtain stable plasma concentrations of dexmedetomidine at the start of the emergence period. This approach also may have clinical relevance because it has been shown recently in vascular surgery patients that most ischemic events occur between 50 minutes before and 60 minutes after the end of surgery ${ }^{20}$.

A critical aspect of our study is the methodology to create a stable coronary stenosis because small changes in diameter may cause large changes in coronary flow. However, immediately after application of the stenosis the relative decrease in poststenotic endocardial flow was the same in both groups. Also, major 


\section{6 \\ CHAPTER 4}

kinking of the plastic screw occluder is unlikely because no sudden decreases of the coronary flow or myocardial shortening signals were observed. Most importantly, it is unlikely that potential variations in diameter of the stenosis explain the differences in myocardial ischemic load between both groups because the probability of these variations is the same in both groups.

In conclusion, a stable plasma concentration of dexmedetomidine of 0.5 $\mathrm{ng} / \mathrm{ml}$ in dogs with a artificial coronary stenosis decreases the myocardial ischemic load during the first 2 hours of emergence from halothane anesthesia. This effect of dexmedetomidine can be explained by its sympatholytic and heart rate-lowering effects improving myocardial oxygen balance. Although extrapolation of our findings to the clinical setting should be performed with care, our study suggests that perioperative infusion of $\alpha_{2}$ adrenergic-receptor agonists may offer a pharmacologic means of decreasing the ischemic load on the myocardium during emergence.

\section{Acknowledgments}

The authors want to thank Ruud Kruger, Theo van der Nagel, Anita Rousseau, and Jean Willigers for their technical assistance, and A. Kester for his statistical advice.

\section{References}

1. Mangano DT, Browner WS, Hollenberg M, et al. Association of perioperative myocardial ischemia with cardiac morbidity and mortality in men undergoing noncardiac surgery. $\mathrm{N}$. Engl. J. Med. 1990;323:1781-8.

2. Warltier DC, Pagel PS, Kersten JR. Approaches to the prevention of perioperative myocardial ischemia. Anesthesiology 2000;92:253-9.

3. Maze M. Alpha-2 adrenoreceptor agonists: Defining the role in clinical anesthesia. Anesthesiology 1991;74:581-605.

4. Talke P, Li J, Jain U, et al. Effects of perioperative dexmedetomidine infusion in patients undergoing vascular surgery. Anesthesiology 1995;82:620-33.

5. Talke P, Richardson CA, Scheinin M, Fisher DM. Postoperative pharmacokinetics and sympatholytic effects of dexmedetomidine. Anesth Analg 1997;85:1136-42.

6. Talke P, Chen R, Thomas B, et al. The hemodynamic and adrenergic effects of perioperative dexmedetomidine infusion after vascular surgery. Anesth Analg 2000;90:834-9.

7. McSPI. Perioperative sympatholysis. Beneficial effects of the $\mathrm{a}_{2}-$ adrenoceptor agonist mivazerol on hemodynamic stability and myocardial ischemia. Anesthesiology 1997;86:34663.

8. Oliver MF, Goldman L, Julian DG, Holme I. Effect of mivazerol on perioperative cardiac complications during non- cardiac surgery in patients with coronary heart disease: the European Mivazerol Trial (EMIT). Anesthesiology 1999;91:951-61.

9. Fleisher LA, Zielski MM, Schulman SP. Perioperative ST-segment depression is rare and may not indicate myocardial ischemia in moderate-risk patients undergoing noncardiac surgery.J Cardiothorac Vasc Anesth 1997;11:155-9. 


\section{DEXMED DECREASES CARDIAC LACTATE RELEASE}

10. Landesberg G, Luria MH, Cotev S, et al. Importance of long-duration postoperative STsegment depression in cardiac morbidity after vascular surgery. The Lancet 1993;341:715-19.

11. Lawrence CJ, Prinzen FW, Lange de S. The effect of dexmedetomidine on the balance of myocardial energy requirement and oxygen supply and demand. Anesth Analg 1996;82:54450.

12. Flacke WE, Flacke JW, Bloor BC, et al. Effects of Dexmedetomidine on systemic and coronary hemodynamics in the anesthetized dog. J of Cardiothorac and Vasc Anesthesia 1993;7:41-9.

13. Flecknell PA. Anaesthesia of animals for biomedical research. Brit J Anaesth 1993;71:885-94.

14. Van Oosterhout MF, Willigers HM, Reneman RS, Prinzen FW. Fluorescent microspheres to measure organ perfusion: validation of a simplified sample processing technique. Am J Physiol 1995;269:H725-33.

15. Hoorn van der FAJ, Boomsma, Man in het Veld AJ, Schalekamp MADH. Determination of catecholamines in human plasma by high-performance liquid chromatography: comparison between a new method with fluorescence detection and an established method with electrochemical detection. J. Chromatogr. 1989;487:17-28.

16. Vuorilehto L, Salonen JS, Anttila M. Picogram level determination of medetomidine in dog serum by capillary gas chromatography with negative ion chemical ionisation mass spectrometry. J. Chromatogr. 1989;497:282-7.

17. Rooke GA, Feigl EO. Work as a correlate of canine left ventricular oxygen consumption, and the problem of catecholamine oxygen wasting. Circ Res 1982;50:273-86.

18. Matthews JNS, Altman DG, Campbell MJ, Royston P. Analysis of serial measurements in medical research. Br. Med. J. 1990;300:230-5.

19. Geft IL, Fishbein MC, Ninomiya K, et al. Intermittent brief periods of ischemia have a cumulative effect and may cause myocardial necrosis. Circulation 1982;66:1150-3.

20. Landesberg G, Mosseri M, Zahger D, et al. Myocardial infarction after vascular surgery: the role of prolonged stress-induced, ST depression-type ischemia. J Am Coll Cardiol 2001;37:1839-45.

21. Proctor LT, Schmeling WT, Roerig D, et al. Oral dexmedetomidine attenuates hemodynamic responses during emergence from general anesthesia in chronically instrumented dogs. Anesthesiology 1991;74:108-14.

22. Practice Guidelines for blood component therapy: A report by the American Society of Anesthesiologists. Task Force on Blood Component Therapy. Anesthesiology 1996;84:73247.

23. Crystal GJ, Salem MR. Myocardial oxygen consumption and segmental shortening during selective coronary hemodilution in dogs. Anesth Analg 1988;67:500-8.

24. Indolfi C, Ross JJ. The role of heart rate in myocardial ischemia and infarction: Implications of myocardial perfusion-contraction matching. Prog. Cardiovasc. Dis. 1993;36:61-74.

25. Roekaerts PM, Prinzen FW, De Lange S. Beneficial effects of dexmedetomidine on ischaemic myocardium of anaesthetized dogs. Br J Anaesth 1996;77:427-9. 


\section{CHAPTER 5}

Comparison of the effects of dexmedetomidine and esmolol on myocardial oxygen consumption in dogs

Henriëtte M. Willigers, Frits W. Prinzen and Paul M. Roekaerts.

European journal of anaesthesiology 2004; 21: 957-66. With small modifications. 


\section{Summary}

Background and objective: The beta-adrenergic blocker esmolol and the alpha $_{2}$-adrenergic agonist dexmedetomidine have the potential to decrease perioperative myocardial ischaemia. The pathophysiologic mechanisms involved in these anti-ischaemic properties have not been thoroughly studied. We compared the effects of esmolol and dexmedetomidine on two haemodynamic indices of overall myocardial oxygen demand and on directly measured myocardial oxygen consumption.

Methods: Eleven mongrel dogs were instrumented to measure aortic and left ventricular pressure, aortic and left anterior coronary artery flow, and myocardial wall thickening.

Variables related to myocardial oxygen metabolism were also determined. Measurements were performed during four sequential experimental conditions (control 1, esmolol, control 2, dexmedetomidine).

Results: Esmolol and dexmedetomidine decreased haemodynamic indices of myocardial oxygen demand to a similar extent: esmolol decreased the rate-pressure-product by $16 \pm 3 \%$ and the pressure-work-index by $16 \pm 3 \%$, dexmedetomidine decreased the rate-pressure-product by $26 \pm 3 \%$ and the pressure-work-index by $16 \pm 7 \%$. However, neither drug had an effect on myocardial oxygen consumption, a direct measure of myocardial oxygen demand. Sympatholytic doses of esmolol and of dexmedetomidine had different haemodynamic effects. Dexmedetomidine had a more pronounced bradycardic effect than esmolol $(\mathrm{P}=0.01)$ and increased systolic aortic pressure by $15 \pm 4 \%$. Esmolol decreased systolic aortic pressure by $8 \pm 2 \%$, and decreased indices of myocardial contractility ( $\mathrm{dPdT}_{\max }$ and regional myocardial area decrease).

Conclusions: Esmolol and dexmedetomidine decreased haemodynamic indices of myocardial oxygen demand to a similar extend but neither drug decreased directly measured myocardial oxygen demand.

Keywords: Sympatholytics, Adrenergic Beta-Antagonists,Esmolol; Sympatholytics, Adrenergic Alpha-Agonists, Dexmedetomidine; Heart, Coronary Circulation, Drug Effects; Myocardium, Metabolism; Heart, Myocardial Contraction 


\section{Introduction}

Perioperative sympatholysis from beta-adrenergic blockers and from alpha $2^{-}$ adrenergic agonists has the potential to decrease the risk of postoperative myocardial ischaemia and of cardiac death ${ }^{1}$. Therefore, the American Heart Association guidelines recommend consideration of the use of either one of these two classes of sympatholytic drugs in patients having or at risk for coronary artery disease ${ }^{2}$. However, the pathophysiologic mechanisms involved in the anti-ischaemic effects of these drugs have not been studied intensively. It is likely that the postoperative increase in myocardial oxygen demand is an important cause of myocardial ischaemia in patients having significant coronary artery disease. This is because this category of patients has a reduced capacity to increase coronary blood flow in response to an increase in myocardial oxygen demand. Both the short-acting beta blocker esmolol and the most specific $\mathrm{alpha}_{2}$ agonist dexmedetomidine have been shown to suppress postoperative increases in blood pressure and heart rate, two important determinants of myocardial oxygen demand ${ }^{3-6}$. Therefore it is likely that these drugs decrease myocardial ischemia from a decrease in myocardial oxygen demand. However, the effects of these drugs on myocardial oxygen demand are unknown, probably because of the invasive nature of the measurements involved. Also, the haemodynamic effects of an alpha $_{2}$-agonist and a beta-blocker have not been compared into detail.

The aim of this study was to determine and to compare the effects of the beta $_{1}$-blocker esmolol and the alpha ${ }_{2}$-agonist dexmedetomidine on myocardial oxygen demand and on various haemodynamic indices of myocardial oxygen demand. Because of the invasiveness of the measurement of myocardial oxygen demand, these studies were performed in chloralose anaesthetized dogs.

\section{Materials and methods}

\section{Animal preparation and instrumentation}

Eleven adult mongrel dogs $(31 \pm 1.9 \mathrm{~kg})$ were studied with the approval of the Animal Care Committee of the University. Anaesthesia was induced with sodium thiopental $25 \mathrm{mg} \mathrm{kg}^{-1}$ intravenously; the dogs were intubated and ventilated with oxygen $30 \%$ in nitrous oxide. Halothane (inspired concentration 1$1.5 \%)$ was added to suppress somatic responses and to maintain haemodynamic stability during thoracotomy and instrumentation. The chest was opened through the left fifth intercostal space and the heart was suspended in a pericardial cradle. The rectal temperature of the dogs was kept between $37^{\circ} \mathrm{C}$ and $39^{\circ} \mathrm{C}$ by means of a thermostatically regulated heating mattress and a 
warmed operating room $\left(24^{\circ} \mathrm{C}\right)$. Heart rate and rhythm were monitored using ECG lead II.

Catheters were inserted into a femoral artery and the vein next to the left anterior descending (LAD) coronary artery for arterial and coronary venous blood sampling respectively. The coronary venous catheter was assumed to drain the region of the myocardium supplied by the LAD artery. Pressure sensors (Sentron 180 S, Cordis, Roden, the Netherlands) were inserted through the right femoral artery into the ascending aorta and left ventricle. Ultrasonic transit-time flow probes (Transonic Systems, Ithaca, NY) were placed around the aortic root and around the LAD artery just proximal to the first diagonal branch. A pulmonary artery catheter (Baxter) was introduced via the right jugular vein into the pulmonary artery and connected to a thermodilution cardiac output computer (Baxter Edwards SAT 2).The cardiac output measurements, obtained by averaging triplicate thermodilution values, were compared at regular intervals with the ultrasonic aortic flow measurements. Three inductive coils were sutured to the left lateral epicardium in an equilateral triangle configuration to measure epicardial area decrease, an index of myocardial wall thickening.

\section{Study protocol}

As soon as instrumentation was completed, nitrous oxide and halothane were discontinued. A chloralose loading dose of $40 \mathrm{mg} \mathrm{kg}^{-1}$ was then administered, followed by a maintenance infusion of $8 \mathrm{mg} \mathrm{kg}^{-1} \mathrm{~h}^{-1}$. The dogs were ventilated with $40 \%$ oxygen in air to normocarbia.

After a stabilization period of at least 60 minutes, the following 4 successive experimental conditions were studied in each dog:

1. Control 1

2. Esmolol: twenty minutes after starting esmolol $\mathrm{HCl}$ infusion (Ohmeda Inc., NJ, USA)

3. Control 2: twenty minutes after stopping the esmolol infusion

4. Dexmedetomidine: twenty minutes after starting dexmetomidine infusion (Orion Corporation, Farmos Research, Turku, Finland) .

After the Control 1 measurements had been performed, the dose of isoprenaline necessary to increase heart rate by more than $20 \%$ was determined as the tachycardic dose in each dog.

After heart rate and other haemodynamic variables had returned to control 1 values, esmolol was given as a loading dose of $0.5 \mathrm{mg} \mathrm{kg}^{-1} \mathrm{~min}^{-1}$ for two minutes, followed by a continuous infusion of $0.3 \mathrm{mg} \mathrm{kg}^{-1} \mathrm{~min}^{-1}$. To check that the beta ${ }^{-}$ 
adrenergic blockade from esmolol was adequate, the response to the tachycardic dose of isoprenaline was tested before stopping the esmolol infusion.

Dexmedetomidine was given as a loading dose of $1 \mu \mathrm{g} \mathrm{kg}^{-1}$ over twenty minutes, followed by a continuous infusion of $1.5 \mu \mathrm{g} \mathrm{kg}^{-1}$ hour $^{-1}$ in $\mathrm{NaCl} 0.9 \%$. We aimed for a target plasma concentration of dexmedetomidine above $0.5 \mathrm{ng}$ $\mathrm{ml}^{-1}$, because this concentration reduces sympathetic tone effectively in $\operatorname{dogs}^{7}$ and in humans ${ }^{5}$. Because the pharmacokinetics of dexmedetomidine in dogs were unknown at the time of the study, we used an infusion regimen advised by Orion Corporation (Turku, Finland) and based on the pharmacokinetic set in the STANPUMP software ${ }^{8}$.

During each experimental condition the following variables were measured:

1. haemodynamic indices: heart rate, systolic and diastolic aortic pressure, left ventricular pressure, aortic flow and myocardial wall thickening.

2. variables related to myocardial oxygen metabolism: Arterial and LAD coronary venous blood gas tensions, LAD coronary flow and, arterial haemoglobin content.

To measure LAD flow relative to myocardial weight, the perfusion area of the LAD was delineated by injecting methylene blue dye in the LAD at the end of each experiment. Then the dogs were euthanized by a pentobarbital overdose, and their hearts were excised. The methylene blue stained portion of the heart was dissected off and weighed.

\section{Data analysis}

All haemodynamic and coronary flow signals were preamplified and then digitized with a 16-channel, 12-bit A/D interface in a IBM-compatible PC. Sampling frequency was $200 \mathrm{~Hz}$ for each channel. Signals were continuously displayed on the computer screen, and during each experimental measurement period beat to beat values were stored on the hard disk. For each measurement period, the average of each variable was calculated over a stable haemodynamic period of two minutes, i.e. less than $5 \%$ heart rate variation. Peak of first derivative of left ventricular pressure $\left(\mathrm{LV} \mathrm{dPdt}_{\max }\right)$ was derived from the left ventricular pressure signal.

Systemic vascular resistance (SVR) was calculated as the quotient of mean aortic pressure and mean aortic blood flow. Coronary vascular resistance (CVR) was calculated as the quotient of mean aortic pressure and mean coronary blood flow.

The following haemodynamic indices of myocardial oxygen demand were measured: 
1. The pressure work index $\mathrm{PWI}^{9}=\mathrm{C} 1(\mathrm{SAP} \times \mathrm{HR})+\mathrm{C} 2(0.8 \mathrm{SAP}+0.2$

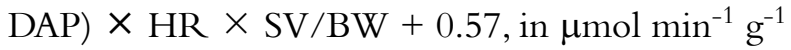

where

$\mathrm{HR}=$ heart rate in beats per minute

$\mathrm{SV}=$ stroke volume in $\mathrm{ml}$

$\mathrm{SAP}=$ systolic aortic pressure in $\mathrm{mmHg}$

$\mathrm{DAP}=$ diastolic aortic pressure in $\mathrm{mmHg}$

$\mathrm{BW}=$ body weight in $\mathrm{kg}$

$\mathrm{C} 1=1.63 \times 10^{-4}$

$\mathrm{C} 2=1.30 \times 10^{-4}$

2. The rate pressure product $\mathrm{RPP}=$ heart rate $\times$ systolic aortic pressure.

To study the effects of esmolol and dexmedetomidine on the relation between haemodynamic indices of myocardial oxygen demand $\left(\mathrm{MVO}_{2}\right)$ and measured myocardial oxygen consumption, percentage changes in RPP and PWI were plotted against percentage changes in measured $\mathrm{MVO}_{2}$.

To measure epicardial deformation, three inductive coils were sutured to the left lateral epicardium. This method for measuring epicardial deformation and its ability to detect changes in regional contractility has been validated in our laboratory ${ }^{10,11}$. The coils were sutured in an equilateral triangle configuration to measure area decrease, e.g. the reduction in area of the epicardial region enclosed by the coils during the ejection period of the systole. Onset and end of the ejection phase were determined from the cross over of the left ventricular pressure and the ascending aortic pressure and from the dicrotic notch in the aortic pressure signal, respectively. Because the volume of a certain part of the ventricular wall does not change significantly throughout the cardiac cycle, surface area decrease during the ejection phase is related to myocardial wall thickening, and thus regional contractility.

All blood samples were collected on ice. Those to be analysed afterwards were centrifuged at $4^{\circ} \mathrm{C}$ within 15 minutes after sampling to separate plasma and then stored at $-70^{\circ} \mathrm{C}$. Blood gas tensions were assessed with a blood gas analyser (ABL 3, Radiometer, Copenhagen, Denmark). Haemoglobin content $(\mathrm{Hb})$ and oxygen saturation $\left(\mathrm{O}_{2}\right.$ sat $)$ were assessed with a haemoximeter (OSM2 , Radiometer). The $\mathrm{O}_{2}$ content $\left(\mathrm{CaO}_{2}\right.$ in $\left.\mathrm{mmol} \mathrm{L}^{-1}\right)$ was calculated as $\mathrm{Hb} \times$ $\mathrm{O}_{2}$ sat $+0.0102 \times \mathrm{PO}_{2}$. From this, oxygen extraction was calculated for the territory of myocardium perfused by the LAD, using a standard formula. To assay plasma concentrations of norepinephrine, high performance liquid chromatography with colometric electrochemical detection was used ${ }^{12,13}$. Plasma concen- 
trations of dexmedetomidine were analysed at the pharmacokinetics laboratory of the Orion Corporation.

\section{Statistical analysis}

The drugs in the present study were investigated in each dog in the same sequence.

Esmolol and dexmedetomidine were compared with their preceding control values and with each other. To minimize a possible time-effect between esmolol and dexmedetomidine measurements the values found during these measurements were first substracted from their preceding control value before a statistical comparison was made.

We used the non-parametric Wilcoxon signed rank test because of the relatively small number of experiments. $\mathrm{P}$ value $\leq 0.05$ was considered statistically significant. Linear regression analysis was used to study the relation between the change in haemodynamic indices of myocardial oxygen demand and change in myocardial oxygen consumption. Data are presented as mean \pm SEM, unless stated otherwise.

\section{Results}

The dogs maintained normothermia throughout the study period, and shivering was not observed.

The infusion regimens of esmolol and dexmedetomidine had sympatholytic effects. Esmolol abolished the tachycardic response to isoprenaline in all dogs. The dose of isoprenaline used to test the beta-adrenergic blockade was $0.45 \pm$ $0.04 \mu \mathrm{g} \mathrm{kg}^{-1}$. The infusion of dexmedetomidine resulted in plasma concentrations of $1.1 \pm 0.3 \mathrm{ng} \mathrm{ml}^{-1}$. Dexmedetomidine decreased plasma norepinephrine concentration from $0.52 \pm 0.15 \mathrm{nmol} \mathrm{L}^{-1}$ to $0.06 \pm 0.03 \mathrm{nmol} \mathrm{L}^{-1}(\mathrm{P}<0.02)$.

Esmolol and dexmedetomidine decreased haemodynamic indices of myocardial oxygen demand to a similar extend: esmolol decreased the RPP by $16 \pm 3 \%$ and the PWI by $16 \pm 3 \%$, dexmedetomidine decreased the RPP by $26 \pm 3 \%$ and the PWI by $16 \pm 7 \%$ Fig. 2). However, these similar decreases in demand resulted from different haemodynamic effects (fig 1). Dexmedetomidine had a more pronounced bradycardic effect than esmolol $(\mathrm{P}=0.01)$. The effects on systolic aortic pressure were opposite with these two drugs: dexmedetomidine increased systolic aortic pressure by $15 \pm 4 \%$ whereas esmolol decreased systolic aortic pressure by $8 \pm 2 \%(\mathrm{P}<0.01)$. The increase in systolic aortic pressure from dexmedetomidine was accompanied by a parallel increase in systemic vascular resistance. The decrease in systolic aortic pressure from esmolol was 


\section{6 \\ CHAPTER 5}
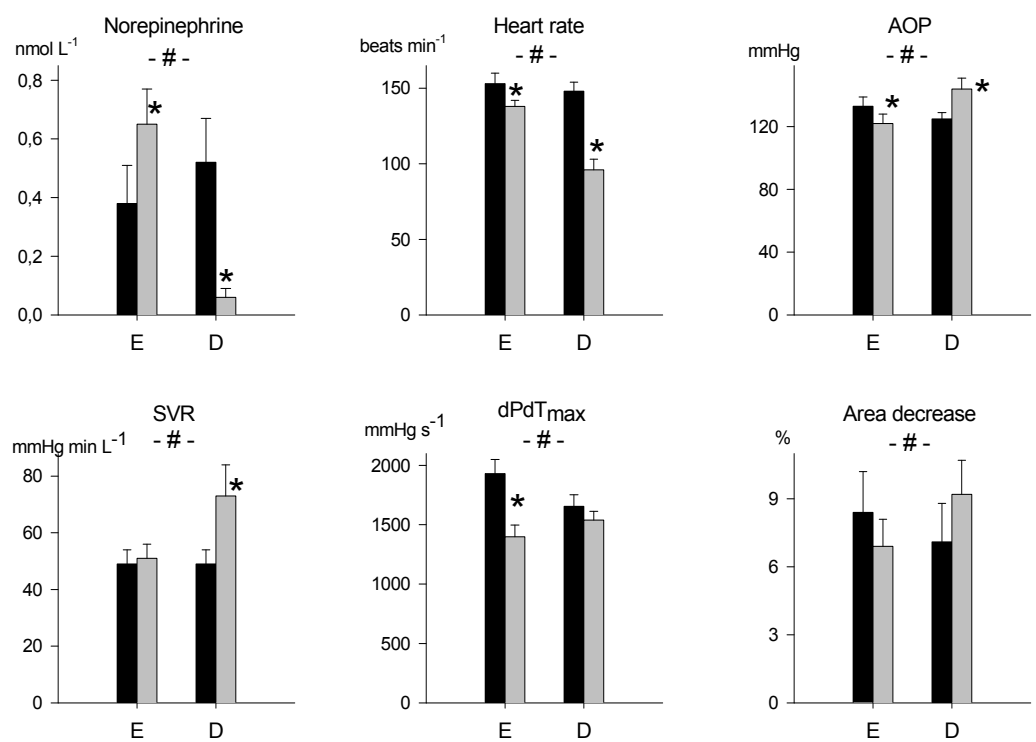

Figure 1. The effects of esmolol and dexmedetomidine on; sympathetic tone, haemodynamic parameters and, indices of myocardial contractility in chloralose anaesthetized dogs.

Black bars indicate control values and grey bars values during the infusion of the respective drug. E: esmolol; D: dexmedetomidine; HR: heart rate; AOP: aortic pressure; SVR: systemic vascular resistance.

$\star: \mathrm{P}<0.05$ vs. preceding control measurement; \# : $\mathrm{P}<0.05$ esmolol vs. dexmedetomidine
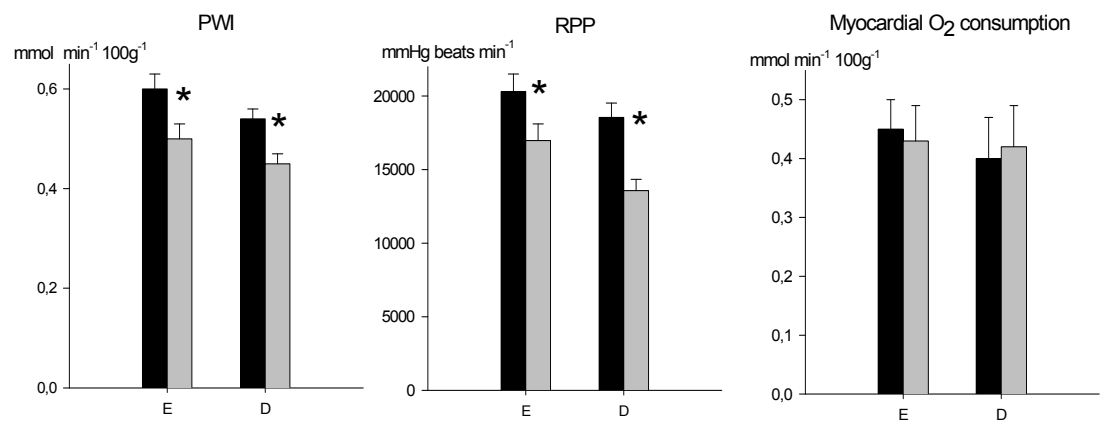

Figure 2. The effects of esmolol and dexmedetomidine on haemodynamic indices of myocardial oxygen demand and on myocardial oxygen consumption, a direct measure of myocardial oxygen demand, in chloralose anesthetized dogs.

Black bars indicate control values and grey bars values during the infusion of the respective drug.E: esmolol; D: dexmedetomidine; PWI: pressure work index; RPP: rate pressure product.

$\star: \mathrm{P}<0.05$ vs preceding control measurement; \# : $\mathrm{P}<0.05$ esmolol vs dexmedetomidine 

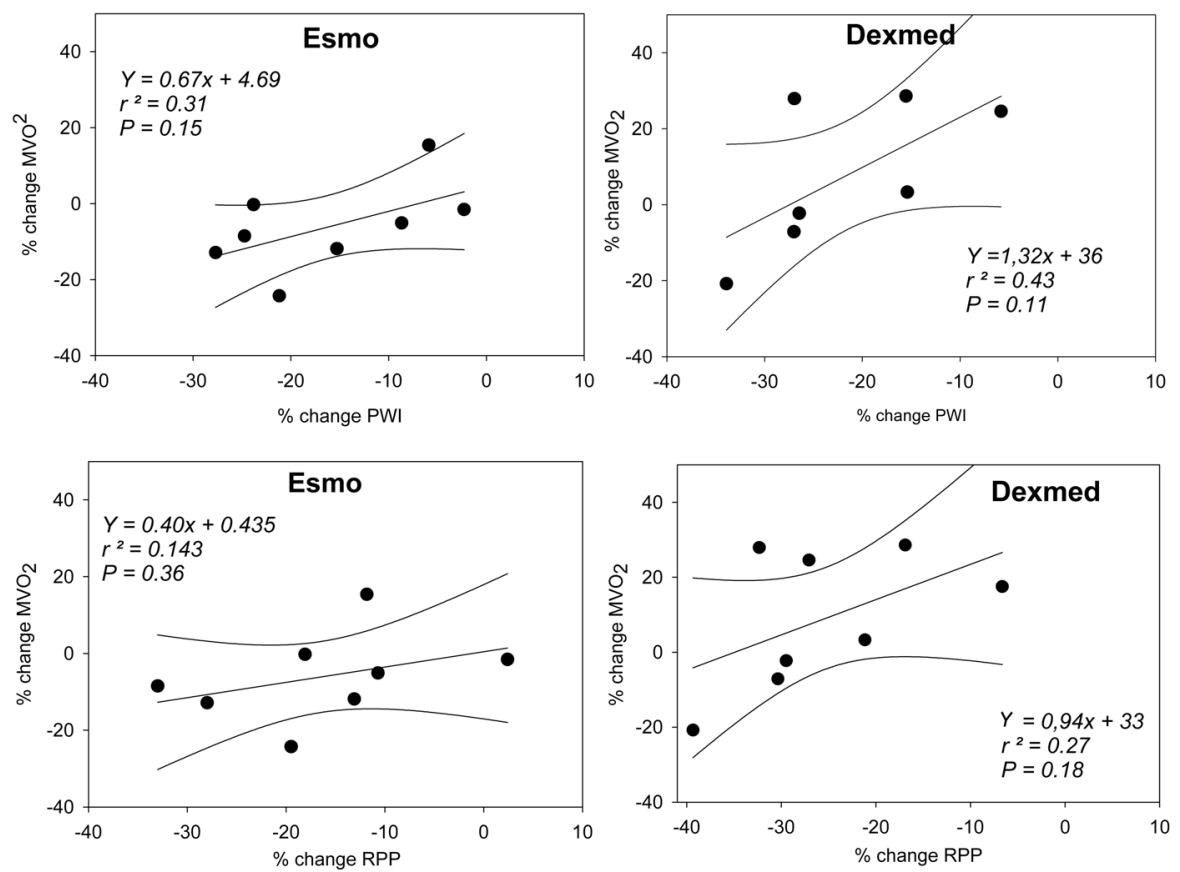

Figure 3. The relation between changes(vs. preceding control value for each experiment) in haemodynamic indices of myocardial oxygen demand and in myocardial oxygen consumption in the presence of esmolol (Esmo) and in the presence of dexmedetomidine (Dexmed).

No significant linear relationship was found.

accompagnied by a decrease in indices of myocardial contractility, dPdtmax and regional myocardial area decrease (Fig.1). The decrease in myocardial contractility after esmolol resulted in a marginal decrease in cardiac output compared to Control 1 (12 $\pm 4 \%$ decrease, $\mathrm{P}=0.05)$ but not compared to dexmedetomidine $(\mathrm{P}=0.17)$.

In contrast to their suppressive effect on haemodynamic indices of myocardial oxygen demand, neither drug decreased measured myocardial oxygen consumption (Fig. 2). To study this finding into more detail we plotted changes in myocardial oxygen consumption as a function of changes in RPP and PWI (haemodynamic indices of demand). No linear relationship was observed (Fig. 3).

Esmolol and dexmedetomidine maintained myocardial oxygen delivery by different mechanisms (Table 1). Dexmedetomidine: increased blood haemoglobin concentration, increased myocardial oxygen extraction, increased coronary vascular resistance, and tended to decrease coronary flow $(\mathrm{P}=0.13)$. Esmolol maintained blood haemoglobin concentration and coronary flow, and 


\section{CHAPTER 5}

Table 1. The effects of esmolol and dexmedetomidine on determinants of myocardial oxygen consumption and delivery in chloralose anaesthetised dogs.

$$
\text { Control 1 Esmolol Control 2 } \begin{aligned}
& \text { Dexmede- } \\
& \text { tomidine }
\end{aligned}
$$

\section{Arterial}

Haemoglobin $\mathrm{mmol} \mathrm{L}^{-1}$

$\begin{array}{llll}8.2 \pm 0.3 & 8.3 \pm 0.3 & 7.7 \pm 0.2 & 9.0 \pm 0.4^{\star \#} \\ 7.47 \pm 0.02 & 7.44 \pm 0.02^{\star} & 7.40 \pm 0.01 & 7.45 \pm 0.03^{\#} \\ 33.4 \pm 5.8 & 30.3 \pm 5.6 & 31.5 \pm 5.6 & 35.7 \pm 5.9 \\ 8.3 \pm 0.3 & 8.3 \pm 0.2 & 7.8 \pm 0.3 & 9.3 \pm 0.4^{\star} \# \\ 4.1 \pm 0.2 & 4.2 \pm 0.2 & 4.2 \pm 0.1 & 4.3 \pm 0.2\end{array}$

$\mathrm{pH}$

$\mathrm{PO}_{2} \mathrm{kPa}$

Oxygen content $\mathrm{mmol} \mathrm{L}^{-1}$

$\mathrm{PCO}_{2} \mathrm{kPa}$

$4.1 \pm 0.2$

$4.2 \pm 0.2$

$4.2 \pm 0.1$

$4.3 \pm 0.2$

\section{Coronary venous}

$\mathrm{pH}$

$\mathrm{PO}_{2} \mathrm{kPa}$

$\mathrm{O}_{2}$ content $\mathrm{mmol} \mathrm{L}^{-1}$

$\begin{array}{llll}7.40 \pm 0.02 & 7.39 \pm 0.02 & 7.35 \pm 0.02 & 7.39 \pm 0.03 \\ 2.5 \pm 0.1 & 3.0 \pm 0.2^{\star} & 3.2 \pm 0.2 & 2.8 \pm 0.2^{\star \#} \\ 2.4 \pm 0.2 & 3.0 \pm 0.2^{\star} & 2.9 \pm 0.2 & 3.0 \pm 0.2^{\#}\end{array}$

Coronary blood flow

$\mathrm{ml} \mathrm{min}{ }^{-1} 100 \mathrm{~g}^{-1}$

$$
76 \pm 10 \quad 78 \pm 10 \quad 80 \pm 11 \quad 69 \pm 14
$$

Myocardial oxygen delivery

$0.63 \pm 0.07 \quad 0.65 \pm 0.09 \quad 0.63 \pm 0.10 \quad 0.61 \pm 0.10$

mmol min ${ }^{-1} 100 \mathrm{~g}^{-1}$

Arterial-coronary venous oxygen content
$5.9 \pm 0.3$
$5.3 \pm 0.3^{\star}$
$4.9 \pm 0.3$
$6.3 \pm 0.4^{\star \#}$

difference $\mathrm{mmol} \mathrm{L}^{-1}$

Myocardial oxygen extraction ratio

$\begin{array}{llll}0.71 \pm 0.02 & 0.64 \pm 0.03^{\star} & 0.63 \pm 0.03 & 0.67 \pm 0.02^{\star \#}\end{array}$

Myocardial oxygen consumption

$0.45 \pm 0.05$

$0.43 \pm 0.06$

$0.40 \pm 0.07$

$0.42 \pm 0.07$

$\mathrm{mmol} \mathrm{m^{-1 }} 100 \mathrm{~g}^{-1}$

$1.77 \pm 0.25 \quad 1.57 \pm 0.22^{\star} \quad 1.62 \pm 0.27 \quad 2.32 \pm 0.43^{\star \#}$

Coronary vascular resistance

$\mathrm{mmHg} \mathrm{ml}{ }^{-1} \mathrm{~min}^{-1} 100 \mathrm{~g}^{-1}$

decreased coronary vascular resistance and myocardial oxygen extraction. Neither drug affected coronary venous $\mathrm{pH}$.

Thus, esmolol and dexmedetomidine decreased haemodynamic indices of myocardial oxygen demand to a similar extent, but neither drug decreased myocardial oxygen consumption, a direct measure of myocardial oxygen demand. 


\section{Discussion}

Profylactic administration of sympatholytic drugs during the emergence period may decrease myocardial ischaemia in certain groups of patients. Theoretically, this beneficial effect is, at least partly, related to their effect on myocardial oxygen demand. The peripherally acting beta-blockers and centrally acting alpha ${ }_{2}-$ agonists are two fundamentally different classes of sympatholytic drugs but their effects on myocardial oxygen demand have not been compared directly. Therefore, we studied in 11 chloralose anaesthetised dogs if a beta blocker and an alpha $_{2}$ agonist have different effects on myocardial oxygen demand and on frequently used haemodynamic indices of myocardial oxygen demand.

An important finding in this study is that both classes of sympatholytic drugs decreased haemodynamic indices of myocardial oxygen demand to a similar extent but did not decrease myocardial oxygen consumption. In this study myocardial oxygen consumption reflected myocardial oxygen demand because the dogs had an unlimited coronary blood flow.

A possible explanation for this finding is that myocardial oxygen consumption measurements may not have been completely accurate. In previous pilot experiments, we observed that measurements of myocardial blood flow using a flow probe and methylene blue to delineate the perfusion area, underestimates myocardial blood flow as measured with microspheres, a gold standard of blood flow measurement. However, the percentage of error was small, systematic and stable. Therefore we concluded that myocardial blood flow measurements using a flow probe can accurately detect a change in oxygen delivery.

A more likely explanation for the discrepancy between myocardial oxygen consumption and haemodynamic indices of myocardial oxygen demand in the current study may be the inaccuracy of haemodynamic indices in predicting myocardial oxygen demand. We studied RPP and PWI because these two indices can be easily calculated in clinical practice from heart rate, systolic pressure and cardiac output. They have been shown to correlate with myocardial oxygen consumption in chloralose anaesthetised $\operatorname{dogs}^{9}$ and in humans ${ }^{14}$. However, it has been argued that the conclusions from these studies may be false because of methodological pitfalls such as pooling of all data instead of using only single data points for each subject ${ }^{15}$. An explanation for the inaccuracy of haemodynamic indices in predicting myocardial oxygen demand may be that they were primarily developed as a clinical useful indices and thus do not include all parameters determining myocardial oxygen demand ${ }^{9}$.

So, we may conclude that neither dexmedetomidine nor esmolol decreased myocardial oxygen demand in the present comparative study in chloralose anaesthetized dogs. This finding is in accordance with previous non-comparative studies. Studies from our laboratory showed that dexmedetomidine does 
not affect myocardial oxygen consumption in anaesthetized dogs and goats ${ }^{16-18}$ and Sidi et all ${ }^{19,20}$ showed that esmolol does not affect myocardial oxygen demand in anaesthetized $\operatorname{dog} s^{19,20}$

Another important finding in the present comparative study is that the beta blocker and the alpha 2 agonist had different haemodynamic effects. Esmolol decreased both blood pressure and heart rate. Dexmedetomidine increased blood pressure, but decreased heart rate to a greater extend than esmolol. The decrease in arterial pressure from esmolol seemed to result from its cardiodepressive effects, because esmolol suppressed indices of myocardial contractility without affecting the systemic vascular resistance. Hypotension is a known adverse effect of esmolol and is not fully explained by its beta receptor blocking effect ${ }^{21}$. The decrease in myocardial contractility from esmolol in the present study is in accordance with previous studies in which doses of more than $300 \mu \mathrm{g} \mathrm{kg}^{-1} \mathrm{~min}^{-1}$ were used ${ }^{22-24}$. The effects of esmolol on peripheral vascular resistance are equivocal; both an increase ${ }^{23}$ and no effect ${ }^{25}$ have been observed. Dexmedetomidine infusion was associated with an increase in blood pressure and systemic vascular resistance. Generally, dexmedetomidine infusion results in biphasic changes in blood pressure. Initially, blood pressure increases for a short period (i.e. less than 20 minutes). This pressor phase is caused by stimulation of alpha $_{2}$-adrenergic receptors in peripheral vessel walls. Over time the central sympatholytic effects predominate with a decline in blood pressure ${ }^{7,26}$. In the present study, blood pressure was still significantly increased approximately one hour after starting the infusion of dexmedetomidine, despite a significant decrease in plasma norepinephrine concentration. This implies a much longer duration of the vasoconstrictive phase which may be explained by the species studied and by the anaesthetic technique used in our experiments. It has been shown that the peripheral vasoconstrictive effect of dexmedetomidine is more pronounced in dogs than in humans $s^{27,28}$. The importance of the anaesthetic technique when studying the effects of dexmedetomidine were already pointed out in a previous study from our laboratory ${ }^{18}$. In the present study, we used $\alpha-$ chloralose anaesthesia because it is known to have no major effect on central neuroregulation and on oxygen metabolism ${ }^{29,30}$. However, $\alpha$-chloralose is also known to potentiate the pressor effects of alpha 2 agonists ${ }^{31}$.

The heart rate lowering effect of dexmedetomidine was more pronounced than that of esmolol. In accordance, a case of tachycardia in a cardiac surgical patient has been reported which was unresponsive to esmolol but resolved after dexmedetomidine ${ }^{32}$. The ability of alpha 2 -agonists to decrease heart rate has been attributed to their central sympatholytic effect, as well as to a decrease in norepinephrine release at the peripheral neuroeffector junction ${ }^{33}$. The more pronounced bradycardic effect of dexmedetomidine suggests that an additional 
vagomimetic effect may be involved in producing bradycardia. This is because

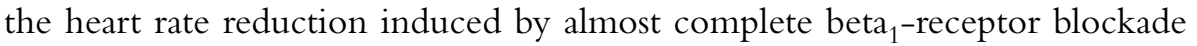
during esmolol infusion was the maximum which could be obtained from sympatholysis alone. It could be argued that the infusion protocol of esmolol in

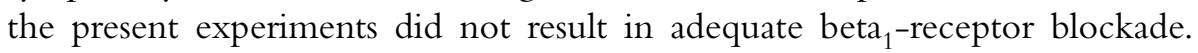
However, baseline plasma norepinephrine concentrations, and thus betaadrenergic stimulation, were low in these chloralose anaesthetized dogs. Also, we

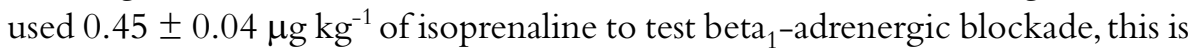
in the higher range of the doses of isoprenaline used in other studies on the beta-blocking effects of esmolol, e.g. $0.125-0.5 \mu \mathrm{g} \mathrm{kg}^{-1}{ }^{34-36}$. Third, it has been shown that the infusion of only one third of the dose of esmolol used in the current study already blocks $70 \%$ of the cardiac beta -receptors $^{36}$.

Esmolol and dexmedetomidine did not affect myocardial oxygen consumption, however they affected coronary vascular resistance and the relative contribution of the individual parameters of myocardial oxygen delivery. Esmolol decreased myocardial oxygen extraction and coronary vascular resistance (CVR) which suggests that esmolol has coronary vasodilating properties. In contrast, dexmedetomidine increased fractional oxygen extraction and CVR ${ }^{16-}$ ${ }^{18}$. It has been suggested that these effects of dexmedetomidine indicate that its alpha $_{2}$-adrenergic coronary vasoconstrictive effects result in a relative shortage of oxygen delivery ${ }^{7}$. However, our findings indicate a possible alternative explanation. Dexmedetomidine increased myocardial oxygen extraction secondary to an increase in haemoglobine and arterial $\mathrm{O}_{2}$ content, and not secondary to a decrease in coronary venous $\mathrm{O}_{2}$ content. Indications that the increase in myocardial oxygen extraction was not associated with a critical shortage of myocardial oxygen delivery when giving dexmedetomidine are:

1. oxygen extraction was still far below maximal ${ }^{37}$

2. coronary venous $\mathrm{pH}$ did not decrease

3. dexmedetomidine suppressed haemodynamic indices of myocardial oxygen demand.

Conversely, the observed increase in arterial $\mathrm{O}_{2}$ content and myocardial oxygen extraction from dexmedetomidine did not increase myocardial oxygen delivery because coronary blood flow tended to decrease.

The increase in haemoglobin from dexmedetomidine is an interesting feature of this study. The most likely explanation for this finding is that alpha $\mathrm{p}_{2}$-receptor activation from dexmedetomidine caused recruitment of erythrocytes from splenic stores. A previous study in dogs showed the effects of alphaadrenoreceptor activation on the splenic capsule and splanchnic capacitance vasculature $^{38}$, and there is evidence that these effects are alpha $\mathrm{p}_{2}$-receptor rather than alpha $_{1}$-receptor mediated ${ }^{39}$. Also in humans alpha-adrenergic induced 


\section{2}

blood volume shifts from the spleen and increases in hematocrit have been described ${ }^{40,41}$. Another possible explanation for the increase in haemoglobin concentration is a transcapillary fluid shift from the intravascular space in those organs were venous vasoconstriction outstands arterial vasoconstriction. This mechanism has already been demonstrated in rats ${ }^{42}$. We believe that this explanation is less likely, because the expected decrease in end-diastolic pressure associated with a fluid shift, was not observed in our experiments. The increase in haemoglobin concentration associated with the administration of dexmedetomidine can also, at least in part, explain the measured increase in coronary vascular resistance. This is because viscosity, of which haematocrit is the major determinant, contributes to vascular resistance ${ }^{43}$.

A limitation of this study is that the results obtained are restricted to dogs; there may be relevant species difference in the effect of sympatholytic drugs on myocardial oxygen consumption. However, myocardial oxygen consumption in the current study was similar to that reported in awake and in anaesthetized humans ${ }^{14}$.

A methodological limitation of the current study is that the drugs were always investigated in the same sequence in each experiment; first esmolol, then dexmedetomidine. This was done because of the relatively long plasma half-life of dexmedetomidine ( 2 hours) compared to the very short plasma half-life of esmolol (9 minutes). However, we applied statistical methods to minimize the possible time effect associated with a sequential study design.

A final limitation is that we studied only one dose of each drug and therefore cannot exclude that higher doses are needed to decrease myocardial oxygen consumption. However, the dose used resulted in adequate sympatholysis for each drug.

In conclusion, peripheral sympatholysis from a beta blocker and central sympatholysis from an alpha $_{2}$-agonist decrease haemodynamic indices of myocardial oxygen demand to a similar extend, but do not decrease myocardial oxygen consumption in chloralose anaesthetized dogs.

\section{Acknowledgements}

The authors thank A. Kester for statistical advice and Orion Corporation, Farmos Research, Turku, Finland, for financial support and plasma concentration measurements of dexmedetomidine.

\section{References}

1 Stevens RD, Burri H, Tramer MR. Pharmacologic Myocardial Protection in Patients Undergoing Noncardiac Surgery: A Quantitative Systematic Review. Anesth Analg 2003; 97: 62333. 
2 Eagle KA, Berger PB, Calkins $\mathrm{H}$ et al. ACC/AHA Guideline Update for Perioperative Cardiovascular Evaluation for Noncardiac Surgery-Executive Summary. Anesth Analg 2002; 94: 1052-64.

3 Urban MK, Markowitz SM, Gordon MA, Urquhart BL, Kligfield P. Postoperative prophylactic administration of beta-adrenergic blockers in patients at risk for myocardial ischemia. Anesth Analg 2000; 90: 1257-61.

4 Raby KE, Brull SJ, Timimi $F$ et al. The effect of heart rate control on myocardial ischemia among high-risk patients after vascular surgery. Anesth Analg 1999; 88: 477-82.

5 Talke P, Li J, Jain U et al. Effects of perioperative dexmedetomidine infusion in patients undergoing vascular surgery. The Study of Perioperative Ischemia Research Group. Anesthesiology 1995; 82: 620-33.

6 Talke $\mathrm{P}$, Chen R, Thomas B et al. The hemodynamic and adrenergic effects of perioperative dexmedetomidine infusion after vascular surgery. Anesth Analg 2000; 90: 834-9.

7 Flacke WE, Flacke JW, Bloor BC, McIntee DF, Sagan M. Effects of Dexmedetomidine on systemic and coronary hemodynamics in the anesthetized dog. J of Cardiothorac and Vasc Anaesthesia 1993; 7: 41-9.

8 Dyck JB, Maze M, Haack C et al. Computer-controlled infusion of intravenous dexmedetomidine hydrochloride in adult human volunteers. Anesthesiology 1993; 78: 8218 .

9 Rooke GA, Feigl EO. Work as a correlate of canine left ventricular oxygen consumption, and the problem of catecholamine oxygen wasting. Circ Res 1982; 50: 273-86.

10 Arts T, Reneman RS. Measurement of deformation of canine epicardium in vivo during cardiac cycle. Am J Physiol 1980; 239: H432-7.

11 Arts T, Veenstra PC, Reneman RS. Epicardial deformation and left ventricular wall mechanics during ejection in the dog. Am. J. Physiol. 1982; 243: H379-H90.

12 Scheinin M, Karhuvaara S, Ojala Karlsson P, Kallio A, Koulu M. Plasma 3,4dihydroxyphenylglycol (DHPG) and 3-methoxy-4-hydroxyphenylglycol (MHPG) are insensitive indicators of alpha 2-adrenoceptor mediated regulation of norepinephrine release in healthy human volunteers. Life Sci 1991; 49: 75-84.

13 Koulu M, Scheinin M, Kaarttinen A et al. Inhibition of monoamine oxidase by moclobemide: effects on monoamine metabolism and secretion of anterior pituary hormones and cortisol in healthy volunteers. Br. J. clin. Pharmac. 1989; 27: 243-55.

14 Hoeft A, Sonntag H, Stephan H, Kettler D. Validation of myocardial oxygen demand indices in patients awake and during anaesthesia. Anesthesiology 1991; 75: 49-56.

15 Kal JE, Van Wezel HB, Vergroesen I. A critical appraisal of the rate pressure product as index of myocardial oxygen consumption for the study of metabolic coronary flow regulation. Int J Cardiol 1999; 71: 141-8.

16 Roekaerts PM, Prinzen FW, De Lange S. Beneficial effects of dexmedetomidine on ischaemic myocardium of anaesthetized dogs. Br J Anaesth 1996; 77: 427-9.

17 Lawrence CJ, Prinzen FW, Lange de S. The effect of dexmedetomidine on the balance of myocardial energy requirement and oxygen supply and demand. Anesth Analg 1996; 82: 54450.

18 Lawrence CJ, Prinzen FW, De Lange S. Hemodynamic and coronary vascular effects of dexmedetomidine in the anesthetized goat. Acta Anaesthesiol Scand 1997; 41: 830-6.

19 Sidi A, Rush W. Decreased regional lactate production and output due to intracoronary continuous infusion of esmolol during acute coronary occlusion in dogs. J Cardiothorac Vasc Anesth 1991; 5: 237-42. 


\section{CHAPTER 5}

20 Sidi A, Davis RF. Esmolol decreases the adverse effects of acute coronary artery occlusion on myocardial metabolism and regional myocardial blood flow in dogs. Anesth. analg. 1988; 67: 124-30.

21 Deegan R, Wood AJ. Beta-receptor antagonism does not fully explain esmolol-induced hypotension. Clin Pharmacol Ther 1994; 56: 223-8.

22 Jacobs JR, Maier GW, Rankin JS, Reves JG. Esmolol and left ventricular function in the awake dog. Anesthesiology 1988; 68: 373-8.

23 Shah N, Del Valle O, Edmondson R et al. Esmolol infusion during nitroprusside-induced hypotension: impact on hemodynamics, ventricular performance, and venous admixture. J Cardiothorac Vasc Anesth 1992; 6: 196-200.

24 Strum DP, Pinsky MR. Esmolol-induced regional wall motion abnormalities do not affect regional ventricular elastances. Anesth Analg 2000; 90: 252-61.

25 Girard D, Shulman BJ, Thys DM et al. The safety and efficacy of esmolol during myocardial revascularisation. Anesthesiology 1986; 65: 157-64.

26 Dyck JB, Maze M, Haack C, Vuorilehto L, Shafer SL. The pharmacokinetics and hemodynamic effects of intravenous and intramuscular dexmedetomidine hydrochloride in adult human volunteers. Anesthesiology 1993; 78: 813-20.

27 Schmeling WT, Kampine JP, Roerig DL, Warltier DC. The effects of the steroisomers of the $\alpha_{2}$-Adrenergic agonist medetomidine on systemic and coronary hemodynamics in conscious dogs. Anesthesiology 1991; 75: 499-511.

28 Kallio A, Scheinin M, Koulu M et al. Effects of demedetomidine, a selective $\alpha_{2}$-adrenoceptor agonist, on hemodynamic control mechanisms. Clin Pharmacol Ther 1989; 46: 33-42.

29 Citters Van RL, Franklin DL, Rushmer RF. Left Ventricular Dynamics in Dogs During Anaesthesia with Alpha-Chloralose and Sodium Pentobarbital. The american journal of cardiology 1964: 349-54.

30 Covert RF, Schreiber MD, Leff AR et al. Oxygen metabolism and catecholamine secretion during chloralose anaesthesia in lambs. J of Developmental Physiology 1992; 17: 125-32.

31 Covert RF, Drummond WH, Gimotty PA. Chloralose alters circulatory response to $\alpha-$ receptor stimulation and blockade. Am. J. Physiol. 1988; 255: H419-H25.

32 Ruesch S, Levy JH. Treatment of persistent tachycardia with dexmedetomidine during offpump cardiac surgery. Anaesth Analg 2002; 95:316-8.

33 Maze M, Tranquilli W. Alpha-2 adrenoceptor agonists: defining the role in clinical anaesthesia. Anesthesiology 1991; 74: 581-605.

34 Quon CY, Gorczynsky RJ. Pharmacodynamics and onset of action of esmolol in anesthetized dogs. The journal of pharmacology and experimental therapeutics 1986; 237: 912-8.

35 Gorczynski RJ, Shaffer JE, Lee RJ. Pharmacology of ASL-8052, a novel $\alpha$-adrenergic receptor antagonist with an ultrashort duration of action. Journal of Cardiovascular Pharmacology 1983; 5: 668-77.

36 Gorczynski RJ, Murthy VS, Hwang TF. $\alpha$-blocking and hemodynamic effects of ASL-8052. Journal of cardiovascular pharmacology 1984; 6: 1048-59.

37 Daniell HB. Coronary flow alterations on myocardial contractility, oxygen extraction, and oxygen consumption. Am J Physiol 1973; 225: 1020-5.

38 Modin A, Pernow J, Lundberg JM. Neuropeptide Y and differential sympathetic control of splenic blood flow and capacitance function in the pig and dog. Acta Physiol Scand 1993; 147: $15-25$.

39 Supple EW, Graham RM, Powell WJ, Jr. Direct effects of alpha 2-adrenergic receptor stimulation on intravascular systemic capacity in the dog. Hypertension 1988; 11: 352-9. 
40 Flamm SD, Taki J, Moore R et al. Redistribution of regional and organ blood volume and effect on cardiac function in relation to upright exercise intensity in healthy human subjects. Circulation 1990; 81: 1550-9.

41 Laub M, Hvid Jacobsen K, Hovind $\mathrm{P}$ et al. Spleen emptying and venous hematocrit in humans during exercise. J Appl Physiol 1993; 74: 1024-6.

42 Trippodo NC. Total circulatory capacity in the rat. Effects of epinephrine and vasopressin on compliance and unstressed volume. Circ Res 1981; 49: 923-31.

43 Fan FC, Chen RY, Schuessler GB, Chien S. Effects of hematocrit variations on regional hemodynamics and oxygen transport in the dog. Am J Physiol 1980; 238: H545-22. 


\section{CHAPTER 6}

The effects of esmolol and dexmedetomidine on myocardial oxygen consumption during sympathetic stimulation in dogs

Henriëtte M. Willigers, Frits W. Prinzen and Paul M.H.J. Roekaerts.

J Cardiothorac Vasc Anesth 2006; 20:364-70. With small modifications. 


\section{Abstract}

Objective: To compare the potential of the $\beta_{1}$-adrenergic receptor blocker esmolol and the $\alpha_{2}$-adrenergic receptor agonist dexmedetomidine to suppress the cardiovascular and neuro-endocrine response to a sympathetic stimulus

Design: Experimental study.

Setting: Laboratory of University.

Participants: Eleven anesthetized dogs.

Interventions: Catheters for arterial and coronary venous blood sampling and calculation of myocardial oxygen consumption were inserted. Pressure sensors were placed in the aorta, in the left ventricle and in a carotid artery. Flow probes were placed around the aortic root and around the left anterior descending coronary artery. Esmolol was infused (loading dose $1 \mathrm{mg} / \mathrm{kg}$, infusion $0.3 \mathrm{mg}^{-}$ ${ }^{1} \cdot \mathrm{kg}^{-1} \cdot \mathrm{min}^{-1}$.), and the adequacy of $\beta$-blockade was checked. Dexmedetomidine infusion was started more than 30 minutes after stopping esmolol (loading dose dexmedetomidine $1 \mu \mathrm{g} / \mathrm{kg}$, infusion $\left.1.5 \mu \mathrm{g}^{-1} \cdot \mathrm{kg}^{-1} \cdot \mathrm{h}^{-1}\right)$. Occlusion of both carotid arteries was used as a sympathetic stimulus before and during infusion of esmolol and before and during infusion of dexmedetomidine.

Measurements and Main Results: The variables were measured just before and during sympathetic stimulation, and changes were calculated. Both drugs suppressed the increase in $\mathrm{dPdT}_{\max }$. Dexmedetomidine suppressed the increase in plasma norepinephrine; and the increase in systemic vascular resistance (dexmedetomidine: $4 \pm 4 \%$, esmolol: $25 \pm 19 \%$; increase, $\mathrm{P}=0.02$ ). Esmolol attenuated the heart rate response (esmolol: $2 \pm 2 \%$ increase, dexmedetomidine: $20 \pm 18 \%$ increase; $\mathrm{P}=0.02$ ). However, dexmedetomidine decreased baseline heart rate more than esmolol; therefore, the absolute maximal heart rate during sympathetic stimulation was lower in the presence of dexmedetomidine (dexmedetomidine $119 \pm 14$, esmolol $141 \pm 15$ beats $\min ^{-1} ; \mathrm{P}=0.01$ ). Neither drug suppressed the increase in myocardial oxygen consumption.

Conclusions: Both dexmedetomidine and esmolol have the potential to suppress some of the cardiovascular and neuro-endocrine changes to a sympathetic stimulus but neither drug suppressed the increase in myocardial oxygen consumption. 


\section{Introduction}

Sympatholytic drugs such as beta-adrenergic blockers and alpha $a_{2}$-adrenergic agonists have a beneficial effect on cardiac outcome in selected surgical patients ${ }^{1,2}$, and therefore the American College of Cardiology / American Heart Association guidelines recommend consideration of administration of one of these drugs during the perioperative period ${ }^{3}$. One reason for the beneficial effect of sympatholytic drugs on cardiac outcome is that they suppress the increase in myocardial oxygen consumption associated with sympathetic stimulation. In accordance, it has been shown that beta-blockade suppresses the increase in myocardial oxygen consumption in exercising $\operatorname{dogs}^{4}$, and the alpha ${ }_{2}$-agonist dexmedetomidine suppresses the increase in heart rate and myocardial lactate release during emergence from anesthesia in $\operatorname{dogs}^{5}$.

To date, there are no comparative studies on the potential of beta-blockers and alpha $_{2}$-adrenergic agonists to decrease perioperative cardiac complications ${ }^{6}$. Clinical studies in which the sympatholytic potential of these drugs were compared suggest that alpha 2 -agonists may be superior ${ }^{7,8}$. This is because the central acting alpha ${ }_{2}$-agonists attenuate the heart rate, blood pressure, and plasma catecholamine response to sympathetic stimulation, whereas the peripheral acting beta-blockers only attenuate the heart rate response. However, it remains unknown if this more complete sympatholytic action of alpha $a_{2}$-agonists translates into a more complete suppression of the sympathetic mediated increase in myocardial oxygen consumption. This is because myocardial oxygen consumption was not measured in these studies.

Therefore the purpose of the current study was to compare the potential of the alpha ${ }_{2}$-agonist dexmedetomidine and the beta ${ }_{1}$-blocker esmolol to suppress the cardiovascular effects and the increase in myocardial consumption associated with a sympathetic stimulus. Because of the invasive nature of the measurements the study was done in anesthetised dogs. Carotid sinus hypotension from bicarotid occlusion was used as a sympathetic stimulus because this is a well known stimulus 9,10 and because it induced the most reliable and reversible hemodynamic changes and increases in myocardial oxygen consumption of all sympathetic stimuli tested in our pilot experiments. The other sympathetic stimuli tested were; application of capsicain on the stomach ${ }^{11}$, in the knee ${ }^{12}$, and on the epicardium ${ }^{13}$.

In each animal, the effects of esmolol and of dexmedetomidine on sympathetic induced changes in: plasma norepinephrine levels, hemodynamic variables, hemodynamic indicices of demand, and myocardial oxygen consumption were measured. 


\section{Methods}

\section{Animal Preparation and Instrumentation}

Eleven adult mongrel dogs $(31 \pm 6 \mathrm{~kg})$ were studied with the approval of the Animal Care Committee of the University. The dogs were anesthetized with sodium thiopental $25 \mathrm{mg} \mathrm{kg}^{-1}$ intravenously; intubated, and ventilated with oxygen $30 \%$ in nitrous oxide. Halothane (inspired concentration 1-1.5\%) was added to maintain hemodynamic stability during thoracotomy and instrumentation. The rectal temperature of the dogs was kept between $37^{\circ} \mathrm{C}$ and $39^{\circ} \mathrm{C}$ by means of a thermostatically regulated heating mattress and a warmed operating room. Heart rate and rhythm were monitored using ECG lead II.

The chest was opened through the left fifth intercostal space and catheters were inserted into the femoral artery and into the coronary vein accompagning the left anterior descending (LAD) artery for arterial and left ventricular coronary venous blood sampling respectively. Pressure sensors (Sentron $180 \mathrm{~S}$, Cordis, Roden, the Netherlands) were inserted through a femoral artery into the ascending aorta and left ventricle. Ultrasonic transit-time flow probes (Transonic Systems, Ithaca, NY) were placed around the aortic root and around the LAD artery just proximal to the first diagonal branch. A pulmonary artery catheter (Baxter) was introduced via the right jugular vein into the pulmonary artery and connected to a thermodilution cardiac output computer (Baxter Edwards SAT 2, Irvine, CA) to compare cardiac output measurements derived from the ultrasonic aortic flow probe with the thermodilution cardiac output measurements.

To be able to induce reversible bicarotid occlusion, both common carotid arteries were dissected free over a distance of $1.5 \mathrm{~cm}$ and care was taken to ensure that nerve branches from the vagosympathetic trunk remained intact. Umbilical tape was placed loosely around each carotid artery, and the two ends of the ties were passed through stiff plastic tubing to form a snare occluder. Carotid pressure distal to the occluder was measured with a catheter (Bardicath, Bard Limited,Murray Hill, NJ) introduced into the cranial thyroid artery and connected to a pressure transducer (Baxter 43-600F).

\section{Study Protocol}

As soon as instrumentation was completed, nitrous oxide and halothane were discontinued. A loading dose of $40 \mathrm{mg} \mathrm{kg}^{-1}$ chloralose was administered, followed by a maintenance infusion of $8 \mathrm{mg} \mathrm{kg}^{-1} \mathrm{~h}^{-1}$. The animals were ventilated with $30 \%$ oxygen in air to normocarbia. After a stabilization period of at 


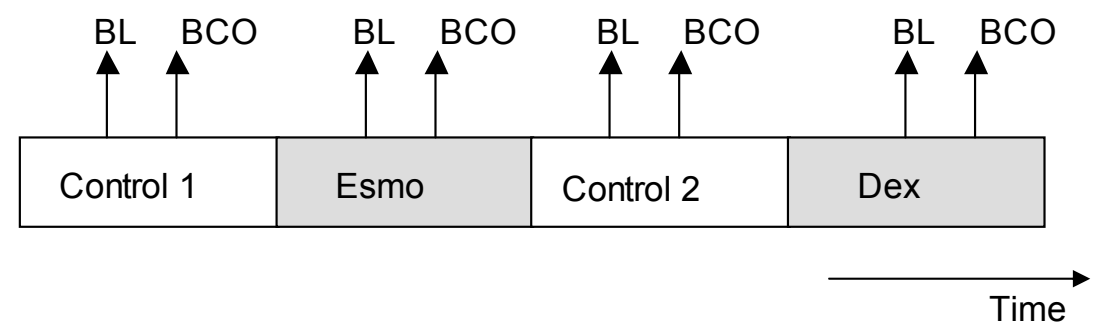

Figure. 1. The study protocol in 11 chloralose-anesthetized dogs. BL, baseline; BCO, bicarotid occlusion; Esmo, esmolol; Dex, dexmedetomidine.

least 60 minutes, 4 successive experimental conditions were studied in each dog (fig.1).

Esmolol (Ohmeda Inc., NJ, USA) was given as a loading dose of $0.5 \mathrm{mg} \mathrm{kg}^{-1}$ $\mathrm{min}^{-1}$ for two minutes, followed by a continuous infusion of $0.3 \mathrm{mg} \mathrm{kg}^{-1} \mathrm{~min}^{-1}$. To check that the beta ${ }_{1}$-adrenergic blockade from esmolol was adequate, the response to the tachycardiac dose of isoprenaline was tested during the esmolol infusion. The tachycardiac dose of isoprenaline was defined as the dose necessary to increase heart rate by more than 20\% during control 1 .

Dexmedetomidine (Orion Corporation, Farmos Research, Turku, Finland) was given as a loading dose of $1 \mu \mathrm{g} \mathrm{kg}^{-1}$ over twenty minutes, followed by a continuous infusion of $1.5 \mu \mathrm{g} \mathrm{kg}^{-1} \mathrm{~h}^{-1}$. With this infusion we aimed at a plasma concentration of dexmedetomidine above $0.5 \mathrm{ng} \cdot \mathrm{mL}^{-1}$ based on the pharmacokinetic set in the STANPUMP software (Department of Anesthesia, Stanford University, Palo Alto, CA $)^{14}$.

Carotid sinus hypotension from bicarotid occlusion was used as a sympathetic stimulus as described in previous studies ${ }^{9,10}$. Baseline measurements were performed 20 minutes after start of each condition, and bicarotid occlusion (BCO) measurements were performed after maximum changes from $\mathrm{BCO}$ had stabilized, which was approximately after one minute of occlusion.

The following variables were measured:

1. Carotid pressure distal to the occlusion.

2. Hemodynamic indices: heart rate, aortic pressure, left ventricular pressure, and cardiac output.

3. Plasma concentration of norepinephrine.

4. Variables related to left ventricular myocardial oxygen metabolism: LAD coronary venous blood gases, LAD coronary flow, and arterial blood gases and hemoglobin content. 


\section{2 \\ CHAPTER 6}

To calculate LAD flow relative to myocardial weight, the perfusion area of the LAD was delineated by injecting methylene blue dye in the LAD at the end of each experiment ${ }^{15}$. Then, the dogs were killed by a pentobarbital overdose and their hearts were excised. The methylene-blue stained portion of the heart was dissected and weighed.

\section{Data Analysis}

All hemodynamic and coronary flow signals were preamplified and then digitized with a 16-channel, 12-bit A/D interface in an IBM-compatible PC. Sampling frequency was $200 \mathrm{~Hz}$ for each channel. The signals were continuously displayed on the computer screen during the experiment and beat-to-beat values were stored on the hard disk during each period of measurement. From these values the mean value over a stable hemodynamic period of two minutes, i.e. less than $5 \%$ heart rate variation, was calculated afterwards. Peak of first derivative of left ventricular pressure ( $\left.\mathrm{LV} \mathrm{dPdt}_{\max }\right)$ was derived from the left ventricular pressure signal. Systemic vascular resistance (SVR) was calculated as the quotient of mean aortic pressure and mean aortic blood flow. Coronary vascular resistance (CVR) was calculated as the quotient of mean aortic pressure and mean coronary blood flow.

The Rate Pressure Product (RPP), which is a frequent used index of myocardial oxygen demand, was calculated as; RPP $=$ heart rate $\times$ systolic aortic pressure.

Arterial plasma norepinephrine concentrations were analyzed with high performance liquid chromatography with colorimetric electrochemical detection $^{16,17}$. Plasma concentrations of dexmedetomidine were determined by gas chromatography-mass spectrometry ${ }^{18}$ at Farmos research, Turku, Finland. All blood samples were collected on ice. Those to be analyzed afterwards were centrifuged at $4^{\circ} \mathrm{C}$ within 15 minutes after sampling and stored as plasma at $-70^{\circ} \mathrm{C}$. Arterial and coronary venous blood gas tensions were assessed with a blood gas analyzer (ABL 3, Radiometer, Copenhagen, Denmark). Hemoglobin content $(\mathrm{Hb})$ and oxygen saturation $\left(\mathrm{O}_{2}\right.$ sat $)$ were assessed with a hemoxymeter (OSM-2, Radiometer). The $\mathrm{O}_{2}$ content ( in $\mathrm{mmol} \mathrm{L}^{-1}$ ) was calculated as $\mathrm{Hb} \times$ $\mathrm{O}_{2}$ sat $+0.0102 \times \mathrm{PO}_{2}$. From this, oxygen extraction was calculated for the territory of myocardium perfused by the LAD, using a standard formula.

\section{Statistical Analysis}

The focus of the current study was on the effect of sympatholytic drugs on sympathetic induced cardiovascular responses. Therefore BCO-induced 
responses were calculated as the difference between the value measured during $\mathrm{BCO}$ and the baseline value, and from this the percentage change from baseline was also calculated. Responses in presence of esmolol or dexmedetomidine were compared to each other and to their preceding control responses. A methodological limitation of the study was that the drugs always had to be investigated in the same sequence in each experiment because of the very short plasma half-life of esmolol and the long plasma half-life of dexmedetomidine. To minimize a possible time-effect of the comparison between esmolol and dexmedetomidine, the corresponding control values were first subtracted from the values found in presence of esmolol or dexmedetomidine. Based on our pilot experiments the present study was powered to detect a suppression of the BCO mediated increase in myocardial oxygen consumption of minimally $50 \%$ (power: 0.80 and $\alpha=0.05$ ). Because of the number of experiments were too few to presume a standard distribution the non-parametric Wilcoxon signed rank test was used as a statistical test. Data are presented as mean \pm standard deviation, unless stated otherwise.

\section{Results}

\section{Baseline experimental conditions}

Throughout the study period, all dogs maintained body temperature and shivering was not observed. Dexmedetomidine infusion resulted in plasma concentration of dexmedetomidine of $1.1 \pm 0.9 \mathrm{ng} \mathrm{ml}^{-1}$.

The change in baseline values from administration of dexmedetomidine or esmolol (Table 1) has been discussed in a previous publication ${ }^{19}$. The infusion protocols used resulted in sympatholysis because dexmedetomidine decreased plasma norepinephrine concentration more than $80 \%$ (table 1) and esmolol abolished the tachycardic response to isoprenaline in all experiments. The mean tachycardic dose of isoprenaline used to test the beta-adrenergic blockade was $0.45 \pm 0.04 \mu \mathrm{g} \mathrm{kg} \mathrm{kg}^{-1}$. Esmolol did not decrease the baseline plasma norepinephrine concentration.

\section{Effect of Bicarotid Occlusion during Control Conditions}

An example of the effect of BCO during control conditions is plotted in figure 2. Occlusion of the carotid arteries resulted in a significant decrease in carotid pressure (Control 1; decrease $22 \pm 11 \%$, Control 2; decrease $15 \pm 8 \%(\mathrm{P}=0.12$, Control 1 vs Control 2). Simultaneously, plasma norepinephrine concentration, heart rate, systolic aortic pressure, SVR, $\mathrm{dPdT}_{\max }, \mathrm{RPP}$, coronary flow and myocardial oxygen consumption increased (Fig. 3 and 4, grey bars). The effects of $\mathrm{BCO}$ were not statistically different between both control measurements, 


\section{CHAPTER 6

Table 1: Baseline values (Mean \pm SD) measured just before sympathetic stimulation during each experimental condition in chloralose anesthetized dogs.

\begin{tabular}{|c|c|c|c|c|}
\hline Variable & Control 1 & Esmolol & Control 2 & $\begin{array}{l}\text { Dexmede- } \\
\text { tomidine }\end{array}$ \\
\hline $\begin{array}{l}\text { Heart rate } \\
\text { beats } \min ^{-1}\end{array}$ & $160 \pm 20$ & $138 \pm 13^{\star}$ & $150 \pm 18$ & $101 \pm 20^{\star \#}$ \\
\hline $\begin{array}{l}\text { Systolic aortic pressure } \\
\mathrm{mm} \mathrm{Hg}\end{array}$ & $127 \pm 20$ & $127 \pm 18$ & $128 \pm 12$ & $139 \pm 25$ \\
\hline $\begin{array}{l}\mathrm{dPdT}_{\max } \\
\mathrm{mmHg} \mathrm{sec}^{-1}\end{array}$ & $2093 \pm 347$ & $1442 \pm 276^{\star}$ & $1706 \pm 285$ & $1465 \pm 265^{\star \#}$ \\
\hline $\begin{array}{l}\text { Cardiac output } \\
\mathrm{L} \min ^{-1}\end{array}$ & $4.2 \pm 1.9$ & $2.7 \pm 1.0^{\star}$ & $2.8 \pm 0.9$ & $2.0 \pm 0.7^{\star}$ \\
\hline $\begin{array}{l}\text { Systemic vascular resistance } \\
\mathrm{mmHg} \text { min. } \mathrm{L}^{-1}\end{array}$ & $37 \pm 22$ & $51 \pm 16$ & $50 \pm 18$ & $76 \pm 32^{\star}$ \\
\hline $\begin{array}{l}\text { Pressure work index } \\
\mathrm{mmol} \mathrm{min}{ }^{-1} 100 \mathrm{~g}^{-1}\end{array}$ & $0.67 \pm 0.16$ & $0.52 \pm 0.09^{\star}$ & $0.56 \pm 0.08$ & $0.45 \pm 0.07^{\star}$ \\
\hline $\begin{array}{l}\text { Rate pressure product } \\
\mathrm{mmHg} \text { beats } \mathrm{min}^{-1}\end{array}$ & $20270 \pm 3272$ & $17556 \pm 3254^{\star}$ & $19176 \pm 2876$ & $13823 \pm 2261^{\star}$ \\
\hline $\begin{array}{l}\text { Norepinephrine } \\
\text { nmol L-1 }\end{array}$ & $0.36 \pm 0.24$ & $0.50 \pm 0.37$ & $0.67 \pm 0.55$ & $0.11 \pm 0.15^{\star \#}$ \\
\hline $\begin{array}{l}\mathrm{O}_{2} \text { consumption } \\
\mathrm{mmol} \mathrm{min}^{-1} 100 \mathrm{~g}^{-1}\end{array}$ & $0.44 \pm 0.11$ & $0.38 \pm 0.14$ & $0.38 \pm 0.15$ & $0.35 \pm 0.11$ \\
\hline $\begin{array}{l}\text { Coronary flow } \\
\mathrm{mL} \mathrm{min}^{-1} 100 \mathrm{~g}^{-1}\end{array}$ & $85 \pm 23$ & $72 \pm 26$ & $71 \pm 24$ & $52 \pm 17$ \\
\hline $\begin{array}{l}\text { Coronary vascular resistance } \\
\mathrm{mm} \mathrm{Hg} \mathrm{ml}\end{array}$ & $1.69 \pm 0.98$ & $1.94 \pm 0.79$ & $1.98 \pm 0.88$ & $2.92 \pm 1.43^{\#}$ \\
\hline
\end{tabular}

$\star \mathrm{P}<0.05$ esmolol or dexmedetomidine compared to preceding control; \# $\mathrm{P}<0.05$ esmolol compared to dexmedetomidine.

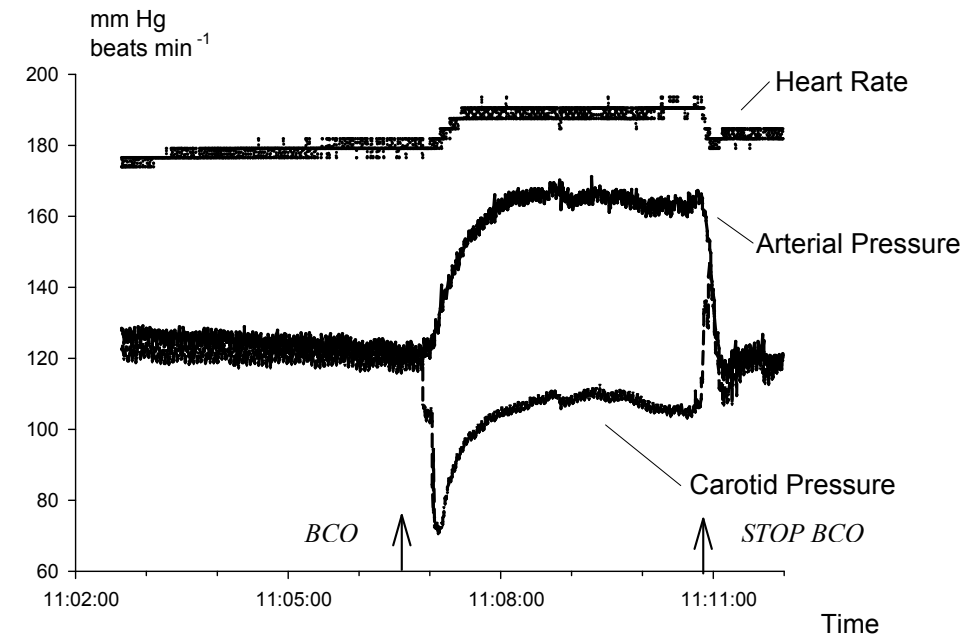

Figure.2. Representative recordings of the effects of bicarotid occlusion $(\mathrm{BCO})$ in one of the dogs. 

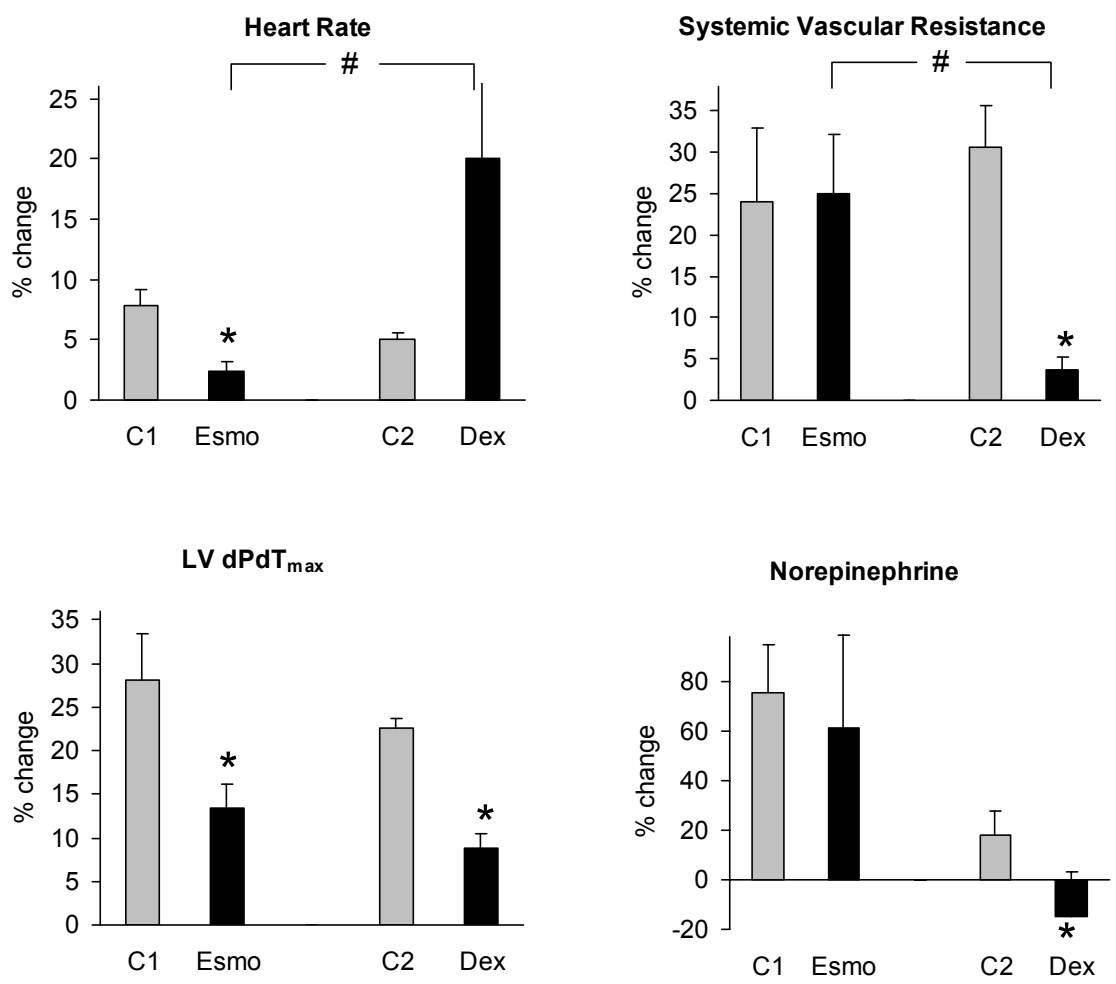

Figure 3. Bar graphs showing the effect of bicarotid occlusion as a sympathetic stimulus on heart rate, SVR, dPdTmax, and norepinephrine plasma concentrations in anesthetized dogs. Data represent percentage changes (mean \pm standard error) during both control measurements $(\mathrm{C} 1, \mathrm{C} 2$; grey bars) and in presence of esmolol or dexmedetomidine (Esmo,Dex; black bars). ${ }^{\star} \mathrm{P}<0.05$; esmolol or dexmedetomidine versus preceding control measurement. $\# \mathrm{P}<0.05$ esmolol versus dexmedetomidine measurement.

except for heart rate which increased more $(\mathrm{P}=0.01)$ and for SVR $(\mathrm{P}=0.03)$ which increased less during Control 1 than during Control 2.

Thus, during control conditions BCO stimulated the sympathetic nervous system and this resulted in a parallel increase of myocardial oxygen consumption and hemodynamic indices of myocardial oxygen demand. 
Rate Pressure Product

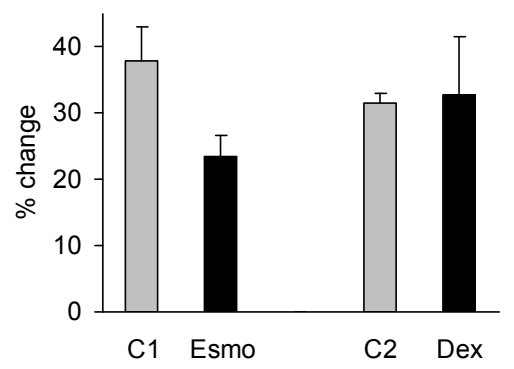

Coronary Flow

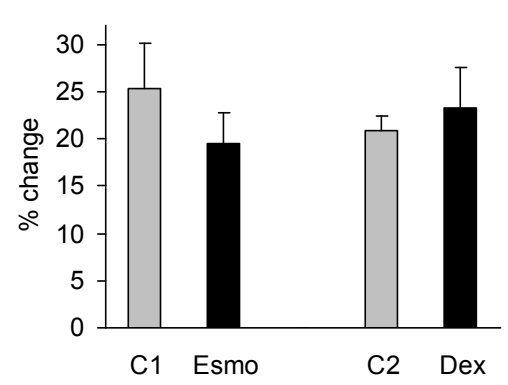

Myocardial Oxygen Consumption

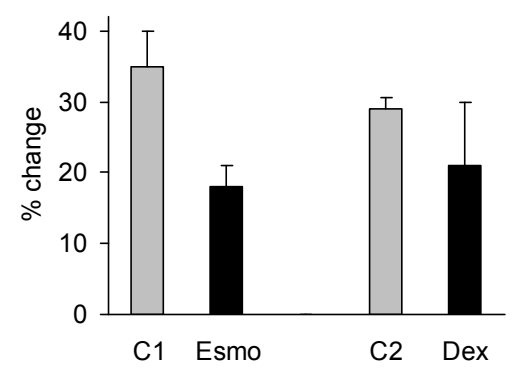

Coronary Vascular Resistance

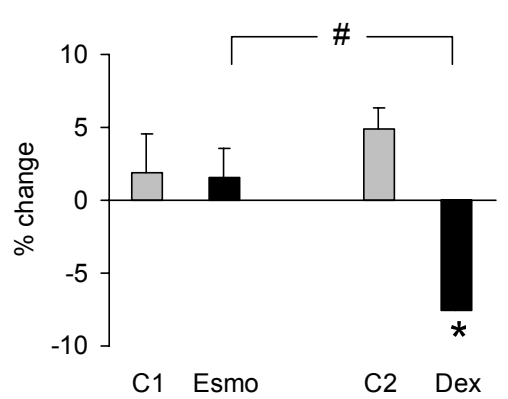

Figure 4. Bar graphs showing the effect of bicarotid occlusion as a sympathetic stimulus on the Rate Pressure Product, myocardial oxygen consumption, flow in LAD coronary artery, and coronary vascular resistance in anesthetized dogs. Data represent percentage changes (mean \pm standard error) during both control measurements (C1, C2; grey bars) and in presence of esmolol or dexmedetomidine (Esmo, Dex; black bars). ${ }^{\star} \mathrm{P}<0.05$; esmolol or dexmedetomidine versus preceding control measurement. \# $\mathrm{P}<0.05$ esmolol versus dexmedetomidine measurement.

\section{Effect of Bicarotid Occlusion in Presence of Esmolol and Dexmedetomidine} Esmolol and dexmedetomidine had different effects on several sympathetic mediated hemodynamic responses. (black bars, Fig. 3 and 4). First, esmolol, but not dexmedetomidine, attenuated the increase in heart rate $(\mathrm{P}=0.02$, esmolol vs dexmedetomidine). However, the absolute maximal heart rate during $\mathrm{BCO}$ was lower in presence of dexmedetomidine (dexmedetomidine $119 \pm 14$, esmolol $141 \pm 15$ beats $\min ^{-1} ; \mathrm{P}=0.01$ ). This can be explained was because dexmedetomidine reduced the baseline heart rate more than esmolol (Table 1). In contrast, dexmedetomidine but not esmolol suppressed the increase in plasma norepinephrine concentration and the increase in SVR (Fig. 3). Both drugs 
suppressed the increase in $\mathrm{dPdT}_{\max }(\mathrm{P}=0.16$, esmolol vs dexmedetomidine $)$. However, despite their effects on hemodynamic responses; neither esmolol nor dexmedetomidine suppressed the sympathetic mediated increase in myocardial oxygen consumption and coronary flow. Simultaneously, coronary vascular resistance remained unchanged during $\mathrm{BCO}$ in presence of esmolol but decreased in presence of dexmedetomidine $(\mathrm{P}=0.03$ esmolol vs dexmedetomidine). Myocardial oxygen extraction remained unaffected (data not shown).

Thus, dexmedetomidine but not esmolol suppressed the BCO-related increase in plasma norepinephrine concentration and SVR. In contrast, esmolol, but not dexmedetomidine, suppressed the increase in heart rate. However, neither drug suppressed the increase in myocardial oxygen consumption.

\section{Discussion}

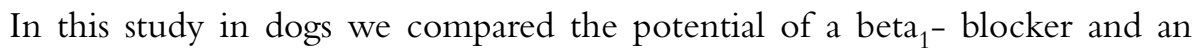
alpha $_{2}$ - agonist to suppress the hemodynamic changes and increase in myocardial oxygen consumption associated with a sympathetic stimulus. The results of the current study confirms and extends findings of previous studies. Although in different ways, both drugs, at a sympatholytic dose, suppressed hemodynamic responses to sympathetic stimulation. However, neither drug affected the increase in myocardial oxygen consumption associated with a sympathetic stimulus to a significant extend.

Until now, few studies have compared the effects of a beta-blocker and an alpha $a_{2}$-agonist on the hemodynamic and neuroendocrine consequences of a sympathetic stimulus. In these studies, the alpha $a_{2}$-agonist clonidine suppressed the sympathetic mediated increase in blood pressure and in plasma catecholamines better than the beta-blocker esmolol ${ }^{7,8}$, which is in accordance with our findings. In contrast to our findings, clonidine suppressed the heart rate response to a similar extend as the beta-blocker. This discrepancy in findings may be the result of different measurements: indeed, in one of these studies ${ }^{20}$, not the heart rate response, but the maximal heart rate in presence of an alpha ${ }_{2}$-agonist was measured. This heart rate was found to be lower than the maximal heart rate during control which is also in accordance with the current findings. Furthermore, these studies differed from the present experiments in several essential ways; they were performed in humans, inhalation anesthesia was used, the less selective alpha $a_{2}$-agonist clonidine was studied, and the stress stimuli used in these studies were "intubation" and "increase in desflurane concentration".

It is not likely that the maintained heart rate response in presence of dexmedetomidine resulted from an increase in sympathetic tone. First; this is 
because the plasma concentration of norepinephrine did not increase, and second; the maximal heart rate remained lower than the maximal heart rate in presence of beta ${ }_{1}$-blockade. We hypothesize that the increase in heart rate during sympathetic stimulation in presence of dexmedetomidine resulted from a decrease of an increased parasympathetic tone. In accordance with parasympathicomimetic effects of dexmedetomidine, a study in dogs showed that the vagus nerve plays an important role in the anti-arrhythmic effects of dexmedetomidine ${ }^{21}$.

The current study extends the findings of previous studies because the effects of a beta-blocker and an alpha ${ }_{2}$-agonist on sympathetic mediated increases in myocardial oxygen consumption were measured in addition to changes in hemodynamic variables. We found that, despite suppression of several hemodynamic responses, neither esmolol nor dexmedetomidine suppressed the increase in myocardial oxygen consumption associated with a sympathetic stimulus. There are several possible explanations for this finding.

First, the sympathetic stimulus could be too weak. In the current study carotid hypotension from bicarotid occlusion was used as a sympathetic stimulus which increased the rate-pressure-product by $40 \%$ and the myocardial oxygen consumption by approximately $30 \%$. In accordance, previous work from our laboratory has shown that the decrease in myocardial energy requirements from dexmedetomidine depends on baseline heart rate and blood pressure ${ }^{22}$. Also, it has been shown that beta-blockade blunts the increase in myocardial oxygen consumption in exercising $\operatorname{dogs}^{4}$ but it does not suppress the increase in myocardial oxygen consumption related to administration of cocaine in conscious dogs ${ }^{23}$. In accordance with these experimental studies in animals, a study in humans showed that beta-blockade had unpredictable effects on myocardial ischemia from mental-stress ${ }^{24}$, but reliably reduced myocardial ischemia from exercisestress. Exercise is one of the most severe physiologic stressors for the cardiovascular system increasing the rate-pressure-product and myocardial oxygen consumption more than $150 \%{ }^{25,26}$, and it has been shown that betablockade limits the exercise induced increase in myocardial oxygen consumption by reducing increases in heart rate and in myocardial contractility ${ }^{25}$. Cocaine increased the rate-pressure-product by only $70 \%{ }^{23}$ indicating that this stimulus has less hemodynamic consequences than exercise. However, measuring the effects of sympatholytic drugs on a stimulus which does not result in a large hemodynamic response seems to be clinically relevant because mental activities are as potent as physical activities in triggering daily life ischemia ${ }^{27}$.

A second possible explanation for the lack of effect of dexmedetomidine and esmolol on myocardial oxygen consumption was that the present study was not powered to detect a suppression of the BCO related increase in myocardial 
oxygen consumption of less than 50\% Therefore it cannot be excluded that esmolol and dexmedetomidine supressed sympathetic mediated increases in myocardio oxygen consumption to a lesser extend.

A final explanation may be that the doses of esmolol and dexmedetomidine used were not adequate. However, the infusion regimens of both esmolol and dexmedetomine resulted in adequate sympatholysis in all experiments, as evidenced by blunting the isoprenaline-mediated tachycardic response and the significant decrease in plasma norepinephrine concentrations, respectively. Also, infusion of one-third of the dose of esmolol used in the current study blocked $70 \%$ of the beta-receptors in another study ${ }^{28}$, and a plasma concentration of dexmedetomidine above $0.5 \mathrm{ng} \cdot \mathrm{mL}^{-1}$ is known to reduce sympathetic tone effectively in $\operatorname{dog} s^{29}$ and in humans ${ }^{30}$.

The current complex experimental study enabled comparison of the effects of a beta ${ }_{1}$-blocker and an alpha ${ }_{2}$-agonist on sympathetic mediated changes in coronary hemodynamics. In presence of dexmedetomidine, sympathetic stimulation induced a decrease in coronary vascular resistance indicating that dexmedetomidine maintains adaptive coronary vascular responses to an increase in myocardial oxygen demand. Alpha ${ }_{2}$-agonists have been shown to enhance the release of endothelium -derived relaxing factor (ERDF) in the coronary circulation $^{31}$, but ERDF was not measured in the current study. It could be argued that a shortage of myocardial oxygen supply explains the sympathetic mediated decrease in CVR in presence of dexmedetomidine. However, we found no indication for this because myocardial oxygen extraction and coronary venous $\mathrm{PH}$ remained unchanged.

In contrast to the decrease in CVR in presence of dexmedetomidine, the sympathetic mediated increase in coronary flow was associated with an unchanged CVR in presence of esmolol. In a previous study CVR increased during sympathetic stimulation in presence of betablockade ${ }^{4}$. However, in that study a non-selective beta blocker was studied in contrast to the beta -adreno- $^{-}$ receptor antagonist studied in the current study.

The results of this study must be interpreted within the constraints of several limitations. First, extrapolation of these data from dogs to humans should be undertaken with caution. Second, a time effect in addition to a pharmacological effect on the BCO-response can not be excluded. However, BCO had similar effects for most variables during both control measurements and we applied statistical methods to minimize a possible time-effect. Finally, anesthesia may have influenced our measurements. However, chloralose anesthesia was used because this is known to have relatively little influence on central neuroregulation $^{32}$ and oxygen metabolism ${ }^{33}$. 
In summary, the effects of dexmedetomidine and esmolol on the neurohumoral and hemodynamic consequences of sympathetic stimulation in chloralose-anesthetized dogs were in accordance with their respective central and peripheral sympatholytic actions. However, neither drug had a significant effect on the increase in myocardial oxygen consumption and coronary flow associated with the applied sympathetic stimulus.

\section{References}

1 Auerbach AD, Goldman L. \{beta\}-Blockers and Reduction of Cardiac Events in Noncardiac Surgery: Scientific Review. JAMA 2002; 287: 1435-44.

2 Wijeysundera DN, Naik JS, Beattie WS. Alpha-2 adrenergic agonists to prevent perioperative cardiovascular complications: a meta-analysis. Am J Med 2003; 114: 742-52.

3 Eagle KA, Berger PB, Calkins $\mathrm{H}$ et al. ACC/AHA Guideline Update for Perioperative Cardiovascular Evaluation for Noncardiac Surgery-Executive Summary: A Report of the American College of Cardiology/American Heart Association Task Force on Practice Guidelines (Committee to Update the 1996 Guidelines on Perioperative Cardiovascular Evaluation for Noncardiac Surgery). Anesth Analg 2002; 94: 1052-64.

4 Heyndrickx GR, Pannier JL, Muylaert P, Mabilde C, Leusen I. Alteration in myocardial oxygen balance during exercise after beta-adrenergic blockade in dogs. J Appl Physiol 1980; 49: 28-33.

5 Willigers HM, Prinzen FW, Roekaerts PM, de Lange S, Durieux ME. Dexmedetomidine Decreases Perioperative Myocardial Lactate Release in Dogs. Anesth Analg 2003; 96: 657-64.

6 Stevens RD, Burri H, Tramer MR. Pharmacologic Myocardial Protection in Patients Undergoing Noncardiac Surgery: A Quantitative Systematic Review. Anesth Analg 2003; 97: 62333.

7 Zalunardo MP, Zollinger A, Szelloe P et al. [Cardiovascular stress protection following anesthesia induction.Comparison of clonidine and esmolol]. Anaesthesist 2001; 50:21-5.

8 Weiskopf RB, Eger EId, Noorani M, Daniel M. Fentanyl, esmolol, and clonidine blunt the transient cardiovascular stimulation induced by desflurane in humans. Anesthesiology 1994; 81: 1350-5.

9 Kirchheim H, Gross R. Hemodynamics of the carotid sinus reflex elicited by bilateral carotid occlusion in the conscious dog: Effect of $\alpha$ - or $\beta$-adrenergic blockade on the reflex response. Pflugers Arch. 1971; 327: 203-24.

10 Disalvo J, Parker PE, Scott JB, Haddy FJ. Carotid baroreceptor influence on coronary vascular resistance in the anesthetized dog. Am. J. Physiology 1971;221(1): 156-60.

11 Martin SE, Pilkington DM, Longhurst JC. Coronary vascular responses to chemical stimulation of abdominal visceral organs. Am J Physiol 1989; 256: H735-H44.

12 Sato Y, Schaible HG, Schmidt RF. Reactions of cardiac postganglionic sympathetic neurons to movements of normal and inflamed knee joints. Journal of the Autonomic Nervous System 1984; 12: 1-13.

13 Staszewska-Woolly J, Luk DE, Nolan NN. Cardiovascular reflexes mediated by capsaicin sensitive cardiac afferent neurones in the dog. Cardiovascular Research 1986; 20: 897-906.

14 Dyck JB, Maze M, Haack C et al. Computer-controlled infusion of intravenous dexmedetomidine hydrochloride in adult human volunteers. anesthesiology 1993; 78: 821-8.

15 Hasegawa S, Kusuoka H, Fukuchi K et al. 14 C-deoxyglucose imaging overestimates myocardial viability in subacute infarction of rats. Nuclear medicine communications 2002; 23: 209-17. 
16 Scheinin M, Karhuvaara S, Ojala Karlsson P, Kallio A, Koulu M. Plasma 3,4dihydroxyphenylglycol (DHPG) and 3-methoxy-4-hydroxyphenylglycol (MHPG) are insensitive indicators of alpha 2-adrenoceptor mediated regulation of norepinephrine release in healthy human volunteers. Life Sci 1991; 49: 75-84.

17 Koulu M, Scheinin M, Kaarttinen A et al. Inhibition of monoamine oxidase by moclobemide: effects on monoamine metabolism and secretion of anterior pituary hormones and cortisol in healthy volunteers. Br. J. clin. Pharmac. 1989; 27: 243-55.

18 Vuorilehto L, Salonen JS, Anttila M. Picogram level determination of medetomidine in dog serum by capillary gas chromatography with negative ion chemical ionisation mass spectrometry. Journal of Chromatography 1989; 497: 282-7.

19 Willigers HM, Prinzen FW, Roekaerts PM. Comparison of the effects of dexmedetomidine and esmolol on myocardial oxygen consumption in dogs. European journal of anaesthesiology 2004; 21: 957-66.

20 Zalunardo MP, Zollinger A, Spahn DR, Seifert B, Pasch T. Preoperative clonidine attenuates stress response during emergence from anesthesia.J Clin Anesth 2000; 12:343-9.

21 Kamibayashi T, Hayashi Y, Mammoto T et al. Role of the vagus nerve in the antidysrhythmic effect of dexmedetomidine on halothane/epinephrine dysrhythmias in dogs. Anesthesiology 1995; 83: 992-9.

22 Lawrence CJ, Prinzen FW, Lange de S. The effect of dexmedetomidine on the balance of myocardial energy requirement and oxygen supply and demand. Anesth Analg 1996; 82: 54450 .

23 Shannon RP, Stambler BS, Komamura K, Ihara T, Vatner SF. Cholinergic modulation of the coronary vasoconstriction induced by cocaine in conscious dogs [see comments]. Circulation 1993; 87: 939-49.

24 Bairy CN, Krantz DS, DeQuattro V, Berman DS, Rozansky A. Effect of beta-blockade on low heart rate-related ischemia during mental stress. JACC 1991; 17: 1388-95.

25 Colin P, Ghaleh B, Monnet X et al. Contributions of heart rate and contractility to myocardial oxygen balance during exercise. American journal of physiology. Heart and circulatory physiology 2003; 284: H676-82.

26 Heyndrickx GR, Muylaert P, Pannier JL. alpha-Adrenergic control of oxygen delivery to myocardium during exercise in conscious dogs. Am J Physiol 1982; 242: H805-9.

27 Krantz DS, Kop WJ, Santiago HT, Gottdiener JS. Mental stress as a trigger of myocardial ischemia and infarction. Cardiology clinics 1996; 14: 271-87.

28 Gorczynski RJ, Murthy VS, Hwang TF. $\beta$-blocking and hemodynamic effects of ASL-8052. Journal of cardiovascular pharmacology 1984; 6: 1048-59.

29 Flacke WE, Flacke JW, Bloor BC, McIntee DF, Sagan M. Effects of Dexmedetomidine on systemic and coronary hemodynamics in the anesthetized dog.J of Cardiothorac and Vasc Anesthesia 1993; 7: 41-9.

30 Talke P, Li J, Jain U et al. Effects of perioperative dexmedetomidine infusion in patients undergoing vascular surgery. The Study of Perioperative Ischemia Research Group. Anesthesiology 1995; 82: 620-33.

31 Coughlan MG, Lee JG, Bosnjak ZJ et al. Direct coronary and cerebral vascular responses to dexmedetomidine. Anesthesiology 1992; 77: 998-1006.

32 Citters Van RL, Franklin DL, Rushmer RF. Left Ventricular Dynamics in Dogs During Anesthesia with Alpha-Chloralose and Sodium Pentobarbital. The american journal of cardiology 1964:349-54.

33 Covert RF, Schreiber MD, Leff AR et al. Oxygen metabolism and catecholamine secretion during chloralose anesthesia in lambs. J of Developmental Physiology 1992; 17: 125-32. 


\section{CHAPTER 7}

Contrasting baroreceptor effects of esmolol and dexmedetomidine in dogs

Henriette M. M. Willigers, Leon A. F. Ledoux, Paul M.H.J. Roekaerts and

Frits W. Prinzen

Submitted to: J Cardiothorac Vasc Anesth 


\section{Abstract}

Background: Beta-blockers and alpha 2 -agonists decrease cardiac complications partly from their effects on baroreceptors. However, these effects have not been compared directly.

Methods: Sequential measurements were performed in chloralose-anaesthetized dogs during: Control 1, Esmo (esmolol (beta ${ }_{1}$-blocker)), Control 2, and Dexmed (dexmedetomidine (alpha ${ }_{2}$-agonist)). We measured: 1) Heart Rate and Arterial Pressure Variability (HRV and APV) using fast Fourier transformation, 2) plasma norepinephrine and arterial pressure response (pressure gain) to a decrease in carotid artery pressure, and 3) the linear HR-pressure relationship to changes in aortic pressure (cardiac baroreflex sensitivity), and minimal and maximal HR plateau.

Results: Both sympatholytic drugs suppressed the maximal HR plateau. Compared to Esmo, Dexmed: 1) maintained the cardiac baroreflex sensitivity better (slope: $-0.7(0.3)$ versus $-0.1(0,2)(\mathrm{bpm} / \mathrm{mmHg}), \mathrm{P}=0.02), 2)$ increased the (vagal) high frequency component of HRV (62 (17) versus 43 (17) $\mathrm{dB}, \mathrm{P}=$ $0.05), 3)$ lowered the minimal HR plateau (77 (8) versus 126 (18) bpm), $\mathrm{P}=$ 0.02 ), and 4) decreased the low frequency component of APV (54 (8) versus 61 (11) $\mathrm{dB}, \mathrm{P}=0.02)$. In contrast Esmo tended to maintain the pressure gain better than Dexmed (1.35 (0.92) versus 0.59 (0.67), $\mathrm{P}=0.07)$.

Conclusions: Dexmed and Esmo have similar cardiac sympatholytic effects but Dexmed has an additional vagomimetic and vascular sympatholytic effect. As a result Dexmed maintains cardiac baroreflex sensitivity at lower heart rates and improves arterial pressure stability, but Esmo maintains baroreceptor-mediated vasoconstriction. 


\section{Introduction}

The mechanisms by which sympatholytic drugs decrease postoperative cardiac complications are still being explored. There are indications from animal ${ }^{1}$ and human research ${ }^{2}$ that these drugs improve myocardial oxygen balance from their ceiling effect on sympathetic mediated tachycardic and hypertensive responses. Recently, evidence has emerged that their effects on autonomic nervous system mediated cardiovascular control may also be important in decreasing cardiac complications ${ }^{3}$. This is because impaired cardiovascular control, which is known to occur after surgery ${ }^{4}$, is a predictor for adverse cardiac outcome in certain groups of patients ${ }^{5}$. The use of either a beta-adrenergic blocker or an alpha $2^{-}$ adrenergic agonist is advised for pharmacological perioperative sympatholysis ${ }^{6}$. This is because it remains unknown which of these groups of sympatholytic drugs is superior in decreasing cardiac complications. To our knowledge, also differences in baroreceptor mediated cardiovascular control of these groups of drugs have not been studied. Our hypothesis is that beta-blockers and alpha $_{2}-$ agonists have different effects on baroreceptor mediated cardiovascular control because of their respective peripheral and central modes of action. Therefore, we compared esmolol, a short acting beta ${ }_{1}$-blocker, to dexmedetomidine, the most specific alpha ${ }_{2}$-agonist available, within chloralose-anaesthetized dogs. Autonomic nervous system tone and baroreceptor mediated cardiovascular control was evaluated from; the power of frequency spectra of heart rate and aortic pressure variability, plasma norepinephrine concentrations, the response to a decrease in carotid artery pressure, and cardiac baroreflex sensitivity.

\section{Materials and methods}

\section{Instrumentation}

Eleven adult Mongrel dogs (31(7) $\mathrm{kg}$ ) were studied with the approval of the Animal Care and Use Committee at the University of Maastricht, the Netherlands. The current study was part of our previous study focussing on the effects of esmolol and dexmedetomidine on sympathetic mediated increases in myocardial oxygen consumption ${ }^{7}$. Details of instrumentation in these dogs have been described in our previous paper. In short; anaesthesia was induced with sodium thiopental $25 \mathrm{mg} \mathrm{kg}^{-1}$ intravenously, the trachea was intubated and the lungs were ventilated with $30 \%$ oxygen in nitrous oxide. Anaesthesia was maintained with halothane (inspired concentration 1-1.5\%). The rectal temperature of the dogs was kept between $37^{\circ} \mathrm{C}$ and $39^{\circ} \mathrm{C}$ by means of a thermostatically regulated heating mattress. Heart rate and rhythm were monitored using limb lead II of the electrocardiogram. To monitor aortic and left ventricular pressure, 
pressure sensors (Sentron 180 S, Cordis, Roden, the Netherlands) were inserted through the right femoral artery into the left ventricle and ascending aorta. Ultrasonic transit-time flow probes (Transonic Systems, Ithaca, NY) were placed around the aortic root and around the LAD artery. Catheters were inserted into the femoral artery and into the left anterior descending (LAD) coronary vein for arterial and coronary venous blood sampling respectively.

Both common carotid arteries were dissected free, taking care that nerve branches from the vagosympathetic trunk remained intact. Umbilical tape was placed loosely around each carotid artery and the two ends of the ties were passed through stiff plastic tubing to form a snare occluder. Carotid pressure distal to the occluder was measured with a catheter (Bardicath, Bard Limited) introduced into the cranial thyroid artery and connected to a pressure transducer (Baxter 43-600F). Balloon tipped catheters (8 Fr, occlusion balloon catheter, Medi-tech, Boston Scientific Cooperation) were introduced into the femoral artery and vein and pushed up into the descending aorta and inferior caval vein respectively to change the arterial pressure for evaluation of cardiac baroreflex sensitivity.

\section{Protocol}

Once surgery was complete, nitrous oxide and halothane were discontinued and chloralose (bolus: $40 \mathrm{mg} \mathrm{kg}^{-1}$, maintenance $8 \mathrm{mg} \mathrm{kg}^{-1} \mathrm{~h}^{-1}$ ) was infused intravenously. After a stabilization period of at least 60 minutes measurements were performed during the following sequential experimental conditions in each dog: Control 1, Esmo (during esmolol infusion), Control 2, and Dex (during dexmedetomidine infusion). This sequence was chosen because esmolol has a much shorter half live than dexmedetomidine ( 9 minutes versus 2.3 hours).

Esmolol (Ohmeda Inc., NJ, USA) was given as a loading dose of $1 \mathrm{mg} \mathrm{kg}^{-1}$ in two minutes, followed by an infusion of $0.3 \mathrm{mg} \mathrm{kg}^{-1} \mathrm{~min}^{-1}$. To check that the beta ${ }_{1}$-adrenergic blockade from esmolol was adequate, the response to the tachycardiac dose of isoprenaline was tested during the esmolol infusion. The tachycardiac dose of isoprenaline was defined as the dose necessary to increase heart rate by more than $20 \%$ during control 1 .

Dexmedetomidine (Orion Corporation, Farmos Research, Turku, Finland) was given as a loading dose of $1 \mu \mathrm{g} \mathrm{kg}^{-1}$ over twenty minutes, followed by a continuous infusion of $1.5 \mu \mathrm{g} \mathrm{kg}^{-1} \mathrm{~h}^{-1}$.

The study protocol is shown in figure 1 . At least 20 minutes after the start of each experimental condition different tests of baroreceptor function were done. First, arterial pressure and heart rate data of a stable hemodynamic period of at least five minutes were stored for off-line spectral analysis of spontaneous heart 


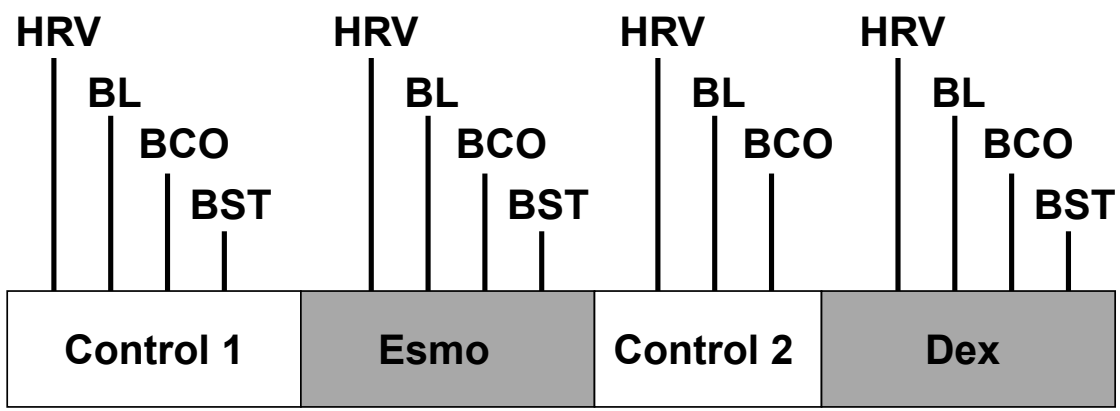

Figure 1. Flow chart of our study protocol in chloralose-anesthetized dogs. HRV, heart rate and arterial pressure variability; BL, baseline; BCO, bicarotid occlusion; BST, cardiac barosensitivity test; Esmo, esmolol; Dex, dexmedetomidine

rate and aortic pressure variability, as measures of cardiac autonomic balance and arterial pressure stability. Then, the effect of a decrease in carotid artery pressure from bilateral carotid artery occlusion on aortic pressure, and plasma norepinephrine concentration was measured to evaluate the efferent sympathetic vascular effects of baroreceptor stimulation. Finally, the effect of arterial pressure variation on the heart rate response was measured to test cardiac baroreceptor sensitivity. At the end of the protocol the dogs were killed by an overdose of pentobarbital.

\section{Data analysis and measurements}

\section{Hemodynamic data}

All hemodynamic signals were preamplified and then digitized with a 16channel, 12-bit A/D interface in an IBM-compatible PC. Sampling frequency was $200 \mathrm{~Hz}$ for each channel. Beat-to-beat values of hemodynamic data were stored on the hard disk during each period of measurement for off line analysis.

Spontaneous Heart Rate Variability (HR Variability) and Aortic Pressure Variability (AOP Variability). Heart rate and systolic aortic pressure variability were measured to quantify cardiac sympathovagal balance and pressure lability respectively ${ }^{8,9}$. Details of the method of spectral analysis have been published previously $^{8}$. This method was chosen because it referred to a study in both dogs and humans and spectral analysis of our data confirmed that the frequency peaks of heart rate and arterial pressure variability were within the suggested predetermined frequency bands. In short: an artefact-free stationary time series of 
approximately 400 beats was selected from the ECG (lead II) signal. In case of a non-sinus beat, this beat was discarded and replaced by the interpolated value. Beat to beat systolic arterial pressure was calculated from the peak of the aortic pressure signal. Spectral components and associated power of the heart rate and arterial pressure data were computed using a computer program based on Fast Fourier analysis. From these computed spectra the power $(\mathrm{dB})$ of total frequency (TF: $0.02-0.35 \mathrm{~Hz}$ ), low frequency (LF: $0.02-0.12 \mathrm{~Hz}$ ), and high frequency (HF: $0.25-0.35 \mathrm{~Hz}$ ) was calculated for each experimental period.

\section{Blood samples}

All blood samples were collected on ice, centrifuged at $4^{\circ} \mathrm{C}$, and stored as plasma at $-70^{\circ} \mathrm{C}$.

Plasma concentrations of dexmedetomidine were determined by gas chromatography-mass spectrometry ${ }^{10}$ at Farmos research, Turku, Finland.

Plasma norepinephrine concentrations were measured as an indicator of sympathetic tone and were analyzed with high performance liquid chromatography with colorimetric electrochemical detection ${ }^{11}$.

Bilateral Carotid artery Occlusion (BCO). To evaluate carotid baroreceptor function, both common carotid arteries were occluded for 3 minutes as described previously $^{12,13}$ and we measured; the carotid pressure distal to the occlusion, heart rate, aortic pressure, and plasma norepinephrine concentrations. Responses were calculated as the difference between the value measured during carotid occlusion (after maximal changes had stabilized) and the value measured immediately before carotid occlusion. The gain of the carotid pressure response, as a measure of the baroreceptor mediated vascular response, was calculated as the ratio of the increase in systolic aortic pressure to the decrease in systolic carotid artery pressure.

Cardiac Baroreceptor Sensitivity Test (cardiac BST): Arterial pressure was randomly varied within a range of $50 \mathrm{mmHg}$ above and below baseline by inflating the intravascular balloons. The number of pressure changes for each test was approximately 9 , and their duration was approximately 30 seconds. The resulting heart rates and arterial pressures were stored for off line analysis. The mean value of systolic aortic pressure and heart rate (sinus rhythm) over the final 10-15 s of each pressure change were calculated. The gain of cardiac baroreceptor reflex sensitivity was calculated as the slope of the regression line relating systolic arterial pressure $(\mathrm{mmHg})$ to heart rate (beats per min $(\mathrm{bpm})$ ). Additionally, the maximal and minimal heart rate values obtained during each test were calculated as measures of sympathetic and parasympathetic cardiac modulation 
respectively. Cardiac BST was not repeated during control 2 because this would increase the length of the experiment too much.

\section{Statistical analysis}

Cardiac BST data from two out of the eleven dogs were missing because of technical problems. These two dogs were excluded from our analysis because cardiac BST was our main outcome measure. Power analysis indicated that the present study was powered to detect a 50\% difference in baroslope changes (power: 0.80 and $\alpha=0.05$ ). Because of the relatively low number of experiments the non-parametric Wilcoxon signed rank test was used to analyse the data. The effects of esmolol and dexmedetomidine were compared to each other and to their preceding control measurements. To minimize a possible time-effect in comparing esmolol and dexmedetomidine values, statistical testing was done on values from which their preceding control values were subtracted. For analysis of the cardiac BST, for which Control 2 measurement was not done, repeated measures analysis (Friedman test) followed by Wilcoxon Signed Ranked test and Bonferroni correction was used. A P-value of $\leq 0.05$ was considered statistically significant. Data are presented as mean (SD), unless stated otherwise.

\section{Results}

Baseline experimental conditions

Esmolol infusion did not affect plasma norepinephrine concentrations (table 1), and resulted in adequate beta-adrenergic blockade because it abolished the response to the tachycardic of dose isoprenaline (mean dose $0.45(0.04) \mu \mathrm{g} \mathrm{kg}^{-1}$ ) in all experiments. The infusion scheme of dexmedetomidine resulted in dexmedetomidine plasma concentrations of $0.94(0.33-3.49) \mathrm{ng} \mathrm{mL}^{-1}$ (median (range)), and was associated with a decrease in plasma norepinephrine concentrations of more than 75\% (Table 1). During baseline dexmedetomidine decreased heart rate more than esmolol but neither drug affected arterial pressure (Table 1).

\section{Heart rate and arterial pressure variability.}

Neither drug affected total spectral frequency power of heart rate and arterial pressure variability (data not shown). Dexmedetomidine increased the power of the HF component of heart rate variability and this was associated with a decrease in power of the LF component of systolic arterial pressure variability. In contrast, esmolol did not affect power of any of the frequency spectra (Fig. 2). 


\section{CHAPTER 7}

Table 1: Baseline values and effect of bicarotid occlusion (BCO) (mean (SD))during the sequential study periods. $\mathrm{BCO}$-effect $=\mathrm{BCO}$ value minus baseline value.

\begin{tabular}{llcccc}
\hline Variable & & Control 1 & Esmolol & Control 2 & Dexmedetomidine \\
\hline $\begin{array}{l}\text { Norepinephrine } \\
\text { nmol L }\end{array}$ & Baseline & $0.36(0.24)$ & $0.50(0.39)$ & $0.67(0.55)$ & $0.11(0.15)^{\star \#}$ \\
& BCO-effect & $0.28(0.25)$ & $0.16(0.20)$ & $0.09(0.09)$ & $-0.06(0.12)^{\star}$ \\
& Baseline & $160(20)$ & $138(13)^{\star}$ & $150(18)$ & $101(20)^{\star \#}$ \\
$\begin{array}{l}\text { Heart rate } \\
\text { beats min }\end{array}$ & BCO-effect & $12(6)$ & $3(3)^{\star}$ & $7(2)$ & $18(15)^{\#}$ \\
& Baseline & $127(20)$ & $127(18)$ & $128(12)$ & $139(25)$ \\
$\begin{array}{l}\text { Syst Aortic pressure } \\
\text { mmHg }\end{array}$ & BCO-effect & $36(19)$ & $26(10)$ & $32(6)$ & $14(9)^{\star}$ \\
& & & & & \\
$\begin{array}{l}\text { Syst Carotid pressure } \\
\text { mmHg }\end{array}$ & BCO-effect & $-31(18)$ & $-24(9)$ & $-21(12)$ & $-34(15)^{\#}$ \\
\hline
\end{tabular}

$\star \mathrm{P} \leq 0.05$ compared to preceding control; \# $\mathrm{P} \leq 0.05$ esmolol compared to dexmedetomidine.

\section{Bilateral Carotid artery Occlusion}

Dexmedetomidine, but not esmolol, suppressed the carotid baroreceptor mediated increase in plasma concentration of norepinephrine and the increase in systolic arterial pressure (table 1, BCO effect). Simultaneously, carotid artery pressure distal to the carotid occlusion decreased more in presence of dexmedetomidine than in presence of esmolol (table 1). This suppression of the carotid baroreceptor mediated vasopressor response from dexmedetomidine in contrast to the maintained response from esmolol is shown in figure 3 as their different effects on the calculated pressure gain (ratio of the increase in systolic aortic pressure to the decrease in systolic carotid artery pressure).

\section{Cardiac Barosensitivity Test}

The range of arterial pressures used to test cardiac barosensitivity was similar during each study period (Control 1: 78 - $178 \mathrm{mmHg}$, Esmo: $70-170 \mathrm{mmHg}$, Dexmed: $81-181 \mathrm{mmHg}, \mathrm{P}>0.05)$. However, the resulting slope and range of heart rate responses were different during each period of measurement as can be seen in a typical example (Fig. 4). Esmolol almost abolished the slope of cardiac barosensitivity; in contrast, dexmedetomidine maintained this slope (Fig 5, upper panel). Dexmedetomidine and esmolol suppressed the maximal heart rate 


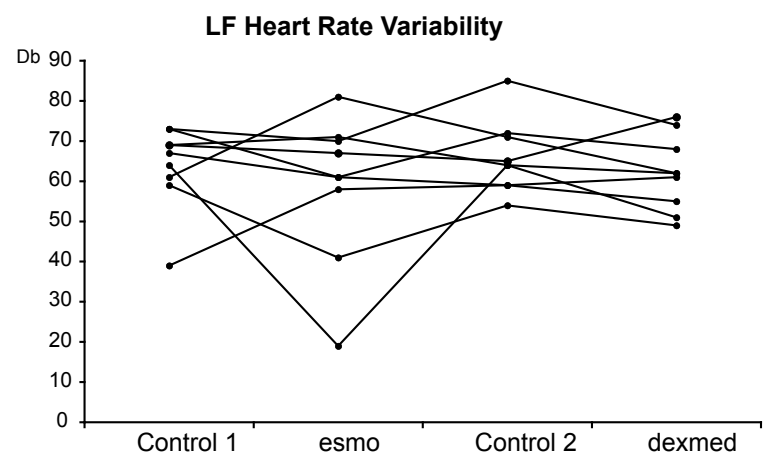

HF Heart Rate Variability

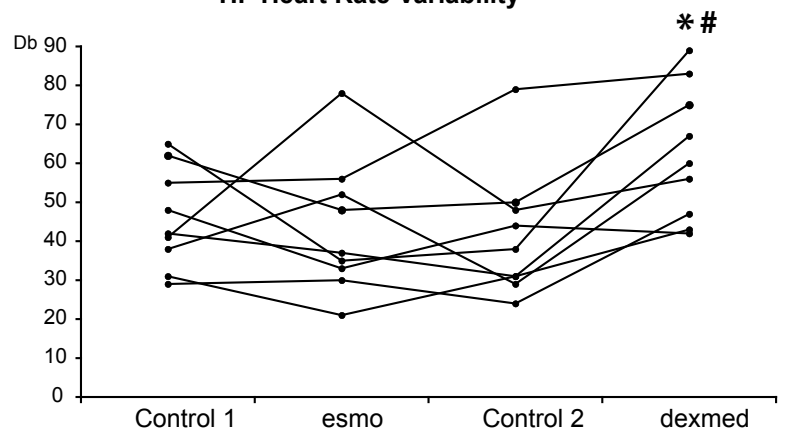

LF Aortic Pressure Variability

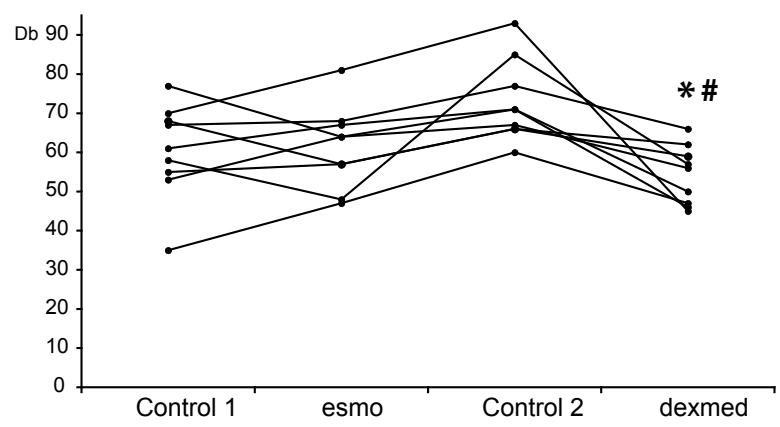

Figure 2. Individual changes in power of Low Frequency (LF) and High Frequency (HF) heart rate variability (upper and middle panels) and LF arterial pressure variability (lower panels). Esmo : during esmolol infusion, Dexmed:during dexmedetomidine infusion $\star=P \leq 0.05$ compared to preceding control measurement. \# $=\mathrm{P} \leq 0.05$ Dexmed compared to Esmo. Dexmedetomidine increased HF heart rate variability and depressed LF arterial pressure variability compared to esmolol. dexmedetomidine 


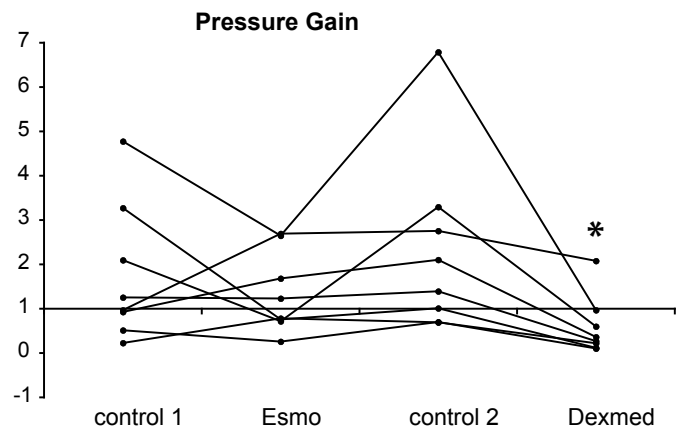

Figure 3. Individual changes in arterial pressure gain calculated as the ratio of the increase in systolic arterial pressure to the decrease in systolic carotid pressure during bicarotid artery occlusion. Dexmedetomidine decreased this gain compared to the preceding control measurement in all experiments. Esmo: during esmolol infusion, Dexmed: during dexmedetomidine infusion. ${ }^{\star}=\mathrm{P} \leq 0.05$ compared to preceding control measurement.dexmedetomidine

Control Esmo Dexmed

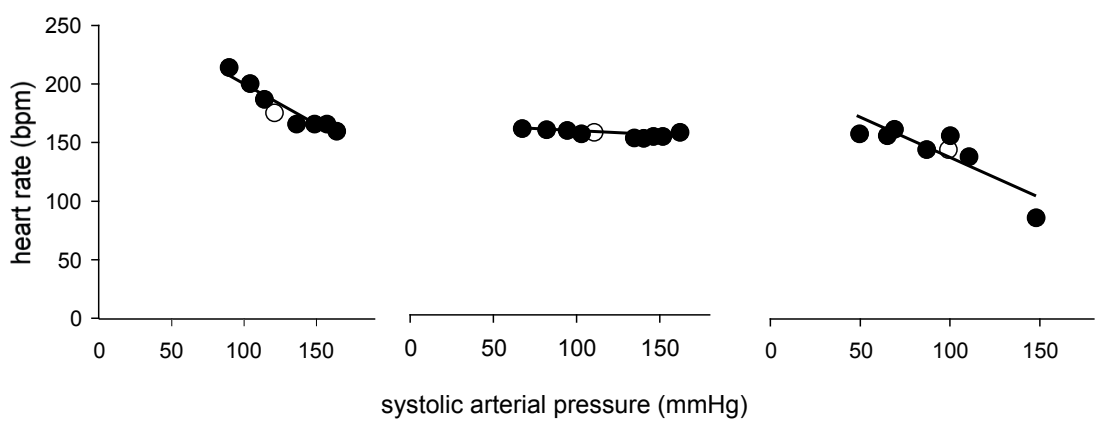

Figure 4. Example of changes in cardiac baroreceptor sensitivity during the sequential experimental conditions in one of the dogs. White dots: baseline values, black dots: values measured during induced pressure changes. Esmolol (esmo) almost abolished the slope relating heart rate responses (y-axis) to changes in systolic arterial pressure ( $\mathrm{x}$-axis). Dexmedetomidine maintained this slope at lower heart rate values compared to control.

plateau in response to a decrease in arterial pressure to a similar extend (Fig. 5, middle panel). However, only dexmedetomidine decreased the minimum heart rate plateau to an increase in arterial pressure (Fig. 5, lower panel). As a result, dexmedetomidine but not esmolol maintained the heart rate range in response to arterial pressure variation (heart rate range: Control 1: 58 (34), Esmo: 17 (14), Dexmed: 55 (18) bpm). Of notice, some dogs developed severe nodal or ventric- 


\section{Barotest Slope}
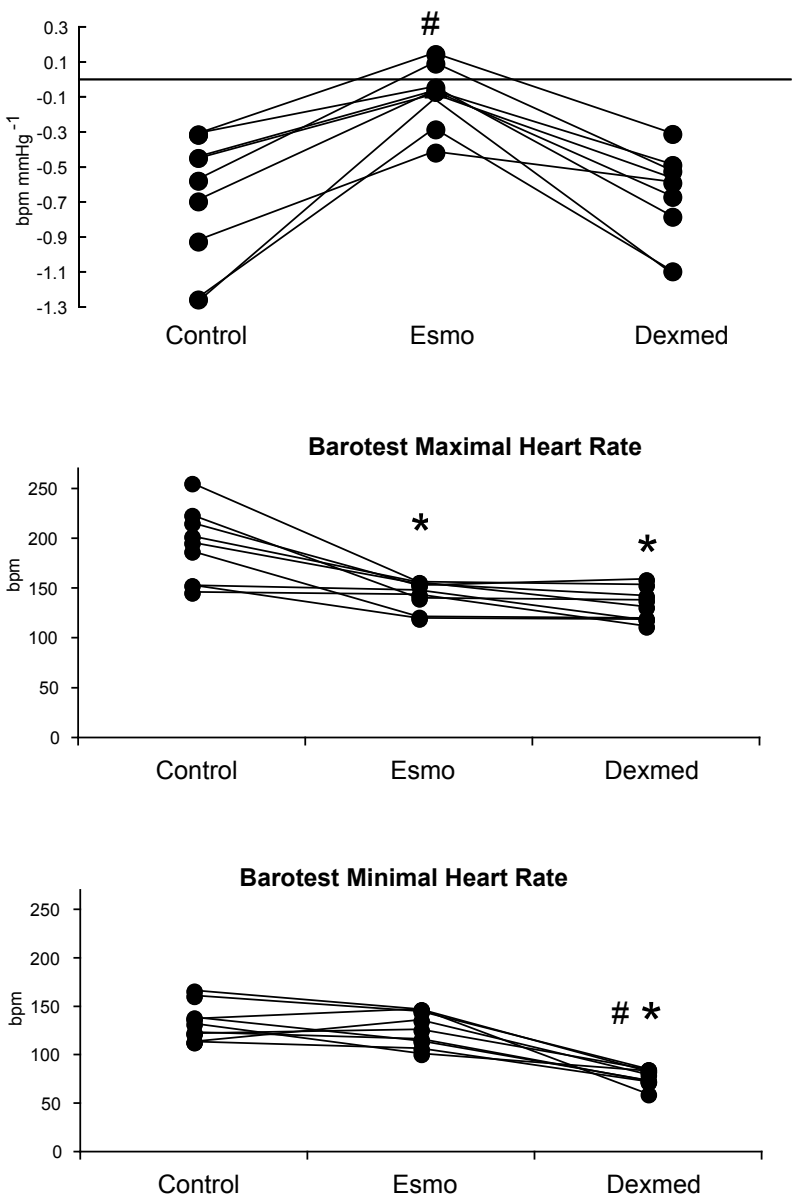

Figure 5. Effects of esmolol (esmo) and dexmedetomidine (dexmed) on cardiac barosensitivity. Data indicate individual results of the slope of the regression line relating heart rate to systolic arterial pressure (upper panel), maximal heart rate response (middle panel), and minimal heart rate response (lower panel). $\star=\mathrm{P}<0.05$ compared to control 1 . \# $=\mathrm{P}<0.05$ dexmed compared to esmo.dexmedetomidine

ular brady-arrhythmias upon maximal inflation of the aortic balloon in presence of dexmedetomidine. However, these arrhythmias resolved spontaneously after deflating the balloon, and only tests without arrhythmias were included in the analysis. 


\section{Discussion}

This is the first comparative study of two different classes of sympatholytic drugs on different measures of baroreceptor function. Arterial baroreflex function is an important regulatory system in maintaining cardiovascular stability, and consists of a cardiac and a vascular effector limb. The current study in chloralose-anaesthetized dogs shows several important differences between the alpha ${ }_{2}$-agonist dexmedetomidine and the beta ${ }_{1}$-antagonist esmolol on arterial baroreflex function.

The most important difference was that dexmedetomidine but not esmolol maintained cardiac baroreceptor gain, as indicated by their effects on the cardiac barosensitivity slope. This maintained cardiac baroreceptor gain from dexmedetomidine is in accordance with previous studies in $\operatorname{dogs}^{14}$ and human volunteers ${ }^{15}$. However, the depressed baroreceptor gain from esmolol contrasts with previous findings which indicate that beta-blockade either has no effect ${ }^{16}$ or even improves cardiac baroreflex function ${ }^{9}$. Differences in methods may explain these contrasting results because in these previous studies cardiac barosensitivity was assessed from rapid changes in arterial pressure, which measures mainly vagally mediated heart rate changes ${ }^{17}$. In contrast, we studied cardiac barosensitivity from "steady state" pressure changes, which measures both the sympathetic and parasympathetic mediated component of the heart rate response.

Our data suggest that the differences in cardiac baroreceptor sensitivity between esmolol and dexmedetomidine may be explained from their effects on cardiac vagal tone. Both drugs decreased the sympathetic controlled maximal heart rate plateau to a similar extend, but only dexmedetomidine increased cardiac vagal tone. This is indicated by a lower minimum heart rate plateau during cardiac barosensitivity testing, and by the increase in power of the HF component of heart rate variablility, an accurate measure of cardiac vagal tone at rest $^{18}$. As a result dexmedetomidine maintained the operating range of the baroreflex system. In contrast, the pure sympatholytic effect of esmolol decreased the range and thus the slope of heart rate responses. Our findings fit well with recent observations in mice ${ }^{19}$ and humans ${ }^{20}$ suggesting that the beneficial effect of alpha $a_{2}$-agonists on baroreceptor sensitivity is mediated by the parasympathetic nervous system. The mechanisms by which alpha ${ }_{2}$-agonists enhance this parasympathetic mediated heart rate control are not known but they may directly influence $\alpha_{2}$-adrenoreceptors in the vagal nuclei of the medulla oblongata ${ }^{21}$. Previous data on parasympathetic effects from beta blockade are equivocal, showing that beta blockade either increases ${ }^{16,22}$ or, in accordance with the current findings, has no parasympathetic effect ${ }^{18,19}$. These conflicting results may be explained by the various conditions determining the 
vagal HF component of heart rate variability such as; baseline autonomic tone ${ }^{23}$, acute versus chronic beta blockade ${ }^{8}$, and the specific beta-blocker studied ${ }^{24}$.

The increased vagal tone and maintainance of baroreceptor gain of dexmedetomidine resulted in an improved hemodynamic stability, as indicated by its suppression of the LF power of arterial pressure variability ${ }^{9}$. In accordance, it has been shown that rapid cardiac vagal modulation is the most important mechanism for correcting high frequency, small magnitude, blood pressure variations $^{25}$. Also, the alpha ${ }_{2}$-agonist clonidine has been shown to have a hemodynamic stabilizing effect during the recovery period in patients with hypertension ${ }^{3}$.

These differences in cardiac autonomic control between dexmedetomidine and esmolol may be clinically relevant because indices of impaired cardiovascular control have been shown to be independent predictors of adverse outcome after myocardial infarction ${ }^{26}$ or after noncardiac surgery ${ }^{5}$. However, extrapolation from animal studies should be done with caution.

In addition to these different effects on the cardiac limb of the baroreceptor reflex, the current study indicates that dexmedetomidine and esmolol had also different effects on the vascular effector limb. Their effects on arterial pressure gain and plasma norepinephrine response during carotid artery occlusion indicate that dexmedetomidine suppressed and esmolol maintained the sympathetic mediated vasopressor response. The conclusions of previous studies on the effects of alpha $_{2}$-agonists on sympathetic mediated increases of vascular tone are equivocal. In accordance with the current study, dexmedetomidine attenuated the vasoconstrictor response to hypotension in rabbits ${ }^{27}$ and clonidine decreased the slope of the arterial pressure - sympathetic nerve activity relationship in human volunteers ${ }^{20}$. It is likely that this reduced sympathetic vasopressor response results from their effects at $\alpha_{2}$-receptors in vasomotor centres in the brainstem $^{28}$, and at pre- and post sympathetic ganglia ${ }^{29}$. In contrast, alpha $2^{-}$ agonists have been shown to maintain adaptive sympathetic vasopressor responses during potential major decreases in blood pressure such as sepsis ${ }^{30}$ or vessel unclamping during liver transplantation ${ }^{31}$. These contrasting effects of alpha $_{2}$-agonists on sympathetic vasopressor responses may be explained because central pathways different from baroreceptor pathways are involved during hypovolemic episodes ${ }^{32}$. In the current study beta-blockade did not affect the sympathetic vasopressor response which is in accordance with findings in human volunteers showing that propanolol does not attenuate the increase in sympathetic nerve activity during orthostatic stress ${ }^{33}$.

The results of this study must be interpreted within the constraints of several limitations. First, it is likely that anaesthesia affected our results. However, chloralose anaesthesia is used widely for neurophysiological experiments and 
offers stable hemodynamics ${ }^{34}$. The presence of anesthesia and controlled ventilation also prevented uncontrolled emotional stress responses and irregular respiration, which are known to interfere with neurophysiological measurements. Another limitation is that the counter regulatory response from the aortic baroreceptors depressed the arterial pressure response during carotid occlusion $^{35}$, thus interfering with the calculation of the pressure gain. However it is likely that this confounding factor had a similar effect during all periods of measurement.

In conclusion, in accordance with our hypothesis we found that an alpha ${ }_{2}^{-}$ agonist and a beta-blocker had different baroreceptor effects. Dexmedetomidine maintained baroreceptor mediated heart rate responses and improved baseline arterial pressure stability from its vagomimetic effect but decreased vascular responsiveness from its central sympatholytic effect. In contrast, peripheral cardiac sympatholysis from esmolol depressed the cardiac effector limb of the baroreceptor but maintained central sympathetic mediated vascular responsiveness.

\section{References}

1 Willigers HM, Prinzen FW, Roekaerts PM, de Lange S, Durieux ME. Dexmedetomidine Decreases Perioperative Myocardial Lactate Release in Dogs. Anesth Analg 2003; 96:657-64.

2 Warltier DC, Pagel PS, Kersten JR. Approaches to the prevention of perioperative myocardial ischemia. Anesthesiology 2000; 92: 253-9.

3 Parlow JL, Begou G, Sagnard P et al. Cardiac baroreflex during the postoperative period in patients with hypertension: effect of clonidine. Anesthesiology 1999; 90: 681-92.

4 Amar D, Fleisher M, Pantuck CB et al. Persistent alterations of the autonomic nervous system after noncardiac surgery. Anesthesiology 1998; 89: 30-42.

5 Filipovic M, Jeger R, Probst $\mathrm{C}$ et al. Heart rate variability and cardiac troponin I are incremental and independent predictors of one-year all-cause mortality after major noncardiac surgery in patients at risk of coronary artery disease. J Am Coll Cardiol 2003; 42: 1767-76.

6 Eagle KA, Berger PB, Calkins $\mathrm{H}$ et al. ACC/AHA Guideline Update for Perioperative Cardiovascular Evaluation for Noncardiac Surgery_Executive Summary Anesth Analg 2002; 94: 1052-64.

7 Willigers HM, Prinzen FW, Roekaerts PM. The effects of esmolol and dexmedetomidine on myocardial oxygen consumption during sympathetic stimulation in dogs. J Cardiothorac Vasc Anesth 2006; 20: 364-70.

8 Pagani M, Lombardi F, Guzzetti S et al. Power spectral analysis of heart rate and arterial pressure variabilities as a marker of sympatho-vagal interaction in man and conscious dog. Circ Res 1986; 59: 178-93.

9 Formes KJ, Wray DW, O Yurvati AH, Weiss MS, Shi X. Sympathetic cardiac influence and arterial blood pressure instability. Autonomic neuroscience basic and clinical 2005; 118: 116-24.

10 Vuorilehto L, Salonen JS, Anttila M. Picogram level determination of medetomidine in dog serum by capillary gas chromatography with negative ion chemical ionisation mass spectrometry. Journal of Chromatography 1989; 497: 282-7. 
11 Hoorn van der FAJ, Boomsma, Man in het Veld AJ, Schalekamp MADH. Determination of catecholamines in human plasma by high-performance liquid chromatography: comparison between a new method with fluorescence detection and an established method with electrochemical detection. Journal of Chromatography 1989; 487: 17-28.

12 Disalvo J, Parker PE, Scott JB, Haddy FJ. Carotid baroreceptor influence on coronary vascular resistance in the anesthetized dog. Am. J. Physiology 1971;221(1): 156-60.

13 Kirchheim H, Gross R. Hemodynamics of the carotid sinus reflex elicited by bilateral carotid occlusion in the conscious dog: Effect of $\alpha$ - or $\beta$-adrenergic blockade on the reflex response. Pflugers Arch. 1971; 327: 203-24.

14 Devcic AD, Schmeling WT, Kampine JP, Warltier DC. Oral dexmedetomidine preserves baroreceptor function and decreases anesthetic requirements of halothane-anesthetized dogs. Anesthesiology 1994; 81: 419-30.

15 Hogue CW,Jr., Talke P, Stein PK et al. Autonomic nervous system responses during sedative infusions of dexmedetomidine. Anesthesiology 2002; 97: 592-8.

16 Cogliati C, Colombo S, Ruscone TG et al. Acute beta-blockade increases muscle sympathetic activity and modifies its frequency distribution. Circulation 2004; 110: 2786-91.

17 Kingwell BA, McPherson GA, Korner PI. Assessment of gain of tachycardia and bradycardia responses of cardiac baroreflex. Am J Physiol 1991; 260: H1254-H63.

18 Hayano J, Sakakibara Y, Yamada A et al. Accuracy of assessment of cardiac vagal tone by heart rate variability in normal subjects. Am J Cardiol 1991; 67: 199-204.

19 Tank J, Jordan J, Diedrich A et al. Clonidine improves spontaneous baroreflex sensitivity in conscious mice through parasympathetic activation. Hypertension 2004; 43: 1042-7.

20 Tank J, Diedrich A, Szczech E, Luft FC, Jordan J. Alpha-2 adrenergic transmission and human baroreflex regulation. Hypertension 2004; 43: 1035-41.

21 Robertson HA, Leslie RA. Noradrenergic alpha 2 binding sites in vagal dorsal motor nucleus and nucleus tractus solitarius: autoradiographic localization. Can J Physiol Pharmacol 1985; 63: 1190-4.

22 Melenovsky V, Simek J, Sperl M, Malik J, Wichterle D. Relation between actual heart rate and autonomic effects of beta blockade in healthy men. Am J Cardiol 2005; 95: 999-1002.

23 Goldberger JJ, Challapalli S, Tung R, Parker MA, Kadish AH. Relationship of heart rate variability to parasympathetic effect. Circulation 2001; 103: 1977-83.

24 Minami N, Yoshikawa T, Kataoka H et al. Effects of exercise and beta-blocker on blood pressure and baroreflexes in spontaneously hypertensive rats. Am J Hypertens 2003; 16: 966-72.

25 Wray DW, Formes KJ, Weiss MS et al. Vagal cardiac function and arterial blood pressure stability. Am J Physiol Heart Circ Physiol 2001; 281: H1870-80.

26 La Rovere MT, Bigger Jr JT, Marcus FI et al. Baroreflex sensitivity and heart-rate variability in prediction of total cardiac mortality after myocardial infarction. The Lancet 1998; 351: 47884.

27 Blake DW. Dexmedetomidine and hemodynamic responses to simulated hemorrhage in experimental heart failure. Anesth Analg 2000; 91:1112-7.

28 Li G, Wang X, Abdel Rahman AA. Neuronal norepinephrine responses of the rostral ventrolateral medulla and nucleus tractus solitarius neurons distinguish the I1- from the alpha2-receptor-mediated hypotension in conscious SHRs.J Cardiovasc Pharmacol 2005; 46: $52-62$.

29 McCallum JB, Boban N, Hogan Q et al. The mechanism of alpha2-adrenergic inhibition of sympathetic ganglionic transmission. Anesth Analg 1998; 87: 503-10.

30 Dodd-o JM, J BM, Dorman T, Rosenfeld BA. Preserved sympathetic response to hypotension despite perioperative $\alpha 2$ agonist administration. Anesth Analg 1997; 84: 1208 10. 


\section{CHAPTER 7}

31 De Kock M, Laterre PF, Van Obbergh L, Carlier M, Lerut J. The effects of intraoperative intravenous clonidine on fluid requirements, hemodynamic variables, and support during liver transplantation: a prospective, randomized study. Anesth Analg 1998; 86: 468-76.

32 Potts PD, Ludbrook J, Gillman Gaspari TA, Horiuchi J, Dampney RA. Activation of brain neurons following central hypervolaemia and hypovolaemia: contribution of baroreceptor and non-baroreceptor inputs. Neuroscience 2000; 95: 499-511.

33 Jacobsen T, Converse R, Jr, Victor R. Contrasting effects of propranolol on sympathetic nerve activity and vascular resistance during orthostatic stress. Circulation 1992; 85: 1072-6.

34 Cox RH. Influence of chloralose anesthesia on cardiovascular function in trained dogs. American Journal of Physiology 1972; 223: 660-7.

35 Brunner MJ, Greene AS, Kallman CH, Shoukas AA. Interaction of canine carotid sinus and aortic arch baroreflexes in the control of total peripheral resistance. Circ Res 1984; 55:740-50. 
CHAPTER 8

General discussion 
CHAPTER 8

120 


\section{General discussion}

Based on the findings in the current thesis there are three major topics which deserve further discussion:

1. Strategies to modulate the perioperative stress response: improving knowledge.

2. Choosing the optimal sympatholytic drug to decrease perioperative myocardial ischemia.

3. Decreasing the stress response, what is the goal ?

\section{Strategies to modulate the perioperative stress response: improving knowledge}

The introduction of anesthesia and the associated reduction in the perioperative stress response was a major step forward in improving morbidity and mortality after surgery. However, modern surgery is still associated with adverse outcome related to the surgical stress response. This is mainly due to adverse cardiac outcome during the first weeks to months after surgery. At this moment clinical studies do not allow definitive conclusions regarding the effectiveness of anesthetic strategies on cardiac outcome. This can be explained by: 1) the low incidence of adverse cardiac outcome, 2) the presence of confounding factors and, 3 ) the difficulty in defining and thus measuring adverse cardiac outcome. Therefore great efforts will be needed to overcome these difficulties in studying the effectiveness of anesthetic techniques on cardiac outcome. An alternative way to increase our knowledge on the relationship between anesthetic strategies and adverse outcome is to study the effect of anesthetic strategies on the stress response to surgery instead of studying their effect on cardiac outcome. Our study in chapter 3 of this thesis is an example of this strategy. In this study the effect of an opioid based anesthetic technique and an epidural technique on the early postoperative stress response were compared. Our main finding was that the plasma concentration of epinephrine was higher and that of the pro-inflammatory cytokine IL-6 was lower in presence of an opioid based anesthetic compared to an epidural based anesthetic. These findings highlight the potential of anesthetic techniques to modulate both the neuro-endocrine and the immunological homeostatic responses to surgery. However, it is difficult to define the implications of our findings. Firstly, this is because all patients had an uneventful recovery. A second difficulty in interpreting our results is that we measured relatively few markers of the stress response. For example, we did not measure cortisol, anti-inflammatory cytokines, and lymphocyte function. Finally, because 


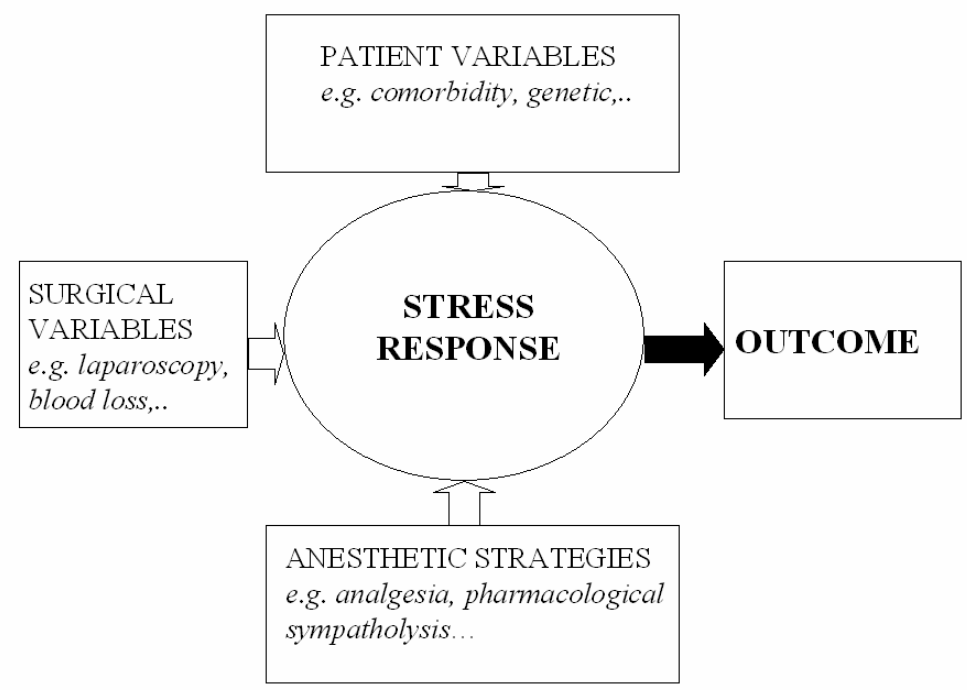

Figure 1

Schematic presentation of different factors which modify outcome after surgery indirectly from their effects on the stress response to tissue injury.

of large inter-individual variations in markers of the stress response it is difficult to compare our findings to those in other studies having different study designs .

To increase our knowledge on anesthetic modulation of the stress response as such we need an enormous amount of data. One possibility is to create an extensive database of patients having surgery. This database should include serial measurements of different markers of the stress response and variables such as surgical procedure, anesthetic technique, and co-morbidity of the patient. In this way we may identify factors, including anesthetic strategy, associated with an excessive or inadequate stress response (fig.1). The resulting knowledge may help to define the optimal perioperative strategy for an individual patient. For example, our findings in chapter 3 suggest that an opioid-based technique is superior in decreasing the inflammatory response to surgery whereas an epidural based technique has superior sympatholytic effects. If this suggestion is confirmed in such a database then we may use an opioid technique if the inflammatory response is to be suppressed, and an epidural technique if decreasing sympathetic activation is important for an individual patient. In the future genetic data may be added as a variable to such a database. This is because there is increasing evidence that differences in genetic expression or genetic polymorphisms are responsible for more than $50 \%$ of the individual differences 
in the stress response ${ }^{2}$. For instance, genetic variants in cytokine and leukocyteendothelial interaction pathways are independently associated with severity of myocardial necrosis after cardiac surgery ${ }^{3}$. Also, it has been identified that a single-nucleotide polymorphism of the alpha ${ }_{2}$-adrenoreceptor contributes to autonomic nervous system responsiveness ${ }^{4}$.

\section{Choosing the optimal sympatholytic drug to decrease myocardial ischemia after surgery}

Clinical studies indicate that sympatholytic drugs decrease perioperative myocardial ischemia. An important draw-back of these studies is the absence of an accepted gold standard indicator for the diagnosis of perioperative myocardial ischemia or myocardial infarction ${ }^{5}$. This beneficial effect of sympatholytic drugs on myocardial ischemia may result from suppressing shear stress on unstable coronary plaques thus decreasing plaque rupture and coronary thrombosis. Also, they may attenuate potentially dangerous mismatches in myocardial oxygen demand and supply in presence of a severe stable coronary stenosis. However, these two potential mechanisms are difficult to separate in patients. In this context, the results of our study in dogs on the anti-ischemic effects of perioperative sympatholysis are important (chapter 4). The experimental model used in this study excluded coronary plaque rupture as a cause of myocardial ischemia because coronary artery stenosis resulted from an occluder applied around a coronary artery. In this way we were able to show that profound perioperative sympatholysis has the potential to decrease myocardial ischemia purely from its effect on myocardial oxygen balance. Another important aspect of this study in dogs is that myocardial ischemia was diagnosed using its gold standard indicator: myocardial lactate release.

The American Heart Association advised the use of either an alpha ${ }_{2}$-agonist or a beta-blocker for perioperative pharmacological sympatholysis ${ }^{6}$. Central sympatholysis produced by an alpha ${ }_{2}$-agonist may have a potential advantage over the use of a beta-blocker because of the ability of the alpha ${ }_{2}$-agonist to attenuate the adverse effects of sympathetic nervous stimulation mediated by peripheral alpha- as well as beta receptors. However, there are no clinical studies in which the potential anti-ischemic effects of alpha ${ }_{2}$-agonists are directly compared to those of beta-blockers ${ }^{7}$. The main drawback of performing such a comparative study is the enormous number of patients needed. At this moment the first adequately powered randomised controlled trial on perioperative betablockers (POISE trial) plans to recruit 10.000 patients $^{8}$. It is likely that many more patients are needed to find a difference between two potentially effective 
sympatholytic therapies. Therefore it is unlikely that both sympatholytic therapies have clinically relevant different anti-ischemic effects.

This leaves us with the question: should we use alpha $a_{2}$-agonists or betablockers for perioperative pharmacological sympatholysis? The results of the experimental studies in this thesis do not give a definite answer to this question. However, they clearly show several differences between both classes of drugs which may help to answer this question. Firstly, findings from this thesis suggest that an alpha ${ }_{2}$-agonist decreases heart rate more than a beta-blocker (chapter 7). This was explained by the additional vagomimetic action of the alpha ${ }_{2}$-agonist in contrast to the pure cardiac sympatholytic effect of the beta-blocker. In accordance with our findings, a case report indicated that dexmedetomidine was more successful than esmolol in treating intraoperative tachycardia ${ }^{9}$. The effect of a drug on heart rate seems to be important for its effect on myocardial ischemia. This is because in our study in dogs emerging from anesthesia (chapter 4) a decreased heart rate from pharmacological sympatholysis was associated with and an improved myocardial blood flow through a stenotic coronary artery. Also clinical studies show the importance of heart rate in decreasing myocardial ischemia. In a study in patients having vascular surgery the use of beta-blockers to keep the heart rate below the pre-operative measured ischemic threshold markedly reduced postoperative myocardial ischemia ${ }^{10}$. In another study, a tight heart rate control with beta-blockers was associated with reduced perioperative myocardial ischemia and troponin $\mathrm{T}^{11}$. Myocardial oxygen balance may also improve from a decrease in myocardial oxygen demand. However, the findings in our study in dogs emerging from anesthesia suggest that sympatholysis has no significant effect on myocardial oxygen demand (chapter 4). Also, our findings in chapter 5 and 6 suggest that neither an alpha ${ }_{2}$-agonist nor a beta-blocker has an important effect on myocardial oxygen demand. In these studies in dogs, myocardial oxygen demand was measured from its effect on myocardial oxygen consumption in presence of an unlimited coronary blood flow. This measurement of demand is more accurate than a hemodynamic index of demand, such as rate pressure product, which is generally used in clinical studies (chapter 5). Thus, it is likely that, in presence of a critical coronary artery stenosis, the heart rate lowering effect of sympatholytic drugs improves myocardial oxygen balance from an increase in myocardial oxygen supply. Therefore, these findings present a reason to study the heart rate lowering effects of beta-blockers and alpha $2^{-}$ agonists during the period early after surgery.

Secondly, our findings suggest that an alpha ${ }_{2}$-agonist, in contrast to a betablocker suppresses stress related increases in systemic vascular resistance (SVR) (chapter 6). An increase in SVR is an important component of the hemodynamic response to mental stress. It is likely that mental stress from 
anxiety and pain is part of the postoperative stress. There are indications that increases in SVR may cause myocardial ischemia in patients having left ventricular dysfunction. It has been shown that beta-blockers may be harmful in patients having mental-stress induced myocardial ischemia ${ }^{12}$. Therefore, an alpha $_{2}$-agonist may be a more appropriate sympatholytic drug than a betablocker in these patients. Additionally, alpha ${ }_{2}$-agonists may decrease mental stress from their sedative and anxiolytic properties.

Finally, the findings in this thesis indicate that alpha 2 -agonists and betablockers have different effects on baroreceptor mediated cardiovascular control. This difference may be important because indices of impaired cardiovascular control are independent predictors of adverse outcome after surgery ${ }^{13}$. First, we found that the alpha ${ }_{2}$-agonist dexmedetomidine maintained baroreceptor sensitivity and baseline hemodynamic stability better than the beta-blocker esmolol (chapter 4). Additionally, the increase in cardiac vagal tone from the alpha $2^{-}$ agonist was associated with an improved ability to correct high frequency, small magnitude, blood pressure variations ${ }^{14}$. A second difference regarding cardiovascular control mechanisms was that the alpha 2 -agonist, in contrast to the betablocker, suppressed the sympathetic vasoconstrictor response. However, the clinical relevance of this potential disadvantageous effect of an alpha ${ }_{2}$-agonist is difficult to predict. There is, on the one hand, a large body of clinical experience of perioperative use of alpha ${ }_{2}$-agonists and no major complications have so far been published. Additionally, several case-reports have shown that $\mathrm{alpha}_{2^{-}}$ agonists maintain adaptive sympathetic vasopressor responses during potential major decreases in blood pressure such as sepsis ${ }^{15}$ or from vessel unclamping during liver transplantation ${ }^{16}$. An explanation for this maintained sympathetic response in the presence of an alpha -agonist is that central pathways different from baroreceptor pathways are involved during hypovolemic episodes ${ }^{17}$. On the other hand, there is evidence that suppression of sympathetic mediated compensatory mechanisms may be disadvantageous in some patient groups. For example, the Moxonidine Congestive Heart Failure Trial (MOXCON) showed that moxonidine, a centrally active sympatholytic imidazoline agonist, increased mortality by more than $50 \%$ in patients having severe heart failure ${ }^{18,19}$. Also, the beta-Blocker Evaluation of Survival Trial (BEST) showed that powerful sympatholyis increased mortality in patients having severe heart failure ${ }^{20}$. These two trials caution against unbounded sympatholysis and may present a reason to study the relation between perioperative sympatholysis and potential shock states. Thus, the main findings from our comparative experimental studies on autonomic nervous system modulation of an alpha ${ }_{2}$-agonist and a beta-blocker were:

1. The vagomimetic effect of the alpha ${ }_{2}$-agonist resulted in a lower heart rate. 
2. In contrast to the beta-blocker, the alpha $a_{2}$-agonist maintained baroreceptor mediated heart rate responses.

3. The alpha $a_{2}$-agonist suppressed the increase in vascular resistance to a stress stimulus more effectively.

In conclusion, the findings in this thesis suggest that an alpha $\mathrm{p}_{2}$-agonist may be more appropriate than a beta-blocker for perioperative sympatholysis. However, studies in patients are needed before more firm advise can be given.

\section{Decreasing the stress response, what is the goal ?}

One view is that the stress response to surgery should be maximally suppressed because it may have adverse effects and is not necessary for survival in hospitalised surgical patients ${ }^{21}$.

Another view is not to intervene aggressively in the stress response. The stress response was programmed in higher organisms to provide homeostatic adjustments to cold, volume loss, hypoglycaemia, and infection. In accordance with this view, Cannon showed 70 years ago that total sympathectomized cats were unable to defend themselves against various stresses such as hypoxia, temperature changes and hemorrhage ${ }^{22}$. The over-aggressive use of therapies to decrease the stress response may be harmful in patients as well. For example, the use of opioids in intensive care patients may have detrimental effects such as increased haemodynamic instability during shock, and suppression of host immune responses ${ }^{23}$. Also, some patients have a defective stress-response secondary to their illness, and suppressing the stress response in these patients may have detrimental effects. For example, Rivers and colleagues ${ }^{24}$ reported that a significant number of patients who needed vasopressor therapy early after surgery had signs of adrenal insufficiency. The administration of the stress hormone hydrocortisone decreased vasopressor requirement and improved survival in these patients. Finally, there are strong indications that intense sympatholytic therapy may be detrimental in patients having severe cardiac failure ${ }^{18} 20$.

In conclusion, to improve perioperative outcome the surgical team should aim to control the stress response in relation to the individual patient. However, precise control of the different components of the surgical stress response is not possible at this moment. Also, it is difficult to predict which patients are at risk of an inappropiate stress response. Therefore, controlling the stress response in relation to the individual patient is a major task in future perioperative medicine. At this moment, we have to continue our current practice of aiming at a profound suppression of the stress response to surgery. However, we must realize that this strategy places large responsibility on care providers to monitor and protect their patients during the perioperative period. 


\section{References}

1 Nathan C. Points of control in inflammation. Nature 2002; 420: 846-52.

2 Chrousos GP. Stressors, stress, and neuroendocrine integration of the adaptive response. The 1997 Hans Selye Memorial Lecture. Ann N Y Acad Sci 1998; 851: 311-35.

3 Podgoreanu MV, White WD, Morris RW et al. Inflammatory gene polymorphisms and risk of postoperative myocardial infarction after cardiac surgery. Circulation 2006; 114: I275-81.

4 Finley JC, Jr., O'Leary M, Wester D et al. A genetic polymorphism of the alpha ${ }_{2}$-adrenergic receptor increases autonomic responses to stress. Journal of applied physiology Bethesda, Md. 1985 2004; 96: 2231-9.

5 Fleisher LA, Zielski MM, Schulman SP. Perioperative ST-segment depression is rare and may not indicate myocardial ischemia in moderate-risk patients undergoing noncardiac surgery. $J$ Cardiothorac Vasc Anesth 1997; 11: 155-9 .

6 Eagle KA, Berger PB, Calkins $\mathrm{H}$ et al. ACC/AHA Guideline Update for Perioperative Cardiovascular Evaluation for Noncardiac Surgery-Executive Summary: A Report of the American College of Cardiology/American Heart Association Task Force on Practice Guidelines (Committee to Update the 1996 Guidelines on Perioperative Cardiovascular Evaluation for Noncardiac Surgery). Anesth Analg 2002; 94: 1052-64.

7 Wijeysundera DN, Naik JS, Beattie WS. Alpha-2 adrenergic agonists to prevent perioperative cardiovascular complications: a meta-analysis. Am J Med 2003; 114: 742-52.

8 Devereaux PJ, Beattie WS, Choi PT et al. How strong is the evidence for the use of perioperative beta blockers in non-cardiac surgery? Systematic review and meta-analysis of randomised controlled trials. BMJ Clinical research; 331:313-21.

9 Ruesch S, Levy JH. Treatment of persistent tachycardia with dexmedetomidine during offpump cardiac surgery. Anesth Analg 2002; 95: 316-8, table of contents.

10 Raby KE, Brull SJ, Timimi $F$ et al. The effect of heart rate control on myocardial ischemia among high-risk patients after vascular surgery. Anesthesia and analgesia 1999; 88: 477-82.

11 Feringa $\mathrm{HH}$, Bax JJ, Boersma $\mathrm{E}$ et al. High-dose beta-blockers and tight heart rate control reduce myocardial ischemia and troponin $\mathrm{T}$ release in vascular surgery patients. Circulation ISE: 15244539 2006; 114: I344-9.

12 Bairy CN, Krantz DS, DeQuattro V, Berman DS, Rozansky A. Effect of beta-blockade on low heart rate-related ischemia during mental stress. JACC 1991; 17: 1388-95.

13 Filipovic M, Jeger R, Probst $\mathrm{C}$ et al. Heart rate variability and cardiac troponin I are incremental and independent predictors of one-year all-cause mortality after major noncardiac surgery in patients at risk of coronary artery disease. J Am Coll Cardiol 2003; 42: 1767-76.

14 Wray DW, Formes KJ, Weiss MS et al. Vagal cardiac function and arterial blood pressure stability. Am J Physiol Heart Circ Physiol 2001; 281: H1870-80.

15 Dodd-o JM, J BM, Dorman T, Rosenfeld BA. Preserved sympathetic response to hypotension despite perioperative $\alpha 2$ agonist administration. anesth analg 1997; 84: 1208-10.

16 De Kock M, Laterre PF, Van Obbergh L, Carlier M, Lerut J. The effects of intraoperative intravenous clonidine on fluid requirements, hemodynamic variables, and support during liver transplantation: a prospective, randomized study. Anesthesia and analgesia 1998; 86: 46876.

17 Potts PD, Ludbrook J, Gillman Gaspari TA, Horiuchi J, Dampney RA. Activation of brain neurons following central hypervolaemia and hypovolaemia: contribution of baroreceptor and non-baroreceptor inputs. Neuroscience 2000; 95: 499-511.

18 Coats AJ. Heart Failure 99 — the MOXCON story. International journal of cardiology 1999; 71: 109-11. 


\section{CHAPTER 8}

19 Cohn JN, Pfeffer MA, Rouleau J et al. Adverse mortality effect of central sympathetic inhibition with sustained-release moxonidine in patients with heart failure (MOXCON). Eur J Heart Fail 2003; 5: 659-67.

20 Bristow MR, Krause-Steinrauf H, Nuzzo R et al. Effect of baseline or changes in adrenergic activity on clinical outcomes in the beta-blocker evaluation of survival trial. Circulation 2004; 110: $1437-42$.

21 Kehlet H. Labat lecture 2005: surgical stress and postoperative outcome-from here to where? Reg Anesth Pain Med 2006; 31: 47-52.

22 Cannon WB. The Wisdom of the body. New York: Norton, W. W, 1932.

23 Molina PE. Opioids and opiates: analgesia with cardiovascular, haemodynamic and immune implications in critical illness. J Intern Med 2006; 259: 138-54.

24 Rivers EP, Gaspari M, Saad GA et al. Adrenal insufficiency in high-risk surgical ICU patients. Chest 2001; 119: 889-96. 